\title{
Atlas das barragens de mineração em Minas Gerais
}

\author{
Atlas of mining tailings dams in Minas Gerais, Brazil
}

Ricardo Motta Pinto-Coelho
Programa de Pós-Graduação em Geografia - PPGEOG, Departamento de Geociênicas-
DEGEO, Universidade Federal de São João del-Rei, São João del-Rei (MG), Brasil.
rpcoelho@ufsj.edu.br

Eliane Maria Vieira

Programa de Pós-Graduação - ProAgua, Instituto de Ciências Puras e Aplicadas, Universidade Federal de Itajubá - UNIFEI, Itabira, (MG), Brasil. elianevieira@unifei.edu.br

Fernanda Paula Bicalho Pio Programa de Pós-Graduação - ProAgua, Instituto de Ciências Puras e Aplicadas, Universidade Federal de Itajubá - UNIFEI, Itabira, (MG), Brasil. fppbicalho@gmail.com

Viviane Fernandes de Almeira Programa de Pós-Graduação - ProAgua, Instituto de Ciências Puras e Aplicadas, Universidade Federal de Itajubá - UNIFEI, Itabira, (MG), Brasil. viviane.fernandesal123@gmail.com

Rangel Eduardo Santos

Programa de Pós-Graduação em Ecologia, Conservação e Manejo da Vida Silvestre -ECMVS, Departamento de Biologia Geral, Universidade Federal de Minas Gerais - UFMG, Belo Horizonte (MG), Brasil. E-mail: rangel_es@msn.com

\section{Resumo}

Nos últimos anos, o estado de Minas Gerais sofreu com repetidas rupturas de barragens que recebem rejeitos de mineração. Esses eventos causaram imensos danos humanos, sociais, econômicos e ambientais. Além disso, a recorrência desses desastres sugere que o gerenciamento desses reservatórios é defeituoso, impreciso e, provavelmente, baseado em premissas técnicas insuficientes ou até falsas. O planejamento e a construção de reservatórios que podem conter dezenas de milhões de metros cúbicos de rejeitos obviamente devem levar em consideração uma série de fatores, ambientais ou relacionados aos diferentes usos do solo pelos seres humanos. Entre esses usos, a urbanização deve ser tratada de uma maneira muito especial. No estado de Minas Gerais, existem cerca de 400 barragens que recebem rejeitos de mineração. Dados oficiais mostram que um número significativo dessas estruturas apresenta problemas relacionados à segurança de barragens. O objetivo do atlas é apresentar de maneira clara e objetiva e utilizando uma linguagem acessível a toda a população uma tipologia dessas barragens, dando uma atenção especial alguns muncípios considerados críticos e tratados como "casos de estudo". As barragens serão agrupadas em diferentes categorias, segundo a sua localização, material acumulado, empreendedor, morfometria e em função de parâmetros ligados à segurança de barragens reconhecidos pelo governo. Em vez agrupar as barragens em função de suas características técnicas ou operacionais, o atlas classificou essas barragens em função da sua proximidade das populações urbanas que estariam expostas a uma possível ruptura.

Palavras-Chave: Ruptura de barragens, desastres ambientais, gestão de reservatórios. 


\begin{abstract}
In the last years, the state of Minas Gerais has suffered with repeated ruptures of dams that receive mining tailings. These events have caused immense human, social, economic and environmental damages. Furthermore, the recurrence of these disasters suggests that the management of these reservoirs is flawed, imprecise and, probably, based on insufficient or even false technical premises. The planning and construction of reservoirs that may contain tens of millions of cubic meters of tailings obviously must take into account a number of factors, whether environmental or factors related to the exiting land uses in their catchment basins. Among these uses, urbanization must be treated in a very special way. In the state of Minas Gerais there are about 400 dams that receive mining tailings. Official data show that a significant number of these structures present problems related to dam safety. The objective of the atlas is to present an updated typology of these reservoirs in a clear, objective way and using a language accessible to the general public. Special attentionis given to a set of 10 "critical municipalities" treated here as special "study cases". The dams will be grouped in different categories according to their location, entrepreneurs, available morphometric features, the nature of the accumulated material or dam safety parameters. Instead of focusing on mining activities, the atlas will rank and classify the dams according to the level of exposition of nearby populations to a possible dam break.
\end{abstract}

Keywords: Dam break, mining tailings, environmental disasters, dam management.

\title{
1. INTRODUÇÃO
}

As raízes e origens do estado de Minas Gerais estão, como o seu nome sugere, na mineração. Essa atividade é, ainda hoje, a segunda mais importante atividade econômica industrial do estado sendo responsável pela manutenção de milhares de empregos diretos e indiretos dos quais depende uma grande parcela da população mineira (FJP, 2018). Portanto, a atividade minerária sempre foi, é e continuará sendo um dos motores da economia do estado.

Muito já se escreveu sobre as relações entre a mineração e o desenvolvimento socioeconômico de Minas Gerais (e.g. SIMINATO et al., 2017). Sabe-se, por exemplo, que a mineração iniciou no estado ainda no século XVI, em pleno regime colonial, e seu desenvolvimento inicial foi completamente dependente do trabalho escravo. As principais cidades do ciclo do ouro em Minas Gerais ainda hoje têm forte influência do contingente populacional de origem Africana.

As principais cidades que participaram do ciclo do ouro, tiveram seu apogeu no século XVIII (SILVA, 1995). No entanto, elas logo entraram em um longo processo de decadência, à medida que o metal precioso foi se exaurindo das minas e lavras. Assim, todo mineiro bem sabe que o progresso regional ou local devido à atividade da mineração é algo efêmero e transitório. A instalação das minas em um município pode trazer rapidamente uma grande riqueza e pujança econômica. Entretanto, nossos governantes e gestores públicos ainda não descobriam a melhor forma de aproveitar esse ciclo econômico de curta duração para trazer bem-estar duradouro às populações. Assim, a regra no estado é que a mineração, no final do seu ciclo, sempre acaba por deixar profundas marcas negativas seja na sociedade, seja na paisagem urbana seja nos ecossistemas do entorno das 
minas. Esse cenário deve ser contextualizado considerando que já existem instrumentos regulatórios com a finalidade de se minimizar os impactos da mineração, tal como a Portaria $n^{0} 237$, de 18.10.2001, alterada pela Portaria $\mathrm{n}^{\circ}$ 12, de 22.01.2002 do DNPM, instituindo as Normas Reguladoras de Mineração (NRM's). A NRM no 20 disciplina os procedimentos administrativos e operacionais em caso de fechamento de mina, suspensão e retomada de operações mineiras, estabelecendo diretrizes para o Plano de Fechamento ou de Suspensão da Mina.

Após o ciclo do ouro e do diamante, já no início do século XX, instala-se, no estado, a mineração do ferro que, salvo algumas poucas exceções, coincide geograficamente com os mesmos municípios que tomaram parte do primeiro ciclo da mineração. Cidades como Ouro Preto, Congonhas, Mariana, Catas Altas, Santa Bárbara, Sabará ou mesmo Nova Lima podem aqui ser citadas (RUCHKYS e MACHADO, 2013).

A inauguração da ferrovia Vitória Minas ligando o porto de Vitória a dezenas de ramais ferroviários que dão acesso a variadas minas de minério de ferro foi um fator decisivo para consolidar o Brasil, ainda na década de 60, como um dos maiores exportadores de minério de ferro do mundo (TEIXEIRA, 2013). Depois, veio a ferrovia do aço ligando Congonhas ao porto de Sepetiba, RJ. Somente muito mais tarde, ao final dos anos oitenta, a província mineral de Carajás, no estado do Pará, aparece no cenário da mineração do Brasil, como a inauguração da ferrovia que liga Carajás ao Porto de Itaqui no Maranhão.

Hoje em dia, a extração, o beneficiamento e o transporte do minério de ferro formam um complexo industrial muito sofisticado que procura atender a elevados padrões internacionais de qualidade. Assim, produzir milhões de toneladas de minério de ferro de tal forma que o produto encontre mercados firmes e preços atraentes exige, além de uma complexa logística de extração, beneficiamento e transporte, uma gigantesca infraestrutura operacional que requer, dentre outros aspectos, elevado consumo de petróleo, uma variada gama de insumos químicos, mão de obra diversificada e altamente qualificada e, principalmente, grande quantidade de água de boa qualidade.

A mineração é reconhecidamente tida como uma das atividades humanas que maiores impactos ambientais causam (PINTO-COELHO e HAVENS, 2017). Além da cava de uma mina que pode atingir de uma a duas centenas de metros de profundidade, uma mina tradicional vai exigir grandes áreas para depositar estéril, grandes pátios para o acúmulo do minério, uma grande rede viária por onde trafegam imensos caminhões fora de estrada, estações ferroviárias, centros de pressurização e peletização, enormes sistemas de correias transportadoras, vários pátios para transbordo de carga, diversas plantas industriais, estações de bombeamento, tratamento de efluentes, etc. Assim, os impactos ambientais são variados e envolvem, em geral, remoção de grandes áreas com vegetação nativa, grande produção de poeira, muita poluição sonora, substanciais emissões de gases formadores do efeito "estufa", elevado consumo de energia elétrica, etc. No entanto, os maiores impactos estão 
concentrados na construção e operação de diversos tipos de barragens ou diques que permitem o acúmulo e/ou desvio, uso e reuso intenso de água de boa qualidade e emissão de efluentes de água com variados níveis de contaminação química ou física. Esses impactos, em geral, acabam por causar o rebaixamento e/ou contaminação do lençol freático e diversas outras modificações da quantidade e qualidade da água em toda a bacia hidrográfica onde a mina está inserida.

As inúmeras barragens encontradas dentro de uma mina destinam-se a variados fins tais como captação de água, decantação de sólidos, filtração de resíduos, recepção de rejeitos de diferentes texturas e granulometrias, etc. Essas barragens exigem diferentes formas de gestão ambiental e o seu controle tanto em termos de segurança das barragens quanto em termos de qualidade de suas águas tem deixado a desejar. E um fator complicador é que toda barragem por definição tem um efluente e situa-se em níveis topográficos mais elevados no terreno. Em sua grande maioria, as barragens associadas à mineração estão na parte mais à montante de suas respectivas bacias hidrográficas. Essa posição coloca as populações do seu entorno sob diferentes tipos de impactos e riscos ambientais.

Se olharmos para o cenário da mineração de ferro no estado de Minas Gerais e compararmos, por exemplo, com outra província mineral de importância mundial, tal como Carajás, no estado do Pará, três fatos se destacam: (a) a produção de minério de ferro de Minas Gerais é tão importante quanto a produção dessa commodity no Pará; (b) ao contrário do que acontece em Carajás, as maiores jazidas de minério de ferro de Minas Gerais estão muito próximas a grandes centros urbanos e (c) a menor qualidade do minério extraído das minas de MG exige um tratamento mais sofisticado e que implica em maior consumo de água (SILVA, 1995).

A implantação de uma mineração em uma dada região também impulsiona a expansão urbana, visto que atrai muita gente graças a oferta de empregos diretos e indiretos. A grande proximidade da mineração aos centros urbanos é um novo desafio para as grandes mineradoras no estado. Elas estiveram sempre acostumadas a operar a grandes distâncias da população urbana. A existência de uma mina de ferro é também um desafio para os gestores públicos. Eles deveriam planejar ou mesmo limitar a expansão urbana por meio dos zoneamentos constantes nos planos diretores. Na realidade, o que se vê, é o resultado de riscos aumentados associados à mineração em função da má qualidade dos planos municipais de zoneamento e de parcelamento urbano.

As recentes tragédias associadas à atividade de mineração causadas principalmente pelas rupturas das barragens de Fundão, em Mariana, e da Mina do Feijão, em Brumadinho, mudaram a percepção vigente de que a mineração, por ser uma atividade extremamente importante para Minas Gerais, impõe que seus impactos ambientais deveriam ser aceitos por todos. Essas tragédias causaram mais de duas centenas de mortes, muitos desaparecidos, milhares de desabrigados, perda de dezenas ou centenas de hectares de terras férteis nos vales dos rios. Tudo isso é assunto diário em inúmeras matérias de jornais, TVs, rádios e motivo para muitos fóruns de discussão em todas as redes socais 
(e.g: RIBEIRO e PINTO-COELHO, 2015; PARREIRAS, 2019; PARANAÍBA, 2019; PIRES e PINTO-COELHO, 2019, dentre outros).

As dezenas de quilômetros quadrados inundados com lama tóxica, as grandes superfícies de florestas ripárias arrancadas pela passagem da onda de rejeitos, as centenas de quilômetros de cursos d'água com sua biota e sedimentos contaminados nas bacias hidrográficas dos rios Doce e Paraopeba formam um passivo ambiental que irá permanecer por décadas nesses ecossistemas (PINTOCOELHO, 2017).

\section{OBJETIVOS}

O objetivo do Atlas das Barragens Associadas à Mineração em Minas Gerais é mostrar a relação de proximidade entre a entre a atividade de mineração no estado de Minas Gerais, as suas águas e o seu povo. Essa proximidade será medida não somente em termos geográficos ou cartográficos, mas também em termos ambientais, hidrográfico e socioeconômico. Pretende-se destacar a necessidade de mudança de rumos nesse que é o principal motor da economia mineira.

Nesse contexto, os seguintes subobjetivos podem ser citados:

(a) Identificar os principais municípios mineiros cujas águas são afetadas pelos diferentes impactos ligados à atividade de mineração;

(b) Identificar e divulgar quais são as barragens associadas à mineração que oferecem os maiores riscos à população local;

(c) sugerir novas diretrizes que possam aumentar a segurança das barragens e minimizar a exposição de riscos das populações envolvidas.

A meta geral do trabalho não é somente contribuir para o aumento do nível de conscientização ambiental das populações que vivem em zonas de risco potencial das barragens associadas à mineração do estado de Minas Gerais, mas, sobretudo, provar que é possível melhorar a convivência do homem com as minas do estado.

\section{3. ÁREA DE ESTUDO}

Minas Gerais é o maior estado da região sudeste do Brasil. Possui uma área de $586.528 \mathrm{~km}^{2}$. É o segundo estado mais populoso do Brasil, onde vivem 20,87 milhões de pessoas (2015). Minas é o terceiro estado mais rico do país, ficando somente atrás de São Paulo e Rio de Janeiro. O estado possui também o terceiro maior parque industrial do país e tem como destaques a indústria de mineração, metalúrgica, automobilística, alimentícia, têxtil, construção civil, produtos químicos e minerais não-metálicos. 
O Quadrilátero Ferrífero é uma região localizada no centro-sul do estado de Minas Gerais, com cerca de $7.000 \mathrm{~km}^{2}$, e que se constitui na segunda maior região produtora nacional de minério de ferro do país (RUCHKYS e MACHADO, 2013). Além do ferro, a região possui minas de onde é extraído ouro e manganês. Adicionalmente, trata-se de uma região com intensa ocupação humana, com dezenas de municípios, em geral com altas densidades demográficas, um intenso uso do solo. Muitas cidades do quadrilátero também muitos fazem parte da região metropolitana de Belo Horizonte (Nova Lima, Itabirito, Sabará, Caeté, Brumadinho, Itatiaiuçu, etc.). Essa região possui uma grande a infraestrutura de transportes, variadas atividades industriais, intensa atividade no setor terciário, etc.

Minas Gerais sempre englobou uma grande parcela da atividade mineira do Brasil, até que, na década de 1980, surgem outros polos importantes, notadamente em Rondônia e no Pará, reduzindo a participação mineira de valor aproximado de $60 \%$ para valores próximos de $40 \%$. Entretanto, esta redução não é absoluta, mantendo Minas Gerais produção crescente, com perdas nos setores de manganês, diamante e cassiterita. Os acréscimos absolutos dão-se nos setores de ferro, ouro, zinco, bauxita. As perdas relativas dão-se nestes mesmos setores, excluído o zinco.

As jazidas de Ferro da Serra dos Carajás, caracterizadas por qualidade excepcional dos minérios e, consequentemente, de tratamento simples e pouco oneroso, já contando com um sistema logístico de alta confiabilidade, deverão sustentar prioritariamente os programas de expansão da Vale, detentora exclusiva dos direitos minerários no Pará. As atividades mineiras (de Minas Gerais) desta empresa e outras, no setor de ferro, são voltadas principalmente ao abastecimento interno e também para complementar nos seus programas de exportação (SILVA, 1995).

O minério de ferro é extraído das minas localizadas em mais de 250 municípios de Minas Gerais e transportado principalmente por ferrovias para os portos do Espírito Santo e do Rio de Janeiro, de onde é exportado para a China e para dezenas de outros países. Os dados mostram que no primeiro bimestre de 2019 as exportações de minério de ferro totalizaram US \$ 1,26 bilhão, 16\% superior aos US \$ 1,08 bilhão registrados no mesmo período de 2018. Em 2018, o estado de Minas Gerais exportou muito mais do que importou. A diferença entre exportações e importações foi positiva em US \$ 14,9 bilhões. O estado exportou US \$23,9 bilhões e importou apenas US \$ 9 bilhões. $60 \%$ de tudo aquilo o que o estado de Minas Gerais exporta é devido ao minério de ferro (PMB, 2019).

\section{METODOLOGIA}


O presente estudo baseia-se em uma análise feita a partir de dados secundários existentes nos seguintes bancos de dados oficiais sobre barragens de mineração e sobre estatística e geografia do Brasil:

1) Agência Nacional de Mineração ANM - Departamento Nacional da Produção Mineral - DNPM - http://www.dnpm.gov.br/assuntos/barragens.

A Lei No 12.334, de 20/9/2010, define que órgão fiscalizador deverá implantar o cadastro das barragens sob sua jurisdição no prazo máximo de 02 (dois) anos, a partir da data de sua publicação. Cabe ao órgão fiscalizador criar e manter cadastro das barragens sob sua jurisdição, com identificação dos empreendedores, para fins de incorporação ao SNISB - Sistema Nacional de Informações sobre Segurança de Barragens de Mineração, assim como exigir do empreendedor o cadastramento e a atualização das informações relativas às barragens de sua responsabilidade. A lei prevê que todos os empreendedores deverão declarar todas as barragens (em construção, em operação e as desativadas) de sua responsabilidade no SIGBM.

No portal acima, pode-se baixar a lista nacional de classificação das barragens de mineração - Data Base Dezembro/2016. Esse banco de dados está disponível no website: http://www.anm.gov.br/assuntos/barragens/pasta-cadastro-nacional-de-barragens-demineracao/cadastro-nacional-de-barragens-de-mineracao. A lista das barragens da ANM/DNPM traz as seguintes informações: Nome da barragem, nome do empreendedor, CPF/CNPJ, altura da barragem (metros), latitude, longitude, posicionamento ( $\mathrm{S}, \mathrm{N})$, município, unidade da federação, tipo de minério, porte pelo volume (muito pequeno, pequeno porte, médio porte, grande porte, muito grande), categoria de risco (baixo, médio, alto), dano potencial (baixo, médio, alto), classe (A, B, C, D e E), inserção no PNSB (sim, não). Doravante, nessa publicação, a citação a esse banco de dados será feita da seguinte forma: ANM/DNPM.

Os critérios para uma barragem ser incluída no Plano Nacional de Segurança de Barragens (PNSB) são: altura da barragem $>=15$ metros, volume acumulado $>=3,0$ milhões de metros cúbicos, resíduo acumulado considerado "perigoso" e dano potencial associado "médio" ou "alto". O banco de dados está no formato PDF.

2) Listas e Inventários das Barragens de Minas Gerais - FEAM (2011, 2012, 2013, 2014, 2015, 2016, 2017, 2017 e 2018).

O cadastramento e o monitoramento das barragens em Minas Gerais estão a cargo da Fundação Estadual do Meio Ambiente- FEAM (http://www.feam.br/monitoramento/gestao-debarragens). Esse programa tem por objetivo promover a classificação quanto ao potencial de dano 
ambiental e a atualização sistemática das informações relativas às auditorias de segurança, visando à minimização da probabilidade da ocorrência de acidentes com danos ambientais.

Os responsáveis por empreendimentos industriais e minerários que possuem barragens de contenção de rejeitos, de resíduos e de reservatórios de água devem apresentar à FEAM o Cadastro de Barragem, em cumprimento à Deliberação Normativa COPAM 87/2005.

A FEAM disponibiliza ao público em geral um banco de dados sobre barragens de mineração que vem sendo atualizado anualmente desde 2011. O banco traz as seguintes informações: CNPJ do empreendimento, nome do empreendimento, classe, município, bacia hidrográfica, tipologia (mineração, indústria, destilaria de álcool, etc.), altura atual $(\mathrm{m})$, volume do reservatório $\left(\mathrm{m}^{3}\right)$, situação de estabilidade (garantida pelo auditor, estabilidade ainda não garantida pelo auditor, etc.) $\mathrm{O}$ banco de dados está no formato MS-Excel. Doravante, a citação a esse banco de dados será feita da seguinte forma: FEAM.

3) Banco de dados "IBGE - Cidades"

O portal Cidades (https://cidades.ibge.gov.br/) é o sistema agregador de informações do Instituto Brasileiro de Geografia e Estatística - IBGE sobre os todos municípios e estados do Brasil. Nesse portal, estão disponíveis os resultados das pesquisas mais recentes do IBGE. Há vários tipos de rankings e séries históricas sobre diversos temas, como trabalho, educação, gênero, saúde, entre outros. Os principais índices de desenvolvimento humano estão disponíveis também: PIB, IPCA, IDH, além de infográficos e mapas.

O trabalho consistiu em estudar, organizar, selecionar as informações de interesse desses três bancos de dados de modo a atingir os objetivos propostos. O foco central desse estudo foi demonstrar a "proximidade" das represas associadas à atividade de mineração e os centros urbanos no estado de MG. Essa "proximidade" não pode ser vista somente em termos de distância linear entre um dado empreendimento minerário e a sede municipal.

Outros fatores, tais como a densidade demográfica, a morfometria e hidrografia das águas municipais e urbanas, a expansão do parcelamento urbano, a rede viária, e os principais índices de desenvolvimento humano também devem ser observados.

Esse estudo analisou os dados das barragens de mineração do estado observando o estabelecido pela matriz para a classificação de barragens para disposição de resíduos e rejeitos. Essa matriz prevê duas avaliações relativas à segurança dessas estruturas: (1) categoria de risco e (2) dano potencial associado.

A categoria de risco - CRI (1) resulta de um somatório de três parâmetros:

$$
\mathrm{CRI}=\mathrm{CT}+\mathrm{EC}+\mathrm{PS}
$$


Onde:

CRI: categoria de risco

CT: características técnicas

EC: Estado de conservação da barragem

PS: Plano de segurança da barragem,

Existem três categorias de risco aplicáveis aos reservatórios que acumulam rejeitos ou resíduos:

\begin{tabular}{|c|c|c|c|c|}
\hline BAIXO: & CRI & $\leq$ & 35 & \\
\hline MÉDIO: & 35 & $<$ & CRI & $<$ \\
\hline ALTO: & CRI & $\geq$ & 60 & \\
\hline
\end{tabular}

As características técnicas levam em conta a altura da barragem, seu comprimento e a vazão de projeto.

O estado de conservação leva em conta a confiabilidade das estruturas extravasoras, o grau de percolação, deformações e recalques e a deterioração dos taludes.

O plano de segurança aborda os seguintes aspectos: estrutura organizacional e qualificação dos profissionais na equipe de segurança da barragem, manuais de procedimentos para inspeções de segurança e monitoramento, plano de ação emergencial - PAE (quando exigido pelo órgão fiscalizador), a documentação de projeto e os relatórios de inspeção e monitoramento da instrumentação e de análise de segurança.

O dando potencial associado - DPA (2) é estimado com base em avaliações quantitativas dos seguintes parâmetros: volume do reservatório, existência de populações humanas à jusante da estrutura da barragem e os impactos ambientais e socioeconômicos.

Os reservatórios são enquadrados em três categorias de danos potenciais associados (DPA):

$\begin{array}{llll}\text { BAIXO: } & \text { DPA } \leq 7,0 & \\ \text { MÉDIO: } & 7,0<\quad \text { DPA }<1,0 \\ \text { ALTO: } & \text { DPA } \geq 13,0\end{array}$

O volume de um reservatório, por exemplo, será enquadrado em uma das seguintes categorias:

$\begin{array}{llll} & \text { Muito Pequeno } & <0,5 \text { milhão de } \mathrm{m}^{3} \\ 0,5 \text { milhão de } \mathrm{m}^{3} & <\text { Pequeno } & <5,0 \text { milhões de } \mathrm{m}^{3} \\ 5,0 \text { milhões de } \mathrm{m}^{3} & <\text { Médio } & <25 \text { milhões de } \mathrm{m}^{3} \\ 25 \text { milhões de } \mathrm{m}^{3} & <\text { Grande }<50 \text { milhões de } \mathrm{m}^{3} \\ 50 \text { milhões de } \mathrm{m}^{3} & <\quad \text { Muito Grande }\end{array}$


Segundo a matriz acima, o potencial de impacto ambiental é avaliado em uma das seguintes categorias:

INSIGNIFICANTE: área afetada a jusante da barragem encontra-se totalmente descaracterizada de suas condições naturais e a estrutura armazena apenas resíduos Classe II B - Inertes, segundo a NBR 10.004 da ABNT.

POUCO SIGNIFICATIVO: área afetada a jusante da barragem não apresenta área de interesse ambiental relevante ou áreas protegidas em legislação específica, excluídas APPs, e armazena apenas resíduos Classe II B - Inertes, segundo a NBR 10.004 da ABNT.

SIGNIFICATIVO: área afetada a jusante da barragem apresenta área de interesse ambiental relevante ou áreas protegidas em legislação específica, excluídas APPs, e armazena apenas resíduos Classe II B - Inertes, segundo a NBR 10.004 da ABNT.

MUITO SIGNIFICATIVO: barragem armazena rejeitos ou resíduos sólidos classificados na Classe II A - Não Inertes, segundo a NBR 10004 da ABNT.

É importante observar que os impactos de uma barragem de mineração não estão restritos somente ao grau de periculosidade dos rejeitos armazenados ou a existência de unidades de conservação a jusante, como dito acima. O capital natural mesmo aquele fora de unidades de conservação e também a biota e os biótopos situados dentro da malha urbana também devem ser observados. E mais. O conceito de "interesse ambiental" é muito subjetivo. Hoje, a literatura internacional recomenda que se considere não somente os atributos estruturais da biodiversidade.

O capital natural engloba não somente os ecossistemas terrestres e a sua biodiversidade. A integridade física e metabólica dos ambientes lênticos (lagos e reservatórios), ambientes lóticos (ribeirões e rios) e todas as áreas úmidas, bem como os ecótonos da interface terra-água devem ser integrados nessa análise. Somente a integração de aspectos estruturais da biota (biodiversidade) com os processos ecológicos necessários à sua manutenção (assimilação, produção, decomposição, regeneração, etc.) é que vão garantir a oferta sustentável de serviços ecossistêmicos às futuras gerações.

4) Espacialização das barragens e dos centros urbanos

Os limites dos municípios foram obtidos do site do IBGE e os limites dos centros urbanos e os limites ausentes complementados por meio da digitalização no Google Earth, o mesmo procedimento foi adotado para a espacialização dos limites das barragens sendo a localização destas identificadas por meio das coordenadas geográficas constantes no Cadastro Nacional de Barragens do ano de 2016, elaborado pelo DNPM, e os limites das represas digitalizados no Google Earth 
empregando imagens com uma variação temporal de 2010 à 2019, com a finalidade de se detectar nas imagens o limite do espelho de cada represa (e diques).

Complementarmente, foi elaborado o mapa de direção do fluxo para cada município analisado, onde pode-se detectar o sentido que o fluxo teria em um processo de escoamento superficial, cabe ressaltar que neste trabalho não foi realizado a simulação do escoamento em caso de rompimento com grandes volumes onde seria possível detectar a extensão da área atingida, visto não ser o objetivo deste trabalho, sendo neste buscado apenas o sentido do fluxo.

Para a elaboração do mapa de direção do fluxo foi empregado o Modelo Digital de Elevação (MDE) derivado dos dados obtidos pela nave espacial americana durante a missão conhecida como SRTM (Shuttle Radar Topography Mission), disponível para download no site da EMBRAPA (https://www.cnpm.embrapa.br/projetos/relevobr/download/index.htm). Para o cálculo da direção do fluxo foi empregado o Sistema de Informação Geográfica (SIG) ArcGis 10.3.

Para as barragens que apresentaram o fluxo direcionado para os centros urbanos foi extraída a distância aproximada destas aos centros no Google Earth.

\section{RESULTADOS}

O número de barragens no estado de Minas Gerais cadastradas nos dois bancos de dados oficiais da União e de MG são, respectivamente, 367 barragens no banco de dados do ANM/DNPM e 698 estruturas, na lista da FEAM. A diferença entre os dois bancos de dados reside nas diferentes tipologias de barragens que o banco de dados mineiro adota. Além das barragens associadas à mineração, a lista da FEAM inclui barragens do setor sucroalcooleiro (170) e do setor industrial (93 estruturas). Em termos de barragens associadas à mineração os dois bancos trazem um número mais similar: 435 (FEAM) e 367 (DNPM), muito embora a lista da FEAM seja maior, contemplando 67 estruturas a mais.

A lista da FEAM nos informa que existem barragens de diversas tipologias em 109 municípios mineiros. Segundo a lista do ANM/DNPM, são 56 os municípios mineiros afetados por barragens exclusivamente associadas à mineração. Cerca de 300 barragens mineiras de mineração (ANM/DNPM=293, FEAM = 305), ou seja, 80\% do total desse tipo de barragens, estão concentradas em 20 municípios, onde vivem 3,78 milhões de pessoas (19,5\% da população mineira) (Tab. 1).

Tabela 1: Os vinte municípios mineiros com maior concentração de barragens associadas à mineração.

\begin{tabular}{ccccccc}
\hline N & Município & $\begin{array}{c}\text { Barragens } \\
\text { DNPM }\end{array}$ & $\begin{array}{c}\text { Barragens } \\
\text { FEAM }\end{array}$ & $\begin{array}{c}\text { Volume } \\
\text { acumulado no } \\
\text { município } \\
\left(\mathbf{x ~ 1 0} \mathbf{~ m}^{\mathbf{3}}\right)\end{array}$ & População & Ind/km $^{2}$ \\
\hline 1 & ITABIRA & 33 & $27(\mathrm{M})$ & 5,71 & 120160 & 87,57 \\
2 & ITATIAIUÇU & 33 & $30(\mathrm{M})$ & 1,35 & 9928 & 33,64
\end{tabular}




\begin{tabular}{|c|c|c|c|c|c|c|}
\hline 3 & ITABIRITO & 30 & $31(\mathrm{M})$ & 3,54 & 51875 & 83,76 \\
\hline 4 & OURO PRETO & 28 & $32(\mathrm{M})$ & 2,04 & 74281 & 56,41 \\
\hline 5 & NOVA LIMA & 27 & $26(\mathrm{M})$ & 0,21 & 94889 & 188,73 \\
\hline 6 & BRUMADINHO & 26 & $32(\mathrm{M})$ & 8,89 & 40103 & 53,13 \\
\hline 7 & CONGONHAS & 18 & $19(\mathrm{M})$ & 14,6 & 54762 & 159,57 \\
\hline 8 & MARIANA & 13 & $18(\mathrm{M})$ & 2,09 & 60724 & 45,40 \\
\hline 9 & BARÃO DE COCAIS & 10 & $11(\mathrm{M})$ & 1,10 & 32485 & 83,51 \\
\hline 10 & PARACATU & 10 & $9(\mathrm{M})$ & 0,07 & 93158 & 10,29 \\
\hline 11 & BELA VISTA DE MINAS & 8 & $7(\mathrm{M})$ & 51,0 & 10255 & 91,66 \\
\hline 12 & SABARÁ & 8 & $5(\mathrm{M})$ & 0,01 & 126.269 & 417,87 \\
\hline 13 & ARAXÁ & 7 & $9(\mathrm{M})$ & 4,26 & 106229 & 80,45 \\
\hline 14 & BELO HORIZONTE & 6 & $3(\mathrm{M})$ & 2,40 & 2505070 & 7167,00 \\
\hline 15 & MATEUS LEME & 6 & $9(\mathrm{M})$ & 0,09 & 31086 & 92,02 \\
\hline 16 & RIO ACIMA & 6 & $8(\mathrm{M})$ & 0,02 & 10302 & 39,55 \\
\hline 17 & RIO PIRACICABA & 6 & $6(\mathrm{M})$ & 0,02 & 14339 & 39,93 \\
\hline 18 & $\begin{array}{c}\text { SÃO GONÇALO DO RIO } \\
\text { ABAIXO }\end{array}$ & 6 & $6(\mathrm{M})$ & 0,01 & 10920 & 26,87 \\
\hline 19 & TAPIRA & 6 & $6(\mathrm{M})$ & 0,01 & 4773 & 3,49 \\
\hline 20 & UBERABA & 6 & $11(\mathrm{M})$ & 0,02 & 333783 & 65,43 \\
\hline & Total & 293 & 305 & & 3785391 & \\
\hline
\end{tabular}

Obs: $(\mathrm{M})$ apenas contadas as barragens associadas à mineração.

Fonte: (ANM/DNPM).

Essas barragens estão concentradas principalmente nos municípios que formam um polígono conhecido como quadrilátero ferrífero de Minas Gerais (Fig. 1).

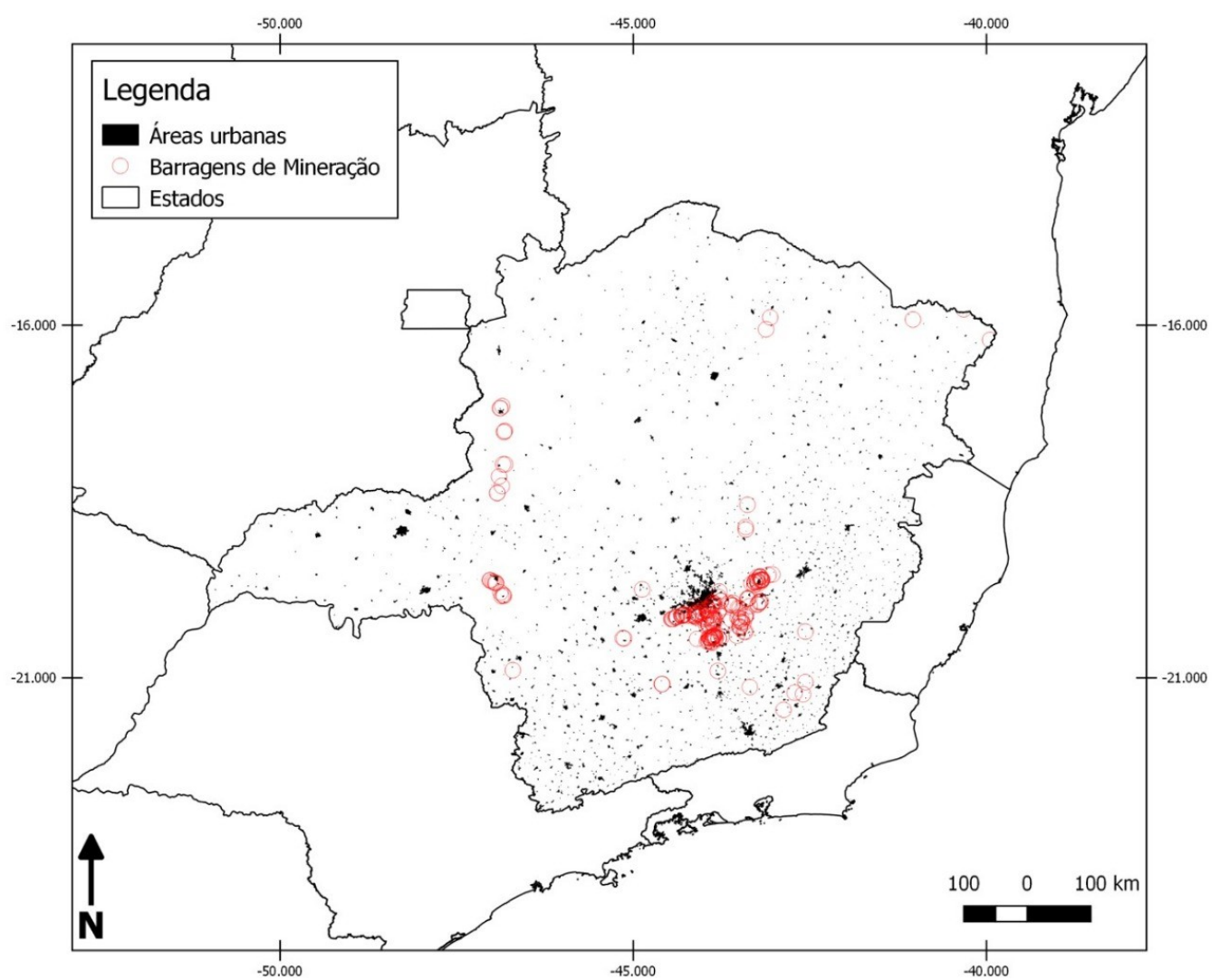

Figura 1 - Áreas urbanas e as principais barragens associadas à mineração no estado de Minas Gerais. 
O estado de Minas Gerais destaca-se não somente pelo elevado número de barragens associadas à mineração existente em seu território, mas também no porte dessas estruturas. Das 20 barragens com os maiores volumes de rejeitos acumulados existentes no Brasil, 15 estão localizadas no estado de Minas Geris (Tab. 2).

Tabela 2: Barragens associadas à mineração com os maiores volumes acumulados de rejeitos.

\begin{tabular}{|c|c|c|c|c|c|c|c|c|c|}
\hline & Barragem & $\begin{array}{c}\text { Empresa } \\
\text { responsável }\end{array}$ & $\begin{array}{c}\text { Altura } \\
\text { (m) }\end{array}$ & $\begin{array}{c}\text { Volume } \\
\left(\mathbf{m}^{\mathbf{3}}\right)\end{array}$ & Minério & UF & Município & CRI & DPA \\
\hline 1 & $\begin{array}{l}\text { Barragem do } \\
\text { Eustáquio }\end{array}$ & $\begin{array}{c}\text { Rio Paracatu } \\
\text { Mineracão S. A. }\end{array}$ & 140 & 750000000 & Ferro & MG & Paracatu & Baixo & Alto \\
\hline 2 & Santarém & $\begin{array}{c}\text { Samarco } \\
\text { Mineração S. A. }\end{array}$ & 31 & 672000000 & Ferro & MG & Mariana & Baixo & Alto \\
\hline 3 & $\begin{array}{l}\text { Santo } \\
\text { Antônio }\end{array}$ & $\begin{array}{c}\text { Rio Paracatu } \\
\text { Mineração S. A. }\end{array}$ & 104 & 483000000 & $\begin{array}{l}\text { Minério de } \\
\text { Ouro }\end{array}$ & MG & Paracatu & Baixo & Alto \\
\hline 4 & $\begin{array}{l}\text { Barragem de } \\
\text { Rejeitos }\end{array}$ & $\begin{array}{c}\text { Anglo American } \\
\text { Minério de Ferro } \\
\text { Brasil S.A. }\end{array}$ & 85 & 380000000 & Ferro & MG & $\begin{array}{l}\text { Conceição do } \\
\text { Mato Dentro }\end{array}$ & Baixo & Alto \\
\hline 5 & $\begin{array}{l}\text { Barragem do } \\
\quad \text { sapo }\end{array}$ & $\begin{array}{l}\text { Anglo Ferrous } \\
\text { Minas Rio } \\
\text { Mineração S.A. }\end{array}$ & 85 & 370000000 & Ferro & MG & $\begin{array}{l}\text { Conceição do } \\
\text { Mato Dentro }\end{array}$ & Baixo & Alto \\
\hline 6 & $\begin{array}{l}\text { Barragens de } \\
\text { Rejeitos }\end{array}$ & Salobo Metais Sa. & 100 & 263300000 & NULL & $\mathrm{PA}$ & Marabá & Baixo & Alto \\
\hline 7 & $\begin{array}{l}\text { Barragem } \\
\text { Itabiruçu }\end{array}$ & Vale S A & 68 & 230000000 & Ferro & MG & Itabira & Baixo & Alto \\
\hline 8 & Barragem BR & $\begin{array}{l}\text { Vale Fertilizantes } \\
\text { S/A }\end{array}$ & 81 & 190000000 & Fosfato & MG & Tapira & Baixo & Alto \\
\hline 9 & $\begin{array}{l}\text { Barragem } \\
\text { BL-1 }\end{array}$ & $\begin{array}{l}\text { Vale Fertilizantes } \\
\text { S/A }\end{array}$ & 96 & 160000000 & NULL & MG & Tapira & Baixo & Alto \\
\hline 10 & $\begin{array}{l}\text { Barragem do } \\
\text { Sossego }\end{array}$ & Vale S. A. & 266,6 & 131760000 & cobre & $\mathrm{PA}$ & $\begin{array}{c}\text { Canaã } \\
\text { dos Carajás }\end{array}$ & Baixo & Alto \\
\hline 11 & $\begin{array}{l}\text { Barragem } \\
\text { Pontal }\end{array}$ & Vale S. A. & 69 & 122500000 & Ferro & MG & Itabira & Baixo & Alto \\
\hline 12 & $\begin{array}{l}\text { Barragem do } \\
\text { Germano }\end{array}$ & $\begin{array}{c}\text { Samarco } \\
\text { Mineração S.a. }\end{array}$ & 165 & 121000000 & Ferro & MG & Mariana & Baixo & Alto \\
\hline 13 & Barragem-BR & $\begin{array}{c}\text { Vale Fertilizantes } \\
\text { S A }\end{array}$ & 61 & 95000000 & Apatita & GO & Catalão & Baixo & Alto \\
\hline 14 & $\begin{array}{l}\text { Barragem do } \\
\text { Fundão }(*)\end{array}$ & $\begin{array}{c}\text { Samarco } \\
\text { Mineração S.A. }\end{array}$ & 130 & 91866000 & Ferro & MG & Mariana & Baixo & Alto \\
\hline 15 & $\begin{array}{c}\text { Barragem } \\
\text { Maravilhas II }\end{array}$ & $\begin{array}{l}\text { Minerações } \\
\text { Brasileiras }\end{array}$ & 93 & 76292000 & Ferro & MG & Itabirito & Baixo & Alto \\
\hline 16 & $\begin{array}{l}\text { Barragem do } \\
\text { Gelado }\end{array}$ & Vale S. A. & 34 & 75000000 & Ouro & $\mathrm{PA}$ & Parauapebas & Baixo & Alto \\
\hline 17 & $\begin{array}{l}\text { Barragem } \\
\text { Santa Rita }\end{array}$ & $\begin{array}{l}\text { Mirabela } \\
\text { Mineração do } \\
\text { Brasil Ltda. }\end{array}$ & 60 & 70556589 & $\begin{array}{l}\text { Minério de } \\
\text { Níquel }\end{array}$ & BA & Itagibá & Baixo & Alto \\
\hline 18 & $\begin{array}{l}\text { Barragem } \\
\text { Casa de } \\
\text { Pedra }\end{array}$ & $\begin{array}{l}\text { Companhia } \\
\text { Siderúrgica } \\
\text { Nacional }\end{array}$ & 95 & 70000000 & $\begin{array}{c}\text { Ferro e } \\
\text { Manganês }\end{array}$ & MG & Congonhas & Baixo & Alto \\
\hline
\end{tabular}

(*) a barragem do Fundão rompeu-se no dia 05/NOV/2015, causando o que ficou conhecido como o "tragédia de Mariana" ou a "tragédia da Samarco".

Apesar das barragens de "grande porte" existentes em Minas Gerais considerando apenas a tipologia "mineração", a grande maioria dessas barragens é constituída por estruturas de porte "muito pequeno" (66\%). Essas barragens acumulam até 5 milhões de $\mathrm{m}^{3}$. No entanto, existem no estado de 
Minas Gerais 37 barragens $\left(10 \%\right.$ do total) com volumes entre 5 e 25 milhões de $\mathrm{m}^{3}$ de rejeitos acumulados e 17 barragens com volumes de rejeitos acumulados superior a 25 milhões de $\mathrm{m}^{3}$ (Tab. $3)$.

Tabela 3: Porte das barragens exclusivamente associadas à mineração do estado de Minas Gerais.

\begin{tabular}{ccc}
\hline Porte das Barragens & Número & Percentual \\
\hline MUITO PEQUENO & 241 & 66 \\
PEQUENO PORTE & 72 & 20 \\
MÉDIO PORTE & 37 & 10 \\
MUITO GRANDE & 11 & 3 \\
GRANDE PORTE & 6 & 2 \\
Total Geral & $\mathbf{3 6 7}$ & $\mathbf{1 0 0}$ \\
\hline
\end{tabular}

Fonte: ANM/DNPM.

Em relação às categorias de risco, um pouco mais da metade $(54,5 \%)$ das estruturas de barragens associadas à mineração do estado de Minas Gerais apresenta a classificação "Baixo Risco" (Tab. 4). Chama a atenção o número de estruturas que sequer foram classificadas em termos de riscos que apresentam às populações humanas (39,8\%). A lista do ANM/DNPM nos informa que 21 barragens apresentam riscos médios ou elevados à população do entorno dessas estruturas $(5,7 \%$ do total de 367 barragens).

Tabela 4: Categorias de risco (CRI) das barragens associadas à mineração do estado de Minas Gerais segundo o Cadastro Nacional de Barragens - ANM/DNPM.

\begin{tabular}{ccc}
\hline Categoria de Risco - CRI & Número & Percentual \\
\hline BAIXO & 200 & 54,5 \\
Sem avaliação (vazio) & 146 & 39,8 \\
ALTO & 11 & 3,0 \\
MÉDIO & 10 & 2,7 \\
Total Geral & $\mathbf{3 6 7}$ & $\mathbf{1 0 0 , 0}$ \\
\hline
\end{tabular}

Existe um número considerável de estruturas de barragens de rejeitos em Minas Gerais que oferecem um elevado potencial de danos às populações ribeirinhas, ao patrimônio histórico-cultural, à infraestrutura urbana e rural, bem como ao meio ambiente. Existem nada menos do que 148 barragens nessa condição no estado de Minas Gerais (40,3 \% do total de 367 barragens cadastradas pelo DNPM (Tab. 5).

Tabela 5: Categorias de dano potencial associado (DPA) das barragens associadas à mineração do estado de Minas Gerais segundo o Cadastro Nacional de Barragens - ANM/DNPM.

\begin{tabular}{ccc}
\hline Dano Potencial Associado - DPA & Número & Percentual \\
\hline ALTO & 148 & 40,3 \\
BAIXO & 23 & 6,3
\end{tabular}




\begin{tabular}{ccc} 
MÉDIO & 50 & 13,6 \\
Sem avaliação (vazio) & 146 & 39,8 \\
Total Geral & 367 & 100,0 \\
\hline
\end{tabular}

A Vale é, sem dúvida alguma, a maior gestora de barragens associadas à mineração no estado de Minas Gerais (Tab. 6). A companhia é responsável por nada menos do que 120 desse tipo de barragens. É interessante notar que desse total, apenas $70 \%$ de estruturas já estão devidamente classificadas com seu valor de dano potencial. Isso significa dizer que a companhia não tem condições de afirmar qual é o dano potencial associado de 36 de suas barragens. Em outubro de 2019, a Vale ainda tinha pelo menos 18 barragens com DCEs negativas (HOJE EM DIA, 01/10/2019)

O segundo grupo de empreendedores é formado pelas empresas Mineração Usiminas, Vale Fertilizantes, Companhia Siderúrgica Nacional, Mineração Serra da Moeda, Minerita Itaúna e Gerdau Açominas. Esse grupo possui um número muito menor de barragens sob a sua responsabilidade (928). Esses empreendedores se destacam por apresentar percentuais muito diferenciados de índices de cadastramento em categorias de danos potenciais. A Mineração Serra da Moeda, por exemplo, é responsável pela gestão de 11 barragens sendo que nenhuma delas recebeu a sua classificação dos danos potenciais.

Tabela 6: Seleção dos vinte empreendimentos que respondem pelo maior número de barragens associadas à mineração no estado de Minas Gerais, segundo o Cadastro Nacional de Barragens - ANM/DNPM.

\begin{tabular}{|c|c|c|c|c|c|c|}
\hline & Rótulos de Linha & Número & $\sum$ & $\begin{array}{l}\text { \% do } \\
\text { Total }\end{array}$ & $\begin{array}{c}\text { Contagem } \\
\text { de Dano } \\
\text { Potencial } \\
\end{array}$ & $\begin{array}{c}\text { Certificação } \\
\text { DCE (\%) }\end{array}$ \\
\hline 1 & Vale S A & 120 & 120 & 32,9 & 85 & 70,8 \\
\hline 2 & Mineração Usiminas S.a. & 28 & 148 & 40,5 & 7 & 25,0 \\
\hline 3 & Vale Fertilizantes S A & 14 & 162 & 44,4 & 12 & 85,7 \\
\hline 4 & Companhia Siderúrgica Nacional SA & 12 & 174 & 47,7 & 8 & 66,7 \\
\hline 5 & $\begin{array}{c}\text { MSM - MINERAÇÃO SERRA DA MOEDA } \\
\text { LTDA }\end{array}$ & 11 & 185 & 50,7 & 0 & 0,0 \\
\hline 6 & MINERITA - MINÉRIOS ITAÚNA LTDA. & 10 & 195 & 53,4 & 3 & 30,0 \\
\hline 7 & GERDAU AÇOMINAS S.A. & 9 & 204 & 55,9 & 7 & 77,8 \\
\hline 8 & Arcelormittal Brasil S.a & 8 & 212 & 58,1 & 0 & 0,0 \\
\hline 9 & SAFM MINERAÇÃO LTDA & 7 & 226 & 61,9 & 1 & 14,3 \\
\hline 10 & Nacional Minerios S/A & 7 & 226 & 61,9 & 6 & 85,7 \\
\hline 11 & KINROSS BRASIL MINERAÇÃO S. A. & 7 & 233 & 63,8 & 7 & 100,0 \\
\hline 12 & Nacional de Grafite Ltda & 6 & 239 & 65,5 & 6 & 100,0 \\
\hline 13 & $\begin{array}{l}\text { ANGLOGOLD ASHANTI CÓRREGO DO } \\
\text { SÍTIO MINERAÇÃO S.A. }\end{array}$ & 6 & 245 & 67,1 & 6 & 100,0 \\
\hline 14 & $\begin{array}{c}\text { IMA - INDÚSTRIA DE MADEIRA } \\
\text { IMUNIZADA LTDA. }\end{array}$ & 6 & 251 & 68,8 & 2 & 33,3 \\
\hline 15 & Magnesita Refratários SA & 6 & 257 & 70,4 & & 0,0 \\
\hline 16 & $\begin{array}{l}\text { MINERACOES BRASILEIRAS REUNIDAS } \\
\text { SA }\end{array}$ & 5 & 262 & 71,8 & 5 & 100,0 \\
\hline 17 & Mmx Sudeste Mineração S.a. & 5 & 267 & 73,2 & 5 & 100,0 \\
\hline
\end{tabular}




\begin{tabular}{ccccccc}
\multicolumn{2}{c}{ COMPANHIA DE MINERAÇÃO SERRA } & & & & & \\
& AZUL & 5 & 272 & 74,5 & 4 & 80,0 \\
19 & - COMISA & & & & & 25,0 \\
20 & EXTRATIVA MINERAL LTDA & 4 & 272 & 74,5 & 1 & 100,0 \\
& Herculano Mineração Ltda. & 4 & 276 & 75,6 & 4 & \\
\hline
\end{tabular}

A seguir, iremos apresentar uma seleção de casos de estudo, envolvendo 10 municípios que consideramos "críticos" no estudo, seja pelo elevado número de barragens, pela categoria de risco de suas estruturas, pelo potencial de danos ou de alarmes envolvendo situações de risco das barragens.

\subsection{Caso de estudo: Itabira (MG)}

O município possui uma população de 120.160 habitantes que se distribuem no território municipal com uma densidade de $87,57 \mathrm{hab} . \mathrm{km}^{2}$. Distando cerca de $105 \mathrm{~km}$ de Belo Horizonte, a cidade tem um PIB per capta de R\$ 30 mil e seu IDHM é de 0,756 (IBGE 2019).

Itabira conta com 27 barragens cadastradas no banco de dados da FEAM. Já o banco de dados da ANM/DNPM lista 33 barragens para o município (Tab. 1).

No presente estudo, foram localizadas 29 barragens (Tab. 7). Se considerarmos os volumes desses reservatórios no banco de dados da Fundação Mineira, todos seriam enquadrados como sendo de pequeno porte. O somatório dos volumes acumulado por elas - segundo a FEAM - é de 5,71 milhões de $\mathrm{m}^{3}$.

O município foi incluído como um caso de estudo graças ao elevado número de barragens de mineração e a grande proximidade dessas barragens com a manha urbana. O sistema de barragens e diques do Pontal é aquele que maior risco oferece à população de Itabira. Em abril de 2019, a Agência Nacional de Mineração suspendeu a DCE do Dique 2 do sistema de barragens de Pontal. Segundo a BBC citando a Agência Nacional de Mineração (BARIFOUSE, 2019), as cinco barragens mais próximas do centro da cidade armazenam 423 milhões de $\mathrm{m}^{3}$ de rejeitos. É um volume equivalente a 33 vezes o que havia na primeira barragem que se rompeu na mina do Córrego do Feijão, em Brumadinho.

As principais barragens de Itabira bem como os seus posicionamentos dentro da rede hidrográfica e em relação à área urbanizada estão ilustradas na Fig. 2. Os possíveis fluxos da onda de lama, em caso de rompimento dessas barragens estão apontados na Fig. 3.

Em caso de ruptura de pelo menos seis represas, a onda de lama e rejeitos atingiria parte da malha urbana da cidade (Tab. 7, Fig. 3). Isso deve-se ao fato de que elas estão à montante, na mesma bacia hidrográfica da cidade. 
Tabela 7: Barragens do município de Itabira, segundo o CADASTRO NACIONAL DE BARRAGENS (2017). No caso de haver rompimento, são fornecidas as distâncias aproximadas que os rejeitos irão percorrer antes de atingir a malha urbana.

\begin{tabular}{|c|c|c|c|c|c|c|c|}
\hline $\mathbf{N}$ & Município & Barragem & $\begin{array}{l}\text { Altura } \\
\text { (m) }\end{array}$ & Latitude & Longitude & $\begin{array}{c}\text { Atinge o } \\
\text { Centro se } \\
\text { romper }\end{array}$ & $\begin{array}{l}\text { Distância do } \\
\text { centro } \\
\text { urbano }(\mathrm{km})\end{array}$ \\
\hline 1 & Itabira & $\begin{array}{c}\text { BARRAGEM ALCINDO } \\
\text { VIEIRA (CAUÊ) }\end{array}$ & 27 & $19^{\circ} 34^{\prime} 28^{\prime \prime} 2$ & $43^{\circ} 14^{\prime} 46^{\prime \prime} 6$ & Não & \\
\hline 2 & Itabira & $\begin{array}{c}\text { BARRAGEM } \\
\text { BORRACHUDO II }\end{array}$ & 20 & $19^{\circ} 36^{\prime} 45^{\prime \prime} 0$ & $43^{\circ} 16^{\prime} 00^{\prime \prime} 4$ & Não & \\
\hline 3 & Itabira & $\begin{array}{c}\text { BARRAGEM CAMBUCAL } \\
\text { I (MINAS DO MEIO) }\end{array}$ & 15,4 & $19^{\circ} 38^{\prime} 26^{\prime \prime} 3$ & $43^{\circ} 14^{\prime} 29^{\prime \prime} 3$ & Sim & 0,5 \\
\hline 4 & Itabira & $\begin{array}{c}\text { BARRAGEM CAMBUCAL } \\
\text { II (Minas do Meio) }\end{array}$ & 17,5 & $19^{\circ} 38^{\prime} 44^{\prime \prime} 1$ & $43^{\circ} 14^{\prime} 32^{\prime \prime} 0$ & Sim & 0,3 \\
\hline 5 & Itabira & BARRAGEM CEMIG I & 32,5 & $19^{\circ} 34^{\prime} 32^{\prime \prime} 2$ & $43^{\circ} 12^{\prime} 17^{\prime \prime} 1$ & Não & \\
\hline 6 & Itabira & BARRAGEM CONCEIÇÃO & 60 & $19^{\circ} 38^{\prime} 51^{\prime \prime} 3$ & $43^{\circ} 16^{\prime} 26^{\prime \prime} 9$ & Sim & 3,3 \\
\hline 7 & Itabira & $\begin{array}{l}\text { BARRAGEM ITABIRUÇU } \\
\text { (Conceição) }\end{array}$ & 68 & $19^{\circ} 41^{\prime} 07^{\prime \prime} 2$ & $43^{\circ} 17^{\prime} 10^{\prime \prime} 0$ & Sim & 5 \\
\hline 8 & Itabira & $\begin{array}{l}\text { BARRAGEM PIABAS } \\
\text { (CAUÊ) }\end{array}$ & 28 & $19^{\circ} 33^{\prime} 48^{\prime \prime} 5$ & $43^{\circ} 12^{\prime} 22^{\prime \prime} 6$ & Não & \\
\hline 9 & Itabira & $\begin{array}{l}\text { BARRAGEM PONTAL } \\
\text { (Mina Cauê) }\end{array}$ & 69 & $19^{\circ} 37^{\prime} 31^{\prime \prime} 6$ & $43^{\circ} 10^{\prime} 58^{\prime \prime} 6$ & Não & \\
\hline $\begin{array}{l}1 \\
0\end{array}$ & Itabira & $\begin{array}{l}\text { BARRAGEM RIO DO } \\
\text { PEIXE (Conceição) }\end{array}$ & 31 & $19^{\circ} 40^{\prime} 27^{\prime \prime} 2$ & $43^{\circ} 14^{\prime} 11^{\prime \prime} 1$ & Sim & 0,7 \\
\hline $\begin{array}{l}1 \\
1\end{array}$ & Itabira & $\begin{array}{l}\text { BARRAGEM SANTANA } \\
\text { (CAUÊ) }\end{array}$ & 52,4 & $19^{\circ} 33^{\prime} 18^{\prime \prime} 1$ & $43^{\circ} 09^{\prime} 38^{\prime \prime} 8$ & Não & \\
\hline $\begin{array}{l}1 \\
2\end{array}$ & Itabira & DIQUE 02 PONTAL & 21 & $19^{\circ} 36^{\prime} 46^{\prime \prime} 5$ & $43^{\circ} 11^{\prime} 26^{\prime \prime} 3$ & Não & \\
\hline $\begin{array}{l}1 \\
3\end{array}$ & Itabira & DIQUE 03 PONTAL & 21 & $19^{\circ} 36^{\prime} 28^{\prime \prime} 7$ & $43^{\circ} 11^{\prime} 03^{\prime \prime} 8$ & Não & \\
\hline $\begin{array}{l}1 \\
4\end{array}$ & Itabira & $\begin{array}{c}\text { DIQUE } 04 \text { PONTAL (ou } \\
\text { Dique } 4 \text { braço) CAUE }\end{array}$ & 13 & $19^{\circ} 36^{\prime} 25^{\prime \prime} 9$ & $43^{\circ} 10^{\prime} 32^{\prime \prime} 4$ & Não & \\
\hline $\begin{array}{l}1 \\
5\end{array}$ & Itabira & DIQUE 05 PONTAL & 13 & $19^{\circ} 36^{\prime} 18^{\prime \prime} 9$ & $43^{\circ} 10^{\prime} 22^{\prime \prime} 4$ & Não & \\
\hline $\begin{array}{l}1 \\
6\end{array}$ & Itabira & $\begin{array}{l}\text { DIQUE } 06 \text { PONTAL } \\
\text { (CAUÊ) }\end{array}$ & 13 & $19^{\circ} 36^{\prime} 48^{\prime \prime} 1$ & $43^{\circ} 10^{\prime} 27^{\prime \prime} 8$ & Não & \\
\hline $\begin{array}{l}1 \\
7\end{array}$ & Itabira & $\begin{array}{l}\text { DIQUE } 105 \text { I (Minas do } \\
\text { Meio) }\end{array}$ & 8,14 & $19^{\circ} 37^{\prime} 37^{\prime \prime} 9$ & $43^{\circ} 14^{\prime} 18^{\prime \prime} 8$ & Não & \\
\hline $\begin{array}{l}1 \\
8\end{array}$ & Itabira & Dique 1A Conceição & 12 & $19^{\circ} 38^{\prime} 38^{\prime \prime} 0$ & $43^{\circ} 16^{\prime} 55^{\prime \prime} 0$ & Não & \\
\hline $\begin{array}{l}1 \\
9\end{array}$ & Itabira & DIQUE 1B CONCEIÇÃO & 18 & $19^{\circ} 38^{\prime} 20^{\prime \prime} 9$ & $43^{\circ} 16^{\prime} 56^{\prime \prime} 8$ & Não & \\
\hline $\begin{array}{l}2 \\
0\end{array}$ & Itabira & $\begin{array}{c}\text { DIQUE CORDÃO NOVA } \\
\text { VISTA (CAUÊ) }\end{array}$ & 17 & $19^{\circ} 37^{\prime} 02^{\prime \prime} 2$ & $43^{\circ} 12^{\prime} 09^{\prime \prime} 1$ & Não & \\
\hline $\begin{array}{l}2 \\
1\end{array}$ & Itabira & $\begin{array}{l}\text { DIQUE QUINZINHO } \\
\text { (Minas do Meio) }\end{array}$ & 16 & $19^{\circ} 36^{\prime} 26^{\prime \prime} 4$ & $43^{\circ} 15^{\prime} 26^{\prime \prime} 1$ & Não & \\
\hline $\begin{array}{l}2 \\
2\end{array}$ & Itabira & DIQUE RIO DO PEIXE & 7 & $19^{\circ} 40^{\prime} 15^{\prime \prime} 9$ & $43^{\circ} 14^{\prime} 32^{\prime \prime} 8$ & Sim & 0,1 \\
\hline 2 & Itabira & $\begin{array}{l}\text { DIQUE TRÊS FONTES } \\
\text { (Minas do Meio) }\end{array}$ & 10 & $19^{\circ} 37^{\prime} 19^{\prime \prime} 5$ & $43^{\circ} 14^{\prime} 02^{\prime \prime} 6$ & Não & \\
\hline $\begin{array}{l}2 \\
4\end{array}$ & Itabira & $\begin{array}{l}\text { BARRAGEM } \\
\text { BORRACHUDO }\end{array}$ & 6 & $19^{\circ} 36^{\prime} 33^{\prime \prime} 2$ & $43^{\circ} 15^{\prime} 48^{\prime \prime} 2$ & Não & \\
\hline $\begin{array}{l}2 \\
5\end{array}$ & Itabira & Barragem Serraria & 9 & $19^{\circ} 36^{\prime} 46^{\prime \prime} 0$ & $43^{\circ} 12^{\prime} 16^{\prime \prime} 0$ & Não & \\
\hline $\begin{array}{l}2 \\
6\end{array}$ & Itabira & Dique 105 II & 7,5 & $19^{\circ} 37^{\prime} 45^{\prime \prime} 0$ & $43^{\circ} 14^{\prime} 24^{\prime \prime} 0$ & Não & \\
\hline $\begin{array}{l}2 \\
7\end{array}$ & Itabira & DIQUE IPOEMA & 7,5 & $19^{\circ} 36^{\prime} 44^{\prime \prime} 0$ & $43^{\circ} 15^{\prime} 20^{\prime \prime} 9$ & Não & \\
\hline $\begin{array}{l}2 \\
8\end{array}$ & Itabira & Dique Subestação & 8,5 & $19^{\circ} 59^{\prime} 21^{\prime \prime} 0$ & $43^{\circ} 20^{\prime} 50^{\prime \prime} 0$ & Não & \\
\hline
\end{tabular}




$\begin{array}{llllll}2 & \text { Itabira } & \text { PDE Engano } & 20^{\circ} 20^{\prime} 18^{\prime \prime} 2 & 43^{\circ} 25^{\prime} 29^{\prime \prime} 2 & \text { Não }\end{array}$

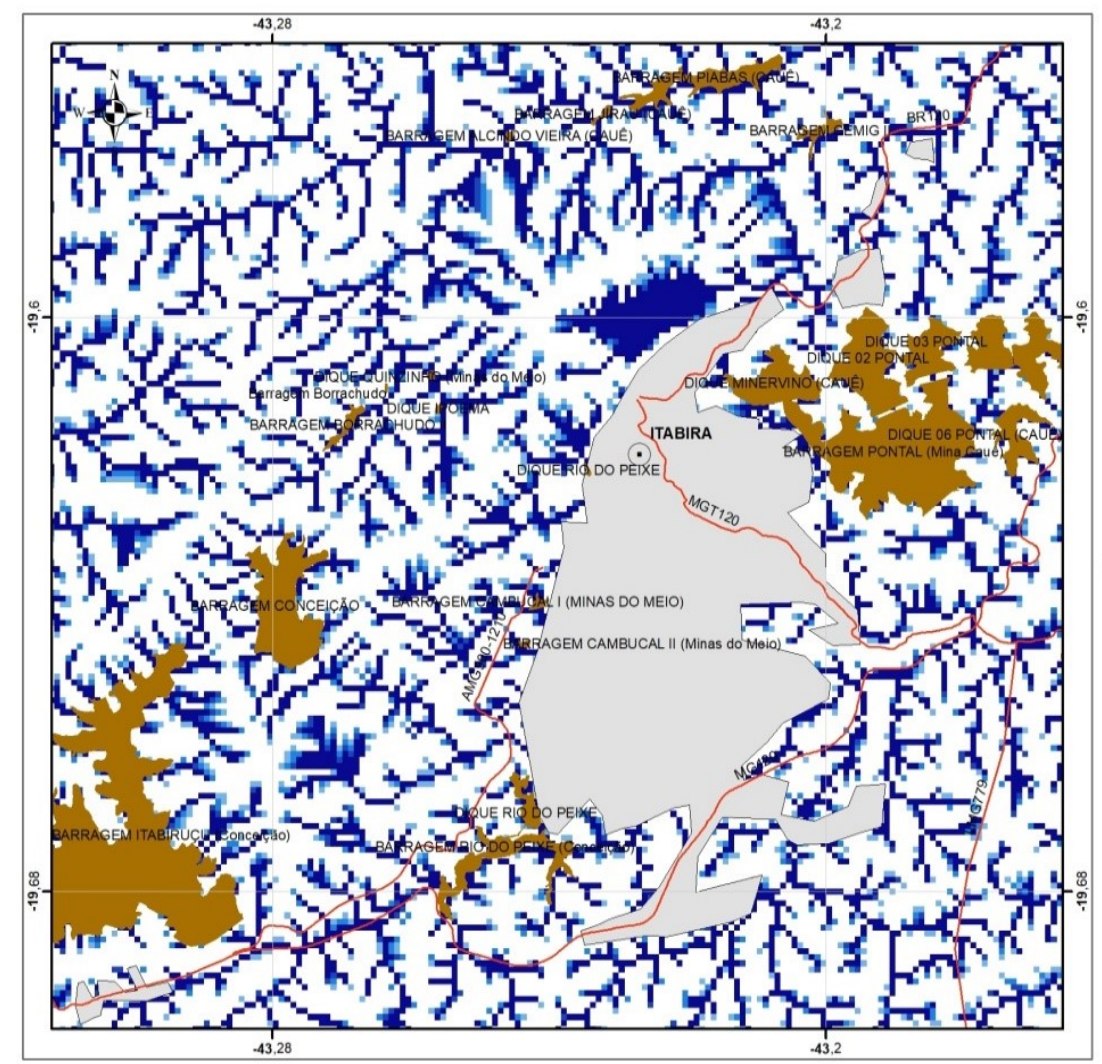

Municipio de Itabira

Figura 2: Fluxo acumulado no município de Itabira (MG).

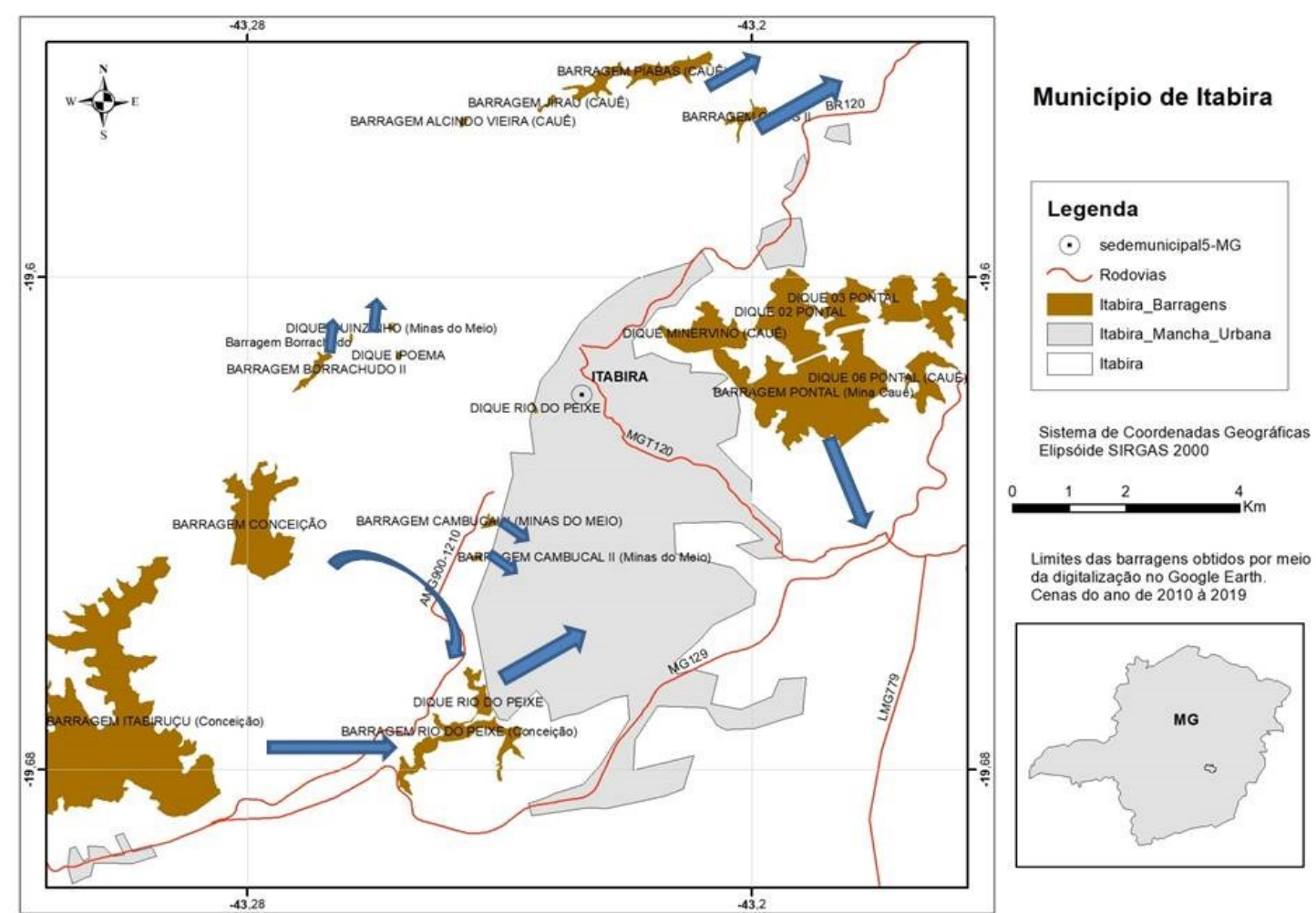

Figura 3 - Sentido do fluxo em caso de rompimento de barragens de mineração em Itabira (MG). 


\subsection{Caso de estudo: Itatiaiuçu (MG)}

O município possui uma população de 9.928 habitantes que se distribuem no território municipal com uma densidade de 33,64 hab./ $\mathrm{km}^{2}$. Distando cerca de $78 \mathrm{~km}$ de Belo Horizonte, a cidade tem um PIB per capta de R\$ 67 mil (IBGE 2019).

O número de barragens associadas à mineração em Itatiaiuçu varia entre 30 (FEAM) e 33 (ANM/DNPM). Nessa pesquisa foram localizadas 41 barragens (Tab. 8). Todas as barragens desse município foram classificadas como sendo de pequeno porte pela FEAM. O somatório do volume de rejeitos acumulados nessas barragens é 1,35 milhões de $\mathrm{m}^{3}$ (Tab. 1).

Em Itatiaiuçu, a Barragem de Serra Azul que fica na mina do mesmo nome (Acelormittal) também teve suspensa a sua DCE pela ANM em 2019. Cerca de 200 moradores do povoado de Pinheiros foram retirados de suas casas no dia 08/FEV/2019. O povoado está a $1,5 \mathrm{~km}$ a jusante da barragem. Caso essa barragem venha a se romper, haverá contaminação do rio Manso um dos mais importantes mananciais de água para Belo Horizonte. Além disso, a onda de lama poderá interromper a BR 381 que liga a capital mineira à São Paulo (PARANAÍBA, 2019; SILVA e PARANAÍBA, 2019).

As principais barragens de Itatiaiuçu bem como os seus posicionamentos dentro da rede hidrográfica e em relação à área urbanizada estão ilustradas na Fig. 4. Os possíveis fluxos da onda de lama, em caso de rompimento dessas barragens estão apontados na Fig. 5.

Em caso de ruptura, nada menos do que 27 represas jogariam seus rejeitos na malha urbana da cidade (Tab. 8, Fig. 5).

Tabela 8: Barragens do município de Itatiaiuçu (MG) segundo o CADASTRO NACIONAL DE BARRAGENS (2017). No caso de haver rompimento, são fornecidas as distâncias aproximadas que os rejeitos irão percorrer antes de atingir a malha urbana.

\begin{tabular}{|c|c|c|c|c|c|c|c|}
\hline $\mathbf{N}$ & Município & Barragem & $\begin{array}{c}\text { Altura } \\
\text { (m) }\end{array}$ & Latitude & Longitude & $\begin{array}{c}\text { Atinge } \\
\text { o centro } \\
\text { se } \\
\text { romper }\end{array}$ & $\begin{array}{c}\text { Distância } \\
\text { do centro } \\
\text { urbano } \\
(\mathbf{k m})\end{array}$ \\
\hline 1 & Itatiaiuçu & Barragem 01 - Jose Jaime & 20 & $20^{\circ} 08^{\prime} 08^{\prime \prime} 4$ & $44^{\circ} 23^{\prime} 02^{\prime \prime} 1$ & Sim & 4,8 \\
\hline 2 & Itatiaiuçu & Barragem 02 - Canindé & 40 & $20^{\circ} 08^{\prime} 21^{\prime \prime} 5$ & $44^{\circ} 22^{\prime} 49^{\prime \prime} 9$ & Sim & 2,0 \\
\hline 3 & Itatiaiuçu & $\begin{array}{c}\text { Barragem } 03 \text { - Zé da } \\
\text { Grota }\end{array}$ & 25 & $20^{\circ} 08^{\prime} 18^{\prime \prime} 9$ & $44^{\circ} 23^{\prime} 16^{\prime \prime} 6$ & Sim & 4,4 \\
\hline 4 & Itatiaiuçu & Barragem Central & 58 & $20^{\circ} 08^{\prime} 51^{\prime \prime} 3$ & $44^{\circ} 24^{\prime} 22^{\prime \prime} 2$ & Sim & 4,8 \\
\hline 5 & Itatiaiuçu & Barragem de Rejeitos & 89 & $20^{\circ} 08^{\prime} 17^{\prime \prime} 6$ & $44^{\circ} 23^{\prime} 39^{\prime \prime} 6$ & Sim & 4,6 \\
\hline 6 & Itatiaiuçu & $\begin{array}{c}\text { Barragem Mina Oeste } \\
\text { (Somisa) }\end{array}$ & 80 & $20^{\circ} 10^{\prime} 02^{\prime \prime} 4$ & $44^{\circ} 27^{\prime} 36^{\prime \prime} 0$ & Sim & 9,8 \\
\hline 7 & Itatiaiuçu & $\begin{array}{c}\text { Barragem Samambaia } 0 \\
\text { (zero) }\end{array}$ & 41 & $20^{\circ} 10^{\prime} 02^{\prime \prime} 0$ & $44^{\circ} 26^{\prime} 05^{\prime \prime} 0$ & Sim & 8,9 \\
\hline 8 & Itatiaiuçu & Dique Couves [MBL] & 24 & $20^{\circ} 09^{\prime} 09^{\prime \prime} 0$ & $44^{\circ} 26^{\prime} 47^{\prime \prime} 0$ & Sim & 8,9 \\
\hline 9 & Itatiaiuçu & Dique Oeste & 20 & $20^{\circ} 10^{\prime} 01^{\prime \prime} 0$ & $44^{\circ} 27^{\prime} 01^{\prime \prime} 0$ & Sim & 9,0 \\
\hline 10 & Itatiaiuçu & $\begin{array}{c}\text { Barragem Captação de } \\
\text { Água }\end{array}$ & 4,46 & $20^{\circ} 09^{\prime} 59^{\prime \prime} 1$ & $44^{\circ} 27^{\prime} 01^{\prime \prime} 4$ & Sim & 8,8 \\
\hline 11 & Itatiaiuçu & Dique 01 de Terra & 3 & $20^{\circ} 08^{\prime} 17^{\prime \prime} 9$ & $44^{\circ} 24^{\prime} 02^{\prime \prime} 4$ & Sim & 5,2 \\
\hline
\end{tabular}


12 Itatiaiuçu

13 Itatiaiuçu

14 Itatiaiuçu

Itatiaiuçu

15 Itatiaiuçu

16 Itatiaiuçu

17 Itatiaiuçu

18 Itatiaiuçu

19 Itatiaiuçu

30 Itatiaiuçu

31 Itatiaiuçu

32 Itatiaiuçu

33 Itatiaiuçu

34 Itatiaiuçu

35 Itatiaiuçu

36 Itatiaiuçu

37 Itatiaiuçu

38 Itatiaiuçu

39 Itatiaiuçu

40 Itatiaiuçu

41 Itatiaiuçu
Dique 02 Serra Azul Dique Vai e Volta 2

Dique 03 Serra Azul Dique Vai e Volta 3

Dique 06

Dique 06 - Véu da Noiva Jusante

Dique 08 - Pátio CMC Dique 13 - Pains Dique 14

Dique 2 de Concreto

Dique 3 - Leira Véu de Noiva

Dique 4 - Santanense Dique Asfalto

Dique BIV-3 - Dique Hércules

Dique Couves[ MUSA]

Dique da Divisa

Dique da Oficina

Dique de Concreto Dique Flotação

Dique Intermediário

Dique Mazano

Dique Mazano II

Dique Mineira
14

14

10

14

12

14

12

3

5

5

3

5

13

12

10

10

14

4

6

10

14,3

12

12 $20^{\circ} 07^{\prime} 48^{\prime \prime} 0 \quad 44^{\circ} 25^{\prime} 20^{\prime \prime} 0 \quad$ Não

$20^{\circ} 07^{\prime} 47^{\prime \prime} 7 \quad 44^{\circ} 25^{\prime} 34^{\prime \prime} 8$ Não

$20^{\circ} 09^{\prime} 42^{\prime \prime} 9 \quad 44^{\circ} 27^{\prime} 22^{\prime \prime} 5$ Não

$20^{\circ} 07^{\prime} 50^{\prime \prime} 0 \quad 44^{\circ} 22^{\prime} 33^{\prime \prime} 3 \quad$ Sim

$20^{\circ} 08^{\prime} 01^{\prime \prime} 0 \quad 44^{\circ} 22^{\prime} 46^{\prime \prime} 5 \quad$ Sim

$20^{\circ} 07^{\prime} 25^{\prime \prime} 6 \quad 44^{\circ} 25^{\prime} 59^{\prime \prime} 8$ Não

$20^{\circ} 09^{\prime} 42^{\prime \prime} 0 \quad 44^{\circ} 26^{\prime} 48^{\prime \prime} 7 \quad$ Sim

8,6

$20^{\circ} 08^{\prime} 21^{\prime \prime} 9 \quad 44^{\circ} 24^{\prime} 02^{\prime \prime} 3 \quad$ Sim

5,1

$20^{\circ} 07^{\prime} 38^{\prime \prime} 7 \quad 44^{\circ} 22^{\prime} 29^{\prime \prime} 5 \quad$ Sim

2,8

$20^{\circ} 07^{\prime} 40^{\prime \prime} 3 \quad 44^{\circ} 22^{\prime} 18^{\prime \prime} 6 \quad$ Sim

$20^{\circ} 09^{\prime} 55^{\prime \prime} 0$

$44^{\circ} 27^{\prime} 02^{\prime \prime} 0 \quad$ Sim

7,9

8,6

$20^{\circ} 09^{\prime} 19^{\prime \prime} 0 \quad 44^{\circ} 26^{\prime} 04^{\prime \prime} 0 \quad$ Sim

$20^{\circ} 08^{\prime} 08^{\prime \prime} 9$

$44^{\circ} 24^{\prime} 17^{\prime \prime} 4 \quad$ Sim

2,2

$20^{\circ} 07^{\prime} 53^{\prime \prime} 7$

44 24' $36^{\prime \prime} 4$ Não

4,7

9,1

9,1

6,0

6,9

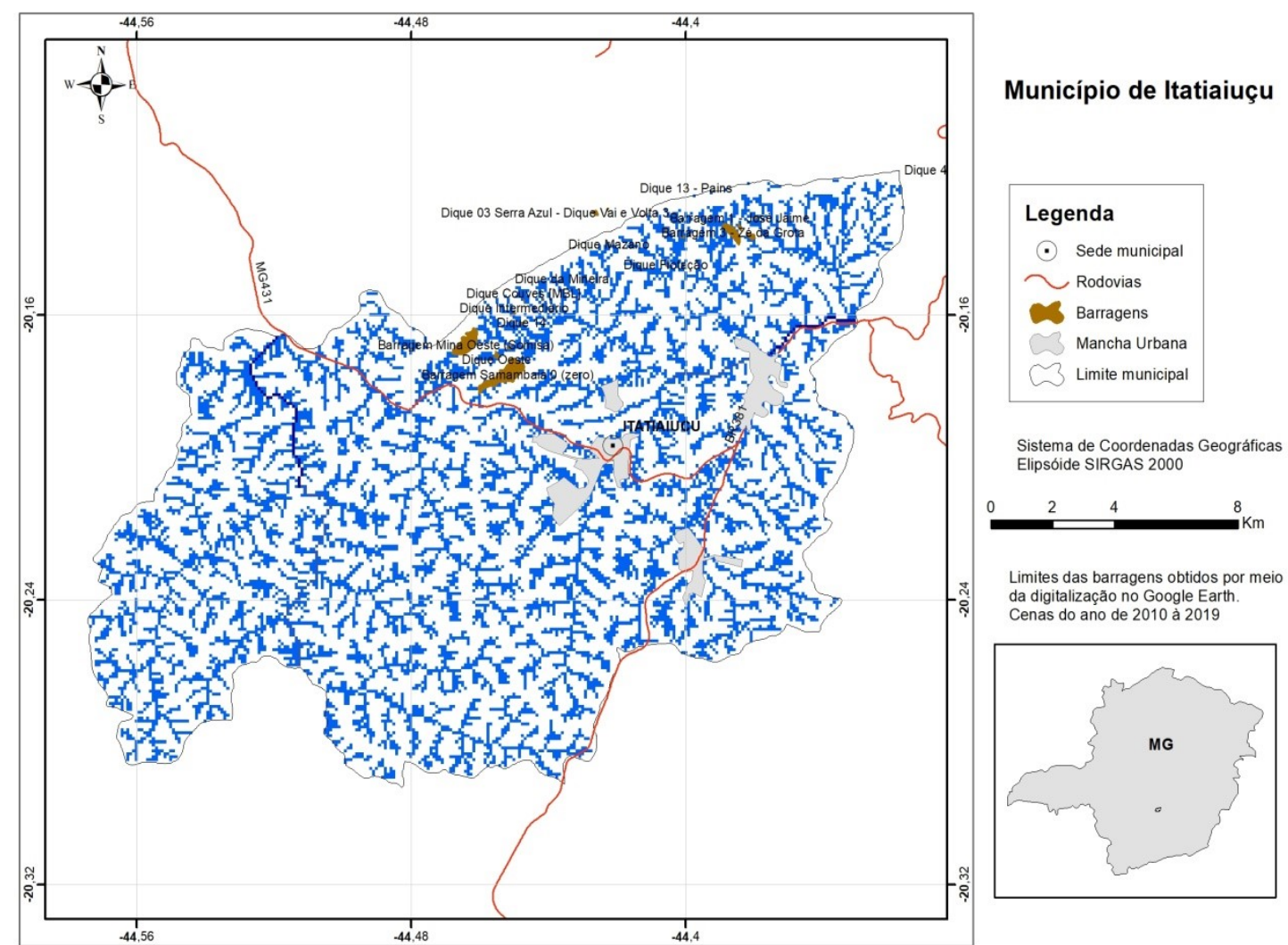

Figura 4 - Fluxo acumulado no município de Itatiaiuçu (MG). 


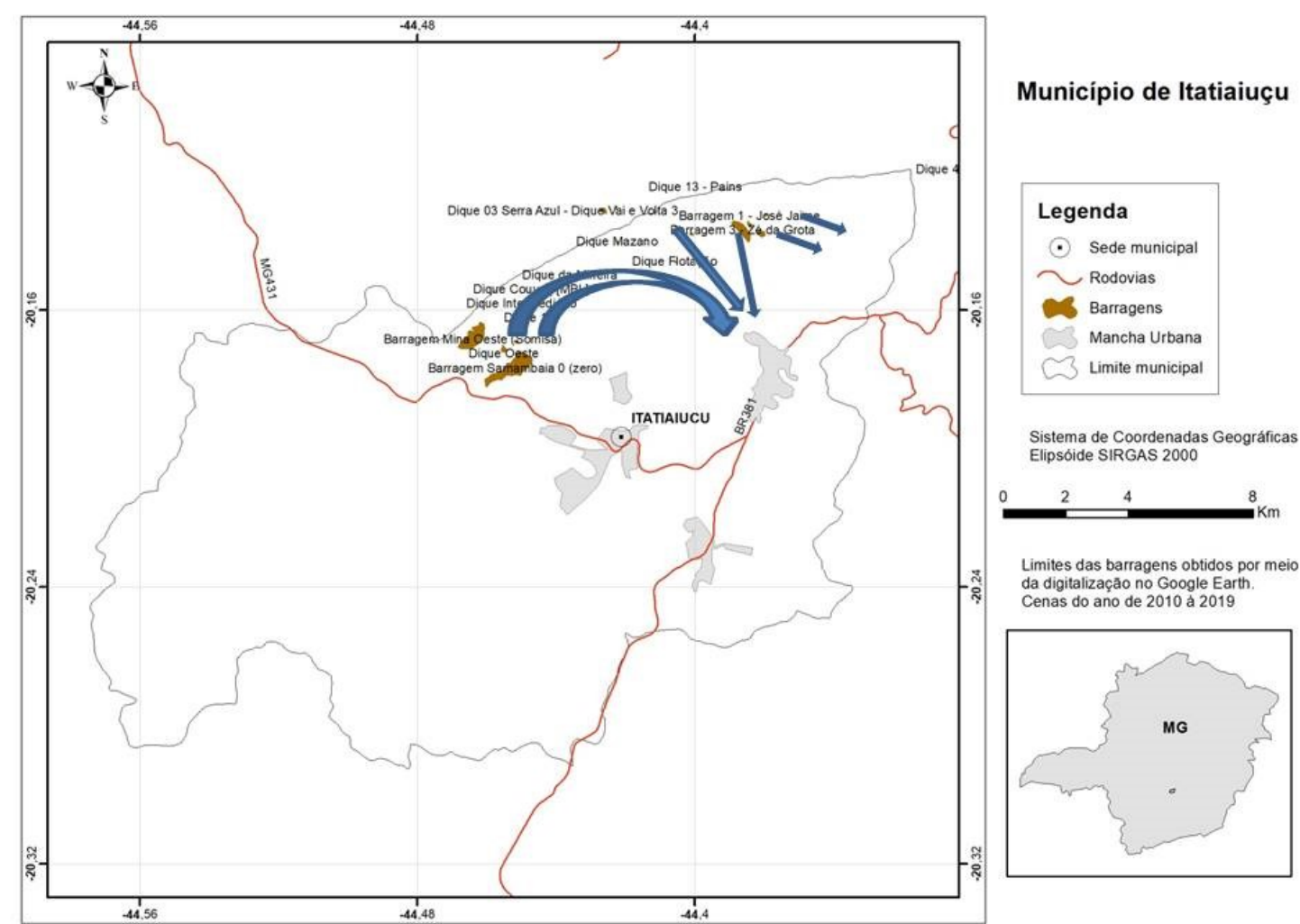

Figura 5 - Sentido do fluxo em caso de rompimento de barragens de mineração do município de Itatiaiuçu (MG).

\subsection{Caso de estudo: Itabirito}

Distando cerca de $133 \mathrm{~km}$ de Belo Horizonte, Itabirito possui uma população de 51.875 habitantes que se distribuem no território municipal com uma densidade de $83,76 \mathrm{hab} . / \mathrm{km}^{2}$. A cidade tem um PIB per capta de R\$ 53 mil (IBGE 2019).

Em Itabirito, a FEAM relaciona 31 barragens de rejeitos enquanto a lista da ANM/DNPM traz apenas 30 represas e o presente estudo, 30 represas foram identificadas (Tabs. 1 e 9). A FEAM assegura que todas essas barragens possuem volumes acumulados menores do que 1 milhão de m³ .

Já existe registro de acidentes com barragens e diques associados à mineração no município. Em setembro de 2014, ocorreu o rompimento da Barragem B1, da empresa Herculano Mineração Ltda. O desastre causou a morte de três operários. A barragem B1 armazenava rejeitos do beneficiamento de minério de ferro. O rompimento da barragem "B1" deixou 300 residências sem fornecimento de água e de energia elétrica. Além disso, causou graves impactos ambientais em córregos da bacia hidrográfica do Rio das Velhas, que abastece a região metropolitana de Belo Horizonte (PEDROZA, 2017).

Não foi possível identificar a localização da barragem Mario Cruz, visto que as coordenadas geográficas se encontravam incompletas no Cadastro do DNPM. 
Percebe-se que três barragens possuem o fluxo direcionado para regiões urbanas ocupadas, sendo uma delas a mais alta do município, além de apresentar esta direção, a barragem ainda encontrase muito próxima à uma área de ocupação humana, fato que requer atenção, visto que os impactos de um rompimento seria de enormes proporções.

As principais barragens de Itabirito bem como os seus posicionamentos dentro da rede hidrográfica e em relação à área urbanizada estão ilustradas na Fig. 6. Os possíveis fluxos da onda de lama, em caso de rompimento dessas barragens estão apontados na Fig. 7.

Em caso de ruptura, 03 represas jogariam seus rejeitos em áreas urbanizadas dentro do município ou de municípios vizinhos (Tab. 9, Fig. 7).

Tabela 9: Barragens do município de Itabirito (MG) segundo o CADASTRO NACIONAL DE BARRAGENS (2017). No caso de haver rompimento, são fornecidas as distâncias aproximadas que os rejeitos irão percorrer antes de atingir a malha urbana.

\begin{tabular}{|c|c|c|c|c|c|c|c|}
\hline $\mathbf{N}$ & Município & Barragem & $\begin{array}{l}\text { Altura } \\
\text { (m) }\end{array}$ & Lat & Long & $\begin{array}{l}\text { Atinge o } \\
\text { Centro em } \\
\text { caso de } \\
\text { rompimento }\end{array}$ & $\begin{array}{c}\text { Distância } \\
\text { do centro } \\
\text { urbano } \\
(\mathbf{k m})\end{array}$ \\
\hline 1 & Itabirito & Mario Cruz & 28 & o $48^{\prime} 05^{\prime \prime} 2$ & $51^{\circ} 52^{\prime} 27^{\prime \prime} 2$ & & \\
\hline 2 & Itabirito & $\begin{array}{c}\text { Bacia Lavador de } \\
\text { Rodas }\end{array}$ & 3 & $20^{\circ} 17^{\prime} 33^{\prime \prime} 5$ & $43^{\circ} 56^{\prime} 17^{\prime \prime} 3$ & Não & \\
\hline 3 & Itabirito & Barragem B1 & 61,5 & $20^{\circ} 15^{\prime} 11^{\prime \prime} 0$ & $43^{\circ} 55^{\prime} 54^{\prime \prime} 8$ & Não & \\
\hline 4 & Itabirito & Barragem B2 & 8 & $20^{\circ} 15^{\prime} 04^{\prime \prime} 5$ & $43^{\circ} 56^{\prime} 08^{\prime \prime} 6$ & Não & \\
\hline 5 & Itabirito & Barragem B3 & 14 & $20^{\circ} 15^{\prime} 08^{\prime \prime} 8$ & $43^{\circ} 56^{\prime} 15^{\prime \prime} 1$ & Não & \\
\hline 6 & Itabirito & Barragem B4 & 38 & $20^{\circ} 15^{\prime} 33^{\prime \prime} 6$ & $43^{\circ} 55^{\prime} 37^{\prime \prime} 4$ & Não & \\
\hline 7 & Itabirito & Barragem Central & 18 & $20^{\circ} 16^{\prime} 19^{\prime \prime} 3$ & $43^{\circ} 53^{\prime} 41^{\prime \prime} 6$ & Não & \\
\hline 8 & Itabirito & $\begin{array}{l}\text { BARRAGEM } \\
\text { MARAVILHAS I }\end{array}$ & 15 & $20^{\circ} 13^{\prime} 29^{\prime \prime} 7$ & $43^{\circ} 52^{\prime} 23^{\prime \prime} 6$ & Sim & 1 \\
\hline 9 & Itabirito & $\begin{array}{c}\text { BARRAGEM } \\
\text { MARAVILHAS II }\end{array}$ & 90 & $20^{\circ} 12^{\prime} 51^{\prime \prime} 9$ & $43^{\circ} 53^{\prime} 30^{\prime \prime} 1$ & Sim & 1 \\
\hline 10 & Itabirito & Barragem Paciência & 34 & $20^{\circ} 12^{\prime} 33^{\prime \prime} 0$ & $43^{\circ} 41^{\prime} 08^{\prime \prime} 8$ & Sim & 4,2 \\
\hline 11 & Itabirito & Dique Norte PDE - 01 & 25 & $20^{\circ} 18^{\prime} 05^{\prime \prime} 6$ & $43^{\circ} 55^{\prime} 21^{\prime \prime} 4$ & Não & \\
\hline 12 & Itabirito & $\begin{array}{c}\text { Bacia de Contenção } \\
\text { de Finos PDE-A } \\
\text { Norte }\end{array}$ & 5 & $20^{\circ} 16^{\prime} 42^{\prime \prime} 2$ & $43^{\circ} 55^{\prime} 51^{\prime \prime} 1$ & Não & \\
\hline 13 & Itabirito & $\begin{array}{l}\text { Bacia de Contenção } \\
\text { de Finos PDE-A Sul }\end{array}$ & 5 & $20^{\circ} 16^{\prime} 58^{\prime \prime} 8$ & $43^{\circ} 55^{\prime} 38^{\prime \prime} 2$ & Não & \\
\hline 14 & Itabirito & $\begin{array}{l}\text { Barragem } 1 \text { - } \\
\text { Decantação }\end{array}$ & 12 & $20^{\circ} 22^{\prime} 43^{\prime \prime} 0$ & $43^{\circ} 54^{\prime} 58^{\prime \prime} 0$ & Não & \\
\hline 15 & Itabirito & $\begin{array}{l}\text { Barragem } 2 \text { - } \\
\text { Decantação }\end{array}$ & 12 & $20^{\circ} 22^{\prime} 41^{\prime \prime} 0$ & $43^{\circ} 54^{\prime} 58^{\prime \prime} 0$ & Não & \\
\hline 16 & Itabirito & $\begin{array}{l}\text { Barragem 3A - } \\
\text { Sedimentação }\end{array}$ & 3 & $20^{\circ} 22^{\prime} 39^{\prime \prime} 0$ & $43^{\circ} 54^{\prime} 56^{\prime \prime} 0$ & Não & \\
\hline 17 & Itabirito & $\begin{array}{l}\text { Barragem 3B - } \\
\text { Sedimentação }\end{array}$ & 3 & $20^{\circ} 22^{\prime} 41^{\prime \prime} 0$ & $43^{\circ} 54^{\prime} 55^{\prime \prime} 0$ & Não & \\
\hline 18 & Itabirito & $\begin{array}{l}\text { Barragem } 4 \text { - } \\
\text { Acumulação }\end{array}$ & 7 & $20^{\circ} 22^{\prime} 40^{\prime \prime} 0$ & $43^{\circ} 54^{\prime} 55^{\prime \prime} 0$ & Não & \\
\hline 19 & Itabirito & $\begin{array}{c}\text { Barragem } 5 \text { - } \\
\text { Captação }\end{array}$ & 4 & $20^{\circ} 22^{\prime} 26^{\prime \prime} 0$ & $43^{\circ} 55^{\prime} 17^{\prime \prime} 0$ & Não & \\
\hline 20 & Itabirito & $\begin{array}{c}\text { Barragem } 6 \text { - Dique } \\
\text { Filtrante }\end{array}$ & 4 & $20^{\circ} 22^{\prime} 38^{\prime \prime} 0$ & $43^{\circ} 54^{\prime} 46^{\prime \prime} 0$ & Não & \\
\hline 21 & Itabirito & $\begin{array}{c}\text { Barragem } 7 \text { - Dique } \\
\text { Filtrante }\end{array}$ & 7 & $20^{\circ} 22^{\prime} 47^{\prime \prime} 0$ & $43^{\circ} 55^{\prime} 01^{\prime \prime} 0$ & Não & \\
\hline
\end{tabular}




$\begin{array}{llccccc}22 & \text { Itabirito } & \begin{array}{c}\text { Barragem 8 - Dique } \\ \text { Filtrante }\end{array} & 6 & 2^{\circ} 22^{\prime} 48^{\prime \prime} 0 & 4^{\circ} 55^{\prime} 07^{\prime \prime} 0 & \text { Não } \\ 23 & \text { Itabirito } & \text { Barragem 9 - Dique } & 6 & 20^{\circ} 22^{\prime} 51^{\prime \prime} 0 & 43^{\circ} 55^{\prime} 17^{\prime \prime} 0 & \text { Não } \\ 24 & \text { Itabirito } & \text { Barragem da Grota } & 13 & 20^{\circ} 16^{\prime} 07^{\prime \prime} 5 & 43^{\circ} 53^{\prime} 35^{\prime \prime} 8 & \text { Não } \\ 25 & \text { Itabirito } & \text { Barragem de Aredes } & 12 & 20^{\circ} 16^{\prime} 32^{\prime \prime} 8 & 43^{\circ} 53^{\prime} 53^{\prime \prime} 6 & \text { Não } \\ 26 & \text { Itabirito } & \text { Dique 1 } & 3 & 20^{\circ} 16^{\prime} 28^{\prime \prime} 7 & 43^{\circ} 53^{\prime} 56^{\prime \prime} 6 & \text { Não } \\ 27 & \text { Itabirito } & \text { Dique 2 } & 3 & 20^{\circ} 16^{\prime} 28^{\prime \prime} 8 & 43^{\circ} 54^{\prime} 03^{\prime \prime} 9 & \text { Não } \\ 28 & \text { Itabirito } & \text { Dique 3 } & 3 & 20^{\circ} 16^{\prime} 04^{\prime \prime} 7 & 43^{\circ} 54^{\prime} 02^{\prime \prime} 2 & \text { Não } \\ 29 & \text { Itabirito } & \text { DIQUE CATA } & 9 & 20^{\circ} 13^{\prime} 59^{\prime \prime} 2 & 43^{\circ} 51^{\prime} 22^{\prime \prime} 8 & \text { Não } \\ 30 & \text { Itabirito } & \text { Dique Longitudinal } & 5,5 & 20^{\circ} 16^{\prime} 14^{\prime \prime} 5 & 43^{\circ} 53^{\prime} 56^{\prime \prime} 6 & \text { Não }\end{array}$

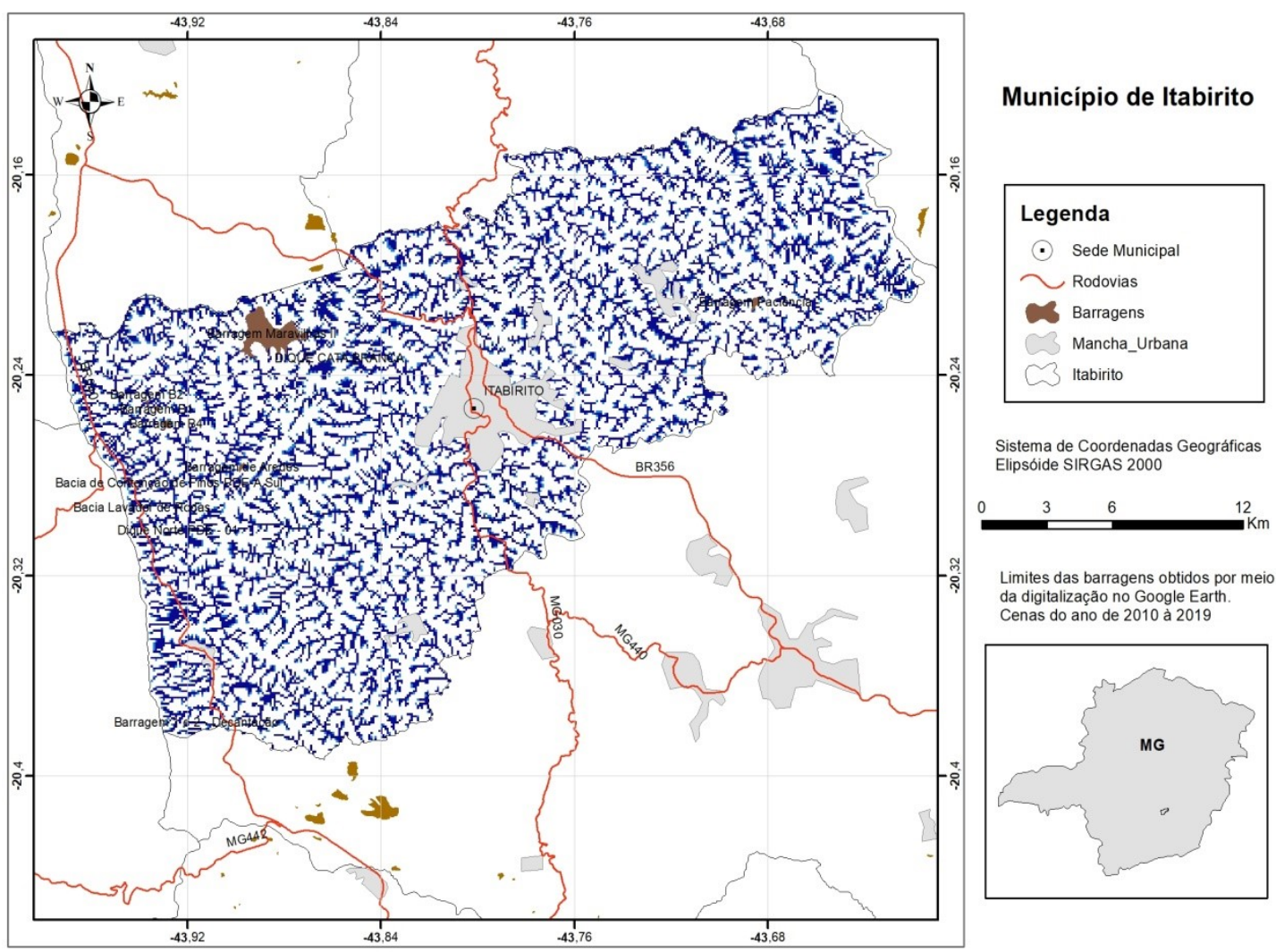

Figura 6 - Fluxo acumulado no município de Itabirito (MG). 


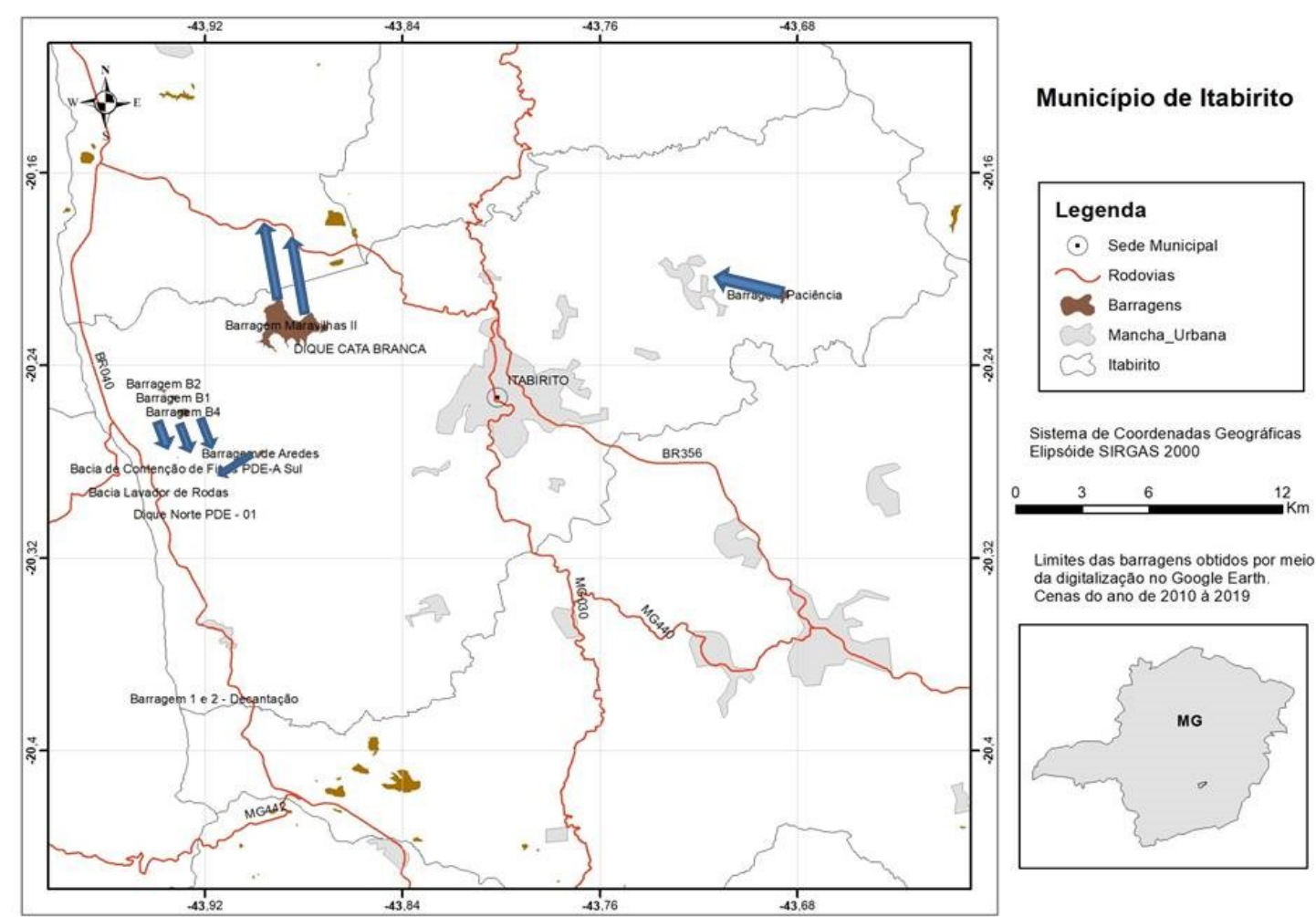

Figura 7 - Sentido do fluxo em caso de rompimento de barragens de mineração do município de Itabirito (MG).

\subsection{Caso de estudo: Ouro Preto}

Em Ouro Preto vivem 74.281 habitantes que se distribuem no território municipal com uma densidade de 56,41 hab. $/ \mathrm{km}^{2}$. Distando cerca de $105 \mathrm{~km}$ de Belo Horizonte, a antiga capital mineira tem hoje um PIB per capta de R \$ 39 mil (IBGE, 2019).

Os dois bancos de dados consultados também trazem informações contrastantes para as barragens desse município. Enquanto a FEAM cita que existem 32 represas de rejeitos, a lista da ANM/DNPM assegura que o número de represas em Ouro Preto não passa de 28. No presente estudo, foram identificadas 27 represas (Tabs. 1 e 10). Segundo a FEAM, todas as represas situadas no município acumulam um volume de apenas 0,2 milhões de $\mathrm{m}^{3}$ quando somadas.

Segundo a Agência Nacional de Mineração, em Ouro Preto existiam, em abril de 2019, pelo menos seis barragens com problemas de segurança: Barragem de Grupo (Complexo de Fábrica), Barragem Marés 2 (Fábrica), Barragens Forquilha I, II e III (Fábrica) e Barragem Doutor (Mina de Timbopeba).

As principais barragens de Ouro Preto, bem como os seus posicionamentos dentro da rede hidrográfica e em relação à área urbanizada estão ilustrados na Fig. 8. Os possíveis fluxos da onda de lama, em caso de rompimento dessas barragens estão apontados na Fig. 9. 
Em caso de ruptura, 06 represas jogariam seus rejeitos em áreas urbanizadas dentro do município ou de municípios vizinhos (Tab. 9, Fig. 7).

Tabela 10: Barragens do município de Ouro Preto (MG) segundo o CADASTRO NACIONAL DE BARRAGENS (2017). No caso de haver rompimento, são fornecidas as distâncias aproximadas que os rejeitos irão percorrer antes de atingir a malha urbana.

\begin{tabular}{|c|c|c|c|c|c|c|c|}
\hline $\mathbf{N}$ & Município & Barragem & $\begin{array}{l}\text { Altura } \\
\text { (m) }\end{array}$ & Latitude & Longitude & $\begin{array}{l}\text { Atinge } \\
\text { o centro } \\
\text { se } \\
\text { romper }\end{array}$ & $\begin{array}{l}\text { Distância } \\
\text { do centro } \\
\text { urbano } \\
(\mathbf{k m}) \\
\end{array}$ \\
\hline 1 & Ouro Preto & Alemães & 57 & $20^{\circ} 25^{\prime} 18^{\prime \prime} 3$ & $43^{\circ} 45^{\prime} 01^{\prime \prime} 7$ & Não & \\
\hline 2 & Ouro Preto & B5 & 26,13 & $20^{\circ} 24^{\prime} 06^{\prime \prime} 5$ & $43^{\circ} 32^{\prime} 03^{\prime \prime} 0$ & Sim & 2,2 \\
\hline 3 & Ouro Preto & Baia da UTM I & 17 & $20^{\circ} 26^{\prime} 10^{\prime \prime} 8$ & $43^{\circ} 46^{\prime} 33^{\prime \prime} 7$ & Não & \\
\hline 4 & Ouro Preto & Baias da UTM II & 22 & $20^{\circ} 27^{\prime} 17^{\prime \prime} 2$ & $43^{\circ} 46^{\prime} 37^{\prime \prime} 0$ & Não & \\
\hline 5 & Ouro Preto & $\begin{array}{l}\text { Barragem Água fria - } \\
\text { rejeito }\end{array}$ & - & $20^{\circ} 25^{\prime} 47^{\prime \prime} 2$ & $43^{\circ} 36^{\prime} 40^{\prime \prime} 6$ & & \\
\hline 6 & Ouro Preto & $\begin{array}{c}\text { BARRAGEM } \\
\text { AUXILIAR DO } \\
\text { VIGIA }\end{array}$ & 36 & $20^{\circ} 26^{\prime} 04^{\prime \prime} 0$ & $43^{\circ} 50^{\prime} 07^{\prime \prime} 1$ & Sim & 0,4 \\
\hline 7 & Ouro Preto & Barragem Captação 1 & - & $20^{\circ} 25^{\prime} 53^{\prime \prime} 2$ & $43^{\circ} 36^{\prime} 50^{\prime \prime} 6$ & Não & \\
\hline 8 & Ouro Preto & Barragem Captação 2 & _ & $20^{\circ} 25^{\prime} 45^{\prime \prime} 2$ & $43^{\circ} 36^{\prime} 42^{\prime \prime} 6$ & Não & \\
\hline 9 & Ouro Preto & $\begin{array}{c}\text { BARRAGEM DO } \\
\text { DOUTOR }\end{array}$ & 77 & $20^{\circ} 17^{\prime} 28^{\prime \prime} 0$ & $43^{\circ} 29^{\prime} 26^{\prime \prime} 8$ & Sim & 2,0 \\
\hline 10 & Ouro Preto & $\begin{array}{l}\text { BARRAGEM DO } \\
\text { GRUPO (Inativa) }\end{array}$ & 37 & $20^{\circ} 24^{\prime} 53^{\prime \prime} 2$ & $43^{\circ} 51^{\prime} 54^{\prime \prime} 5$ & Não & \\
\hline 11 & Ouro Preto & Barragem do Josino & 9 & $20^{\circ} 25^{\prime} 29^{\prime \prime} 9$ & $43^{\circ} 51^{\prime} 56^{\prime \prime} 2$ & Não & \\
\hline 12 & Ouro Preto & $\begin{array}{l}\text { BARRAGEM DO } \\
\text { VIGIA }\end{array}$ & 25 & $20^{\circ} 26^{\prime} 17^{\prime \prime} 0$ & $43^{\circ} 50^{\prime} 00^{\prime \prime} 1$ & Sim & 0,4 \\
\hline 13 & Ouro Preto & $\begin{array}{l}\text { BARRAGEM } \\
\text { FORQUILHA I }\end{array}$ & 93 & $20^{\circ} 24^{\prime} 21^{\prime \prime} 8$ & $43^{\circ} 51^{\prime} 20^{\prime \prime} 6$ & Não & \\
\hline 14 & Ouro Preto & $\begin{array}{l}\text { BARRAGEM } \\
\text { FORQUILHA II }\end{array}$ & 88 & $20^{\circ} 24^{\prime} 29^{\prime \prime} 8$ & $43^{\circ} 51^{\prime} 06^{\prime \prime} 5$ & Não & \\
\hline 15 & Ouro Preto & $\begin{array}{l}\text { BARRAGEM } \\
\text { FORQUILHA III }\end{array}$ & 77 & $20^{\circ} 24^{\prime} 39^{\prime \prime} 4$ & $43^{\circ} 50^{\prime} 11^{\prime \prime} 8$ & Não & \\
\hline 16 & Ouro Preto & $\begin{array}{l}\text { BARRAGEM } \\
\text { FORQUILHA IV }\end{array}$ & 90 & $20^{\circ} 23^{\prime} 41^{\prime \prime} 4$ & $43^{\circ} 51^{\prime} 06^{\prime \prime} 2$ & Não & \\
\hline 17 & Ouro Preto & $\begin{array}{l}\text { BARRAGEM } \\
\text { NATIVIDADE } \\
\text { (TIMBOPEBA) }\end{array}$ & 11,45 & $20^{\circ} 16^{\prime} 47^{\prime \prime} 5$ & $43^{\circ} 29^{\prime} 07^{\prime \prime} 6$ & Sim & 2,7 \\
\hline 18 & Ouro Preto & $\begin{array}{l}\text { BARRAGEM } \\
\text { TIMBOPEBA }\end{array}$ & 64,9 & $20^{\circ} 16^{\prime} 18^{\prime \prime} 3$ & $43^{\circ} 29^{\prime} 48^{\prime \prime} 1$ & Sim & 4,9 \\
\hline 19 & Ouro Preto & Bocaina & 56 & $20^{\circ} 26^{\prime} 33^{\prime \prime} 9$ & $43^{\circ} 47^{\prime} 31^{\prime \prime} 9$ & Não & \\
\hline 20 & Ouro Preto & Clarificação Bocaina & 21 & $20^{\circ} 26^{\prime} 26^{\prime \prime} 3$ & $43^{\circ} 47^{\prime} 19^{\prime \prime} 2$ & Não & \\
\hline 21 & Ouro Preto & Dique Corte Azul & 19,5 & $20^{\circ} 25^{\prime} 04^{\prime \prime} 0$ & $43^{\circ} 53^{\prime} 59^{\prime \prime} 1$ & Não & \\
\hline 22 & Ouro Preto & $\begin{array}{l}\text { DIQUE DO } \\
\text { ENGENHO }\end{array}$ & 6 & $20^{\circ} 27^{\prime} 23^{\prime \prime} 3$ & $43^{\circ} 53^{\prime} 40^{\prime \prime} 1$ & Não & \\
\hline 23 & Ouro Preto & $\begin{array}{l}\text { BARRAGEM CB-3 } \\
\text { (Barragem de água) }\end{array}$ & 4,9 & $20^{\circ} 24^{\prime} 46^{\prime \prime} 8$ & $43^{\circ} 52^{\prime} 28^{\prime \prime} 9$ & Não & \\
\hline 24 & Ouro Preto & $\begin{array}{c}\text { BARRAGEM DO } \\
\text { PRATA }\end{array}$ & 7,5 & $20^{\circ} 24^{\prime} 42^{\prime \prime} 2$ & $43^{\circ} 51^{\prime} 55^{\prime \prime} 0$ & Não & \\
\hline 25 & Ouro Preto & $\begin{array}{c}\text { DIQUE B1 MIGUEL } \\
\text { BURNIER }\end{array}$ & 3 & $20^{\circ} 27^{\prime} 23^{\prime \prime} 2$ & $43^{\circ} 44^{\prime} 59^{\prime \prime} 0$ & Não & \\
\hline 26 & Ouro Preto & $\begin{array}{c}\text { DIQUE B2 MIGUEL } \\
\text { BURNIER }\end{array}$ & 2 & $20^{\circ} 27^{\prime} 23^{\prime \prime} 2$ & $43^{\circ} 44^{\prime} 59^{\prime \prime} 9$ & Não & \\
\hline 27 & Ouro Preto & $\begin{array}{c}\text { DIQUE B3 MIGUEL } \\
\text { BURNIER }\end{array}$ & 3 & $20^{\circ} 27^{\prime} 29^{\prime \prime} 6$ & $43^{\circ} 44^{\prime} 01^{\prime \prime} 1$ & Não & \\
\hline
\end{tabular}



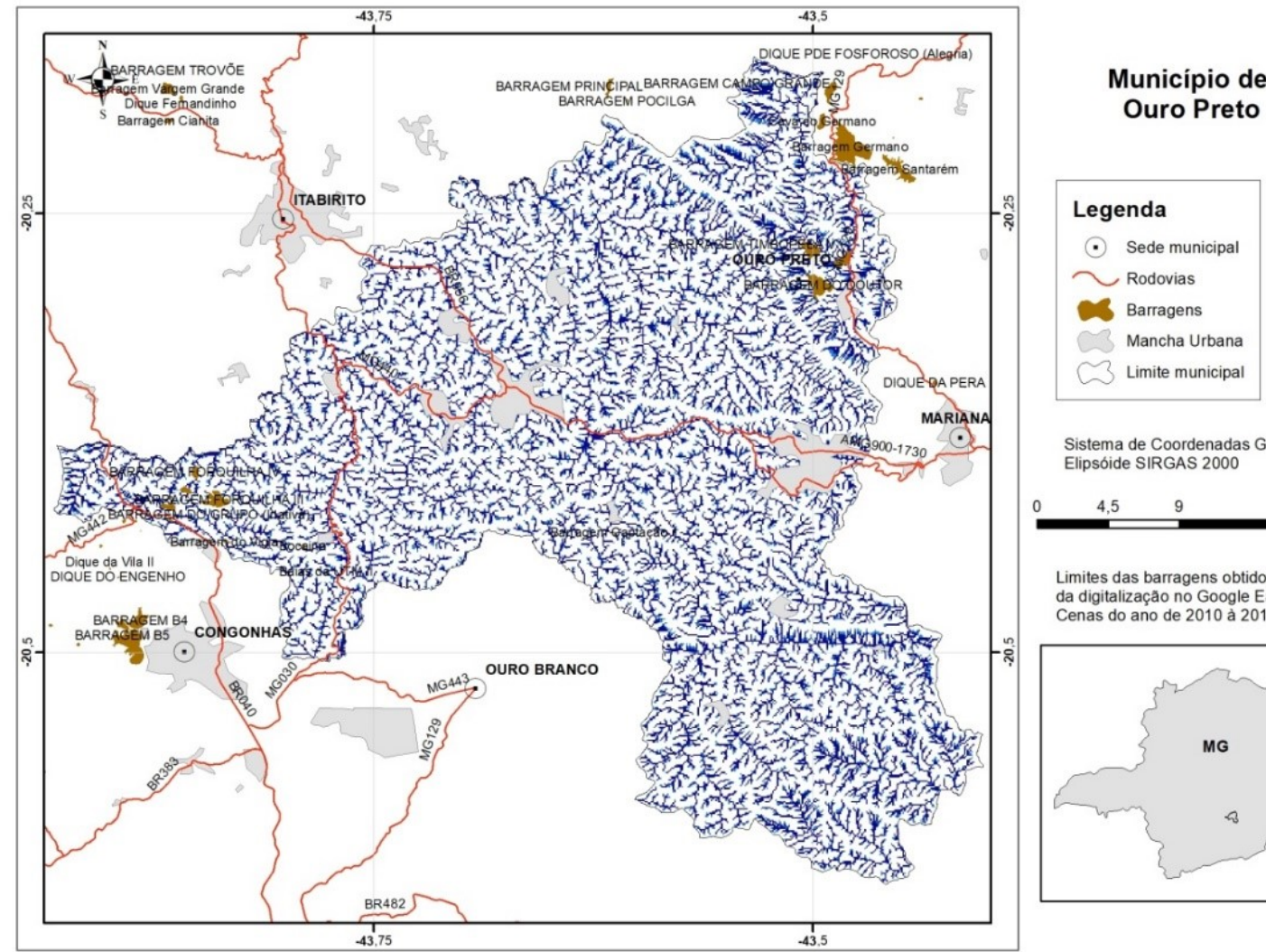

Figura 8 - Fluxo acumulado no município de Ouro Preto MG).

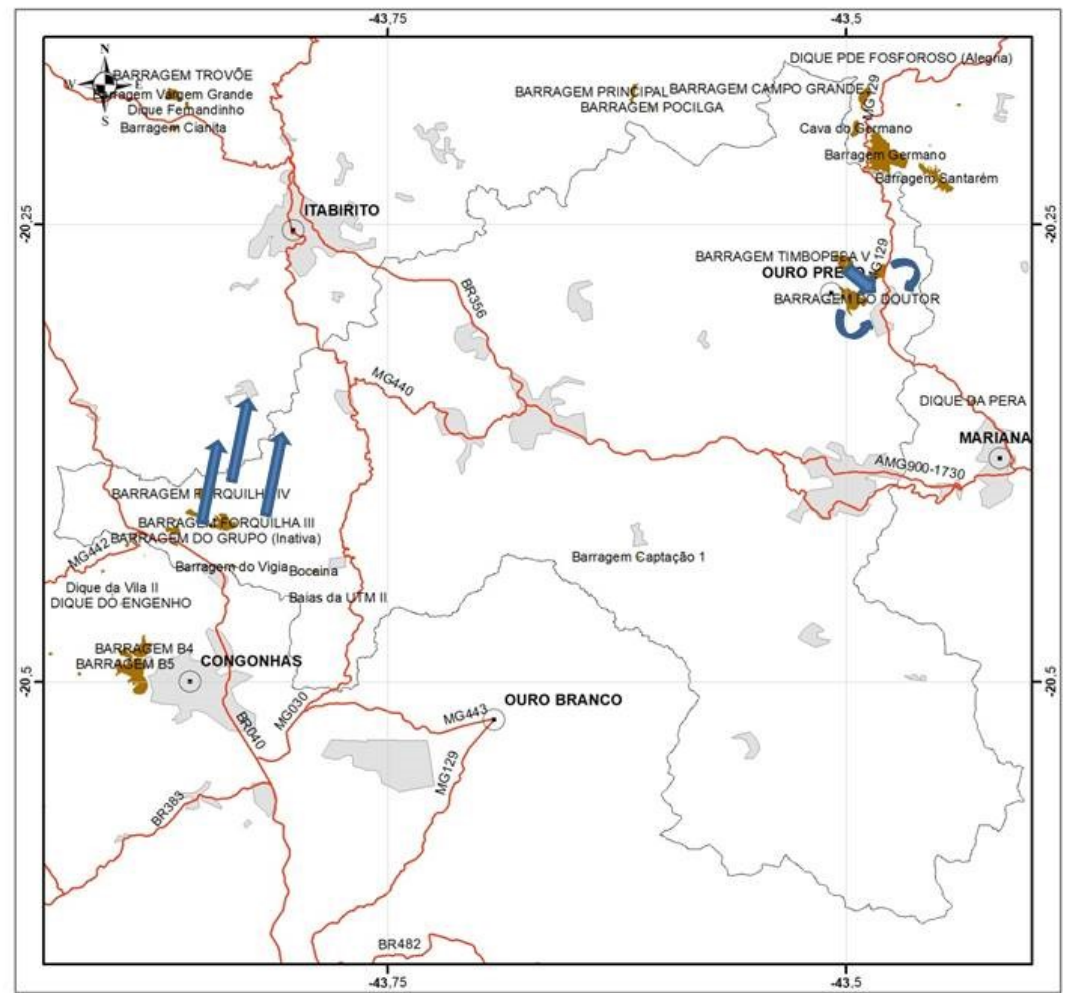

Municipio de

Ouro Preto

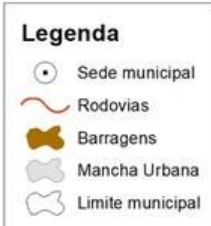

Sistema de Coordenadas Geográficas Elipsoide SIRGAS 2000

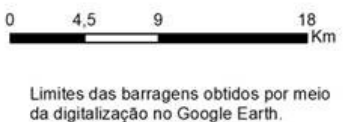
da digitalizaçăo no Google Earth

Figura 9 - Sentido do fluxo em caso de rompimento de barragens de mineração do município de Ouro Preto (MG). 


\subsection{Caso de estudo: Nova Lima (MG)}

O município possui uma população de 94.889 habitantes que se distribuem no território municipal com uma densidade de 188,73 hab. $/ \mathrm{km}^{2}$. Distando apenas 24,3 km de Belo Horizonte, a cidade tem um PIB per capta de R\$ 82 mil (IBGE 2019).

O número total de represas associadas à mineração variou de 26 (FEAM) para 27 represas (ANM/DNPM) para o município de Nova Lima. Nessa pesquisa foram localizadas 27 barragens para esse município. O segundo o banco de dados da FEAM, o volume acumulado de todas essas represas é de 0,21 milhões de $\mathrm{m}^{3}$ (Tab. 1). No presente estudo, foram identificadas todas as 27 represas citadas pelo ANM/DNPM (Tab. 11).

O município conta com várias represas com problemas de segurança. Um dos casos mais graves refere-se à Barragem de Capão da Serra, com seus 47 metros de altura, também conhecida como Barragem de Pasárgada. Há pelo menos 50 residências no traçado considerado de alto risco. A represa retém 2,23 milhões de metros cúbicos de rejeitos e água (ESTADO DE MINAS, 2018).

A Barragem B3/B4 (Mina Mar Azul, Vale) está localizada no distrito de Macacos que pertence a Nova Lima. A Agência Nacional de Mineração emitiu um alerta máximo para essa estrutura no dia 27/03/2019. Todos os moradores da zona de auto salvamento foram retirados de suas moradias durante alguns dias. A Barragem B3/B4 tem aproximadamente 3,0 milhões de $\mathrm{m}^{3}$ de rejeito com expansões feitas através do método pouco seguro de alteamento à montante (PORTAL G1, 2019). É interessante notar que o volume declarado para essa barragem no banco da dados da FEAM é de apenas $8.000 \mathrm{~m}^{3}$.

Além de Capão da Serra, outras sete barragens do município tiveram a sua DCE negada pela Agência Nacional de Mineração, em 2019 (ESTADO DE MINAS, 2019): dique auxiliar da mina de Águas Claras, Dique B da Mina Capitão do Mato, Barragem de Capitão do Mato, Barragem Maravilhas II (Complexo Vargem Grande), Barragem Vargem Grande, Dique Taquaras da Mina Mar Azul (Macacos), Barragens B3/B4 da Mina Mar Azul (Macacos).

As principais barragens de Nova Lima bem como os seus posicionamentos dentro da rede hidrográfica e em relação à área urbanizada estão ilustradas na Fig. 10. Os possíveis fluxos da onda de lama, em caso de rompimento dessas barragens estão apontados na Fig. 11.

Em caso de ruptura, nada menos do que 9 represas jogariam seus rejeitos na malha urbana da cidade (Tab. 11, Fig. 11).

Tabela 11: Barragens situadas em Nova Lima (MG) de acordo com o CADASTRO NACIONAL DE BARRAGENS (2017). No caso de haver rompimento, são fornecidas as distâncias aproximadas que os rejeitos irão percorrer antes de atingir a malha urbana. 


\begin{tabular}{|c|c|c|c|c|c|c|c|}
\hline $\mathbf{N}$ & Município & Barragem & $\begin{array}{l}\text { Altura } \\
\text { (m) }\end{array}$ & Latitude & Longitude & $\begin{array}{l}\text { Atinge o } \\
\text { centro se } \\
\text { romper }\end{array}$ & $\begin{array}{c}\text { Distância } \\
\text { do centro } \\
\text { urbano } \\
(\mathbf{k m})\end{array}$ \\
\hline 1 & Nova Lima & BARRAGEM 5 & 78 & $19^{\circ} 58^{\prime} 37^{\prime \prime} 5$ & $43^{\circ} 53^{\prime} 34^{\prime \prime} 8$ & Sim & 4,3 \\
\hline 2 & Nova Lima & BARRAGEM 5 (Mutuca) & 55 & $20^{\circ} 01^{\prime} 34^{\prime \prime} 4$ & $43^{\circ} 56^{\prime} 33^{\prime \prime} 2$ & Sim & 17,6 \\
\hline 3 & Nova Lima & BARRAGEM 7B & 27,4 & $19^{\circ} 58^{\prime} 02^{\prime \prime} 5$ & $43^{\circ} 52^{\prime} 58^{\prime \prime} 7$ & $\operatorname{Sim}$ & 3,7 \\
\hline 4 & Nova Lima & BARRAGEM 8B & 28 & $19^{\circ} 57^{\prime} 33^{\prime \prime} 7$ & $43^{\circ} 52^{\prime} 21^{\prime \prime} 3$ & Sim & 3,6 \\
\hline 5 & Nova Lima & BARRAGEM B3-B4 & 55 & $20^{\circ} 02^{\prime} 50^{\prime \prime} 4$ & $43^{\circ} 57^{\prime} 13^{\prime \prime} 9$ & Não & \\
\hline 6 & Nova Lima & BARRAGEM B6 & 20 & $20^{\circ} 03^{\prime} 29^{\prime \prime} 7$ & $43^{\circ} 57^{\prime} 50^{\prime \prime} 7$ & Não & \\
\hline 7 & Nova Lima & BARRAGEM B7 & 24 & $20^{\circ} 02^{\prime} 21^{\prime \prime} 5$ & $43^{\circ} 55^{\prime} 44^{\prime \prime} 9$ & Não & \\
\hline 8 & Nova Lima & $\begin{array}{c}\text { BARRAGEM CAPÃO } \\
\text { DA SERRA }\end{array}$ & 47 & $20^{\circ} 04^{\prime} 00^{\prime \prime} 7$ & $43^{\circ} 55^{\prime} 50^{\prime \prime} 1$ & $\operatorname{sim}$ & 17,8 \\
\hline 9 & Nova Lima & $\begin{array}{c}\text { BARRAGEM CIANITA } \\
\text { I }\end{array}$ & 17 & $20^{\circ} 11^{\prime} 47^{\prime \prime} 7$ & $43^{\circ} 52^{\prime} 01^{\prime \prime} 5$ & Não & \\
\hline 10 & Nova Lima & $\begin{array}{l}\text { BARRAGEM } \\
\text { PENEIRINHA }\end{array}$ & 40 & $20^{\circ} 06^{\prime} 38^{\prime \prime} 2$ & $43^{\circ} 57^{\prime} 49^{\prime \prime} 0$ & Não & \\
\hline 11 & Nova Lima & $\begin{array}{l}\text { BARRAGEM } \\
\text { TAQUARAS }\end{array}$ & 25 & $20^{\circ} 02^{\prime} 21^{\prime \prime} 5$ & $43^{\circ} 55^{\prime} 44^{\prime \prime} 9$ & $\operatorname{sim}$ & 14,3 \\
\hline 12 & Nova Lima & $\begin{array}{l}\text { BARRAGEM VARGEM } \\
\text { GRANDE }\end{array}$ & 35 & $20^{\circ} 10^{\prime} 54^{\prime \prime} 7$ & $43^{\circ} 52^{\prime} 01^{\prime \prime} 2$ & Não & \\
\hline 13 & Nova Lima & Cachoeirinha & 45 & $20^{\circ} 09^{\prime} 09^{\prime \prime} 8$ & $43^{\circ} 57^{\prime} 55^{\prime \prime} 6$ & Não & \\
\hline 14 & Nova Lima & Calcinados & 52 & $19^{\circ} 58^{\prime} 25^{\prime \prime} 0$ & $43^{\circ} 49^{\prime} 46^{\prime \prime} 0$ & Sim & 2,1 \\
\hline 15 & Nova Lima & Cocoruto & 41 & $19^{\circ} 58^{\prime} 25^{\prime \prime} 0$ & $43^{\circ} 49^{\prime} 46^{\prime \prime} 0$ & $\operatorname{Sim}$ & 0,4 \\
\hline 16 & Nova Lima & DIQUE B & 30 & $20^{\circ} 07^{\prime} 27^{\prime \prime} 9$ & $43^{\circ} 55^{\prime} 30^{\prime \prime} 8$ & Não & \\
\hline 17 & Nova Lima & $\begin{array}{c}\text { DIQUE } \\
\text { FERNANDINHO }\end{array}$ & 19 & $20^{\circ} 10^{\prime} 59^{\prime \prime} 9$ & $43^{\circ} 51^{\prime} 34^{\prime \prime} 2$ & Não & \\
\hline 18 & Nova Lima & DIQUE II & 20 & $20^{\circ} 10^{\prime} 59^{\prime \prime} 9$ & $43^{\circ} 51^{\prime} 34^{\prime \prime} 2$ & Não & \\
\hline 19 & Nova Lima & DIQUE III & 11 & $20^{\circ} 09^{\prime} 20^{\prime \prime} 5$ & $43^{\circ} 53^{\prime} 13^{\prime \prime} 6$ & Não & \\
\hline 20 & Nova Lima & Dique Lisa & 12 & $20^{\circ} 08^{\prime} 59^{\prime \prime} 1$ & $43^{\circ} 57^{\prime} 52^{\prime \prime} 5$ & Não & \\
\hline 21 & Nova Lima & Pilha Barragem & 25 & $20^{\circ} 06^{\prime} 44^{\prime \prime} 7$ & $43^{\circ} 54^{\prime} 28^{\prime \prime} 5$ & Não & \\
\hline 22 & Nova Lima & Rapaunha & 50,5 & $19^{\circ} 57^{\prime} 54^{\prime \prime} 0$ & $43^{\circ} 50^{\prime} 29^{\prime \prime} 0$ & Sim & 2,0 \\
\hline 23 & Nova Lima & $\begin{array}{l}\text { Barragem de Contenção } \\
\text { de Sólidos Carreados }\end{array}$ & 8 & $20^{\circ} 06^{\prime} 38^{\prime \prime} 7$ & $43^{\circ} 54^{\prime} 11^{\prime \prime} 5$ & Não & \\
\hline 24 & Nova Lima & $\begin{array}{l}\text { BARRAGEM TROVÕES } \\
\text { (Barragem de água) }\end{array}$ & 8,28 & $20^{\circ} 10^{\prime} 07^{\prime \prime} 3$ & $43^{\circ} 51^{\prime} 41^{\prime \prime} 3$ & Não & \\
\hline 25 & Nova Lima & $\begin{array}{c}\text { BARRAGEM/BARRAM } \\
\text { ENTO }\end{array}$ & 8 & $20^{\circ} 06^{\prime} 36^{\prime \prime} 4$ & $43^{\circ} 54^{\prime} 13^{\prime \prime} 4$ & Não & \\
\hline 26 & Nova Lima & Dique - Pilha de Rejeito & 10 & $20^{\circ} 06^{\prime} 39^{\prime \prime} 7$ & $43^{\circ} 54^{\prime} 31^{\prime \prime} 5$ & Não & \\
\hline 27 & Nova Lima & $\begin{array}{l}\text { Dique de contenção de } \\
\text { finos }\end{array}$ & 14,87 & $20^{\circ} 06^{\prime} 58^{\prime \prime} 0$ & $43^{\circ} 52^{\prime} 25^{\prime \prime} 4$ & Não & \\
\hline
\end{tabular}




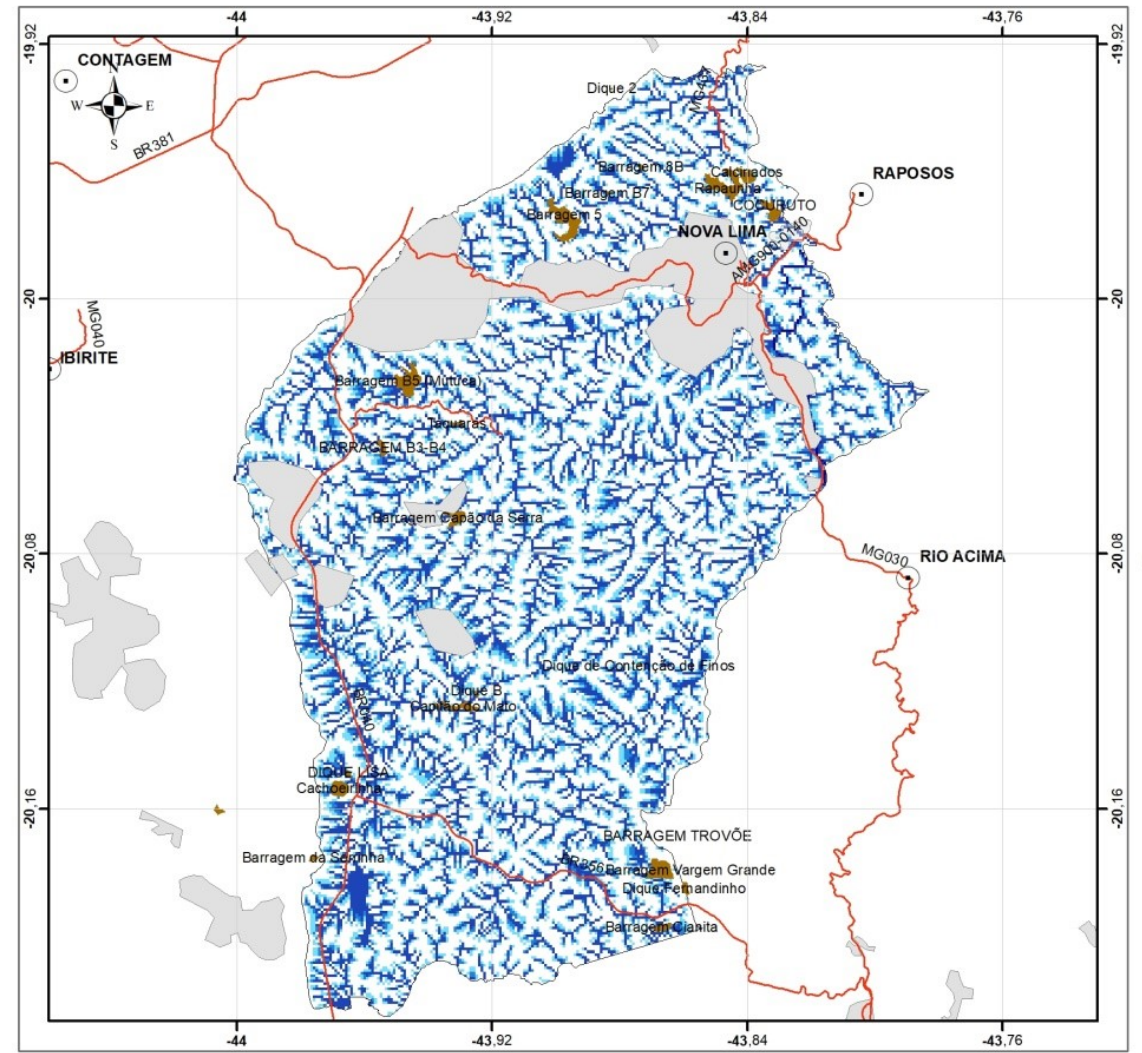

Município de Nova Lima

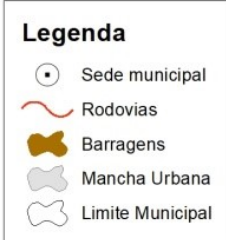

Sistema de Coordenadas Geográficas Elipsóide SIRGAS 2000

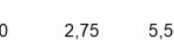

Limites das barragens obtidos por meio da digitalização no Google Earth

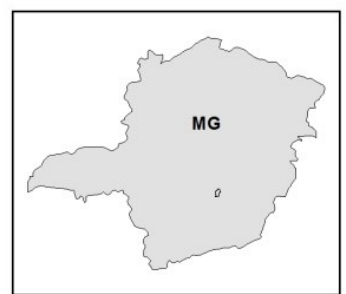

Figura 10 - Fluxo acumulado no município de Nova Lima (MG)

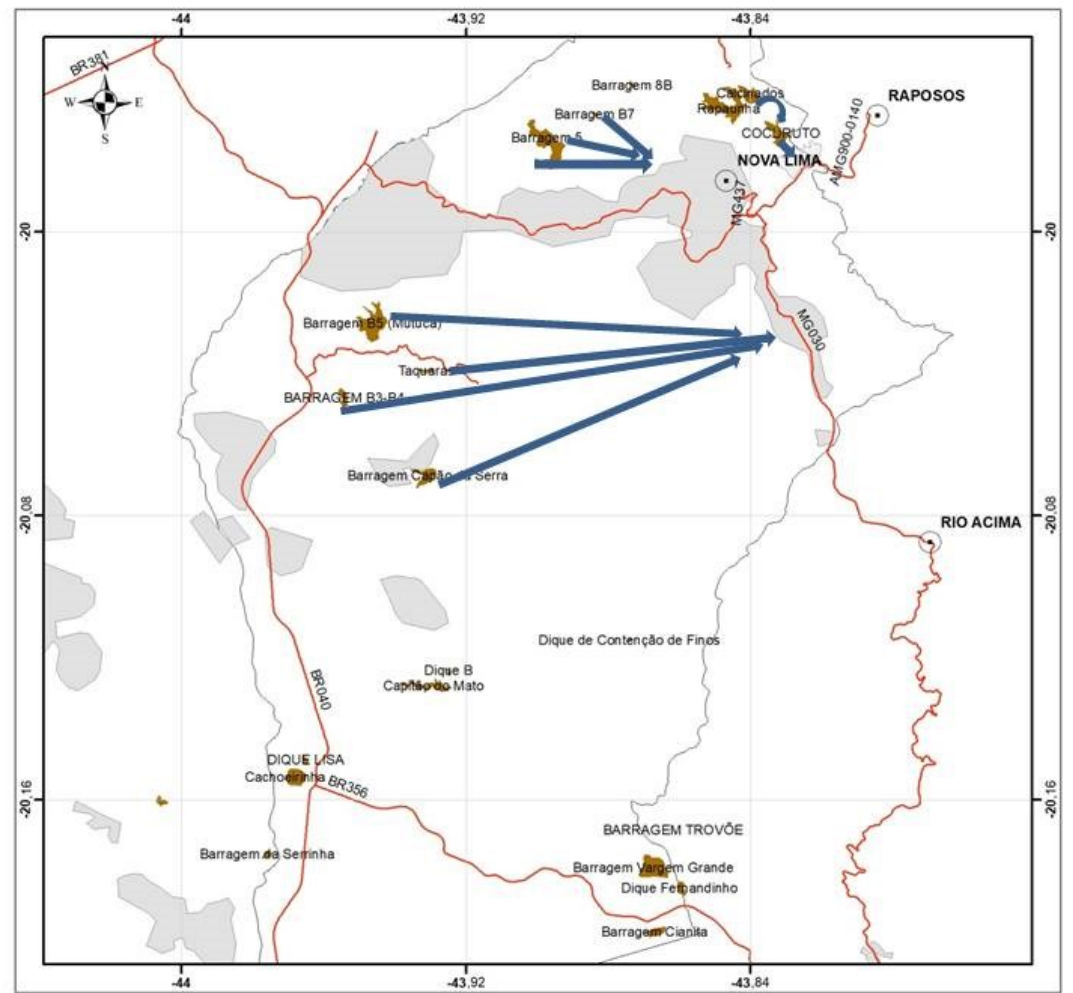

Município de Nova Lima

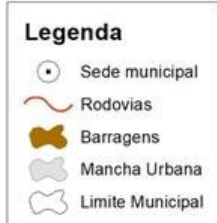

Sistema de Coordenadas Geográficas Elipsoide SIRGAS 2000

$0 \quad 2.25 \quad 4.5$

Limites das barragens obtidos por meio da digitalização no Google Earh

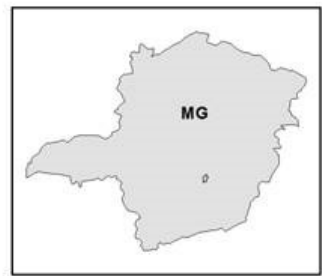

Figura 11 - Sentido do fluxo em caso de rompimento de barragens em Nova Lima (MG). 


\subsection{Caso de estudo: Brumadinho (MG)}

Em Brumadinho, vivem 40.103 habitantes que se distribuem no território municipal com uma densidade de 53,13 hab. $/ \mathrm{km}^{2}$. Distando cerca de 62,6 km de Belo Horizonte, a cidade que é banhada pelo rio Paraopeba tem hoje um PIB per capta de R 40 mil (IBGE 2019).

O banco de dados da ANM/DNPM relaciona 27 represas para Brumadinho, ao passo que a FEAM cita apenas 26 barragens. Nessa pesquisa foram localizadas 24 barragens (Tab. 12). O volume acumulado total dessas estruturas, segundo a FEAM, chega a 88,9 milhões de $\mathrm{m}^{3}$. A fundação mineira assegura que todas elas possuem volumes maiores do que 1,0 milhão de $\mathrm{m}^{3}$.

No dia 25 de janeiro de 2019, aproximadamente às 13:40 hs, rompeu-se a Barragem-1 do complexo da Mina do Feijão, localizada no município de Brumadinho. A barragem inaugurada em 1976, tinha 87 metros de altura e acumulava cerca de 12,7 milhões de $\mathrm{m}^{3}$. Após seis meses de buscas intensas, a conta da tragédia registrava 248 mortos e 22 desparecidos. Considerando o número de trabalhadores da mineração que perderam as suas vidas na tragédia, esse foi o maior acidente de trabalho já registrado no Brasil.

Em 2018, o complexo do Feijão produziu 8,5 milhões de toneladas de minério de ferro, o equivalente a $2 \%$ da produção da Vale. A mina faz parte do Complexo Paraopeba, que produz anualmente algo em torno de 30 milhões de toneladas de minério de ferro o que corresponde a cerca de $7 \%$ de toda a produção deste minério pela Vale. Mesmo estando a barragem inativa, não recendo rejeitos desde 2015, esse fato não impediu o seu rompimento que acabou causando uma das maiores tragédias humanas e um dos maiores desastres ambientais do Brasil.

Segundo os bancos de dados nos quais se baseia o presente estudo a barragem que se rompeu era classificada como sendo de "MÉDIO PORTE", categoria de risco - CRI: "BAIXO", danos potenciais - DPA: = “ALTO”. A barragem estava incluída no Plano Nacional de Segurança de Barragens - PNSB.

Em abril de 2019, a Agência Nacional de Mineração suspendeu a DCE da Barragem 6 da Mina de Feijão (ESTADO DE MINAS, 2019). A DCE é o documento que permite a operação e uso de uma barragem de rejeitos de minérios.

As principais barragens de Brumadinho, bem como os seus posicionamentos dentro da rede hidrográfica e em relação à área urbanizada estão ilustradas na Fig. 12. Os possíveis fluxos da onda de lama, em caso de rompimento dessas barragens estão apontados na Fig. 13. Em caso de ruptura, ao menos uma das represas do município teria seus rejeitos invadindo a malha urbana da cidade (Tab. 12, Fig. 13). 
Tabela 12: Barragens situadas no município de Brumadinho, segundo o CADASTRO NACIONAL DE BARRAGENS (2017). No caso de haver rompimento, são fornecidas as distâncias aproximadas que os rejeitos irão percorrer antes de atingir a malha urbana.

\begin{tabular}{|c|c|c|c|c|c|c|c|}
\hline $\mathbf{N}$ & Município & Barragem & $\begin{array}{l}\text { Altura } \\
\text { (m) }\end{array}$ & Latitude & Longitude & $\begin{array}{l}\text { Atinge } \\
\text { o } \\
\text { centro } \\
\text { se } \\
\text { romper } \\
\end{array}$ & $\begin{array}{l}\text { Distância do } \\
\text { centro } \\
\text { urbano }(\mathbf{k m})\end{array}$ \\
\hline 1 & Brumadinho & $\begin{array}{c}\text { BARRAGEM I (Córrego } \\
\text { Feijão) }\end{array}$ & 87 & $20^{\circ} 07^{\prime} 08^{\prime \prime} 8$ & $44^{\circ} 07^{\prime} 12^{\prime \prime} 9$ & Rompeu & \\
\hline 2 & Brumadinho & $\begin{array}{l}\text { BARRAGEM VI (Córrego } \\
\text { do Feijão) }\end{array}$ & 40 & $20^{\circ} 07^{\prime} 08^{\prime \prime} 6$ & $44^{\circ} 07^{\prime} 27^{\prime \prime} 8$ & Não & \\
\hline 3 & Brumadinho & $\begin{array}{l}\text { BARRAGEM VII (Córrego } \\
\text { do Feijão) }\end{array}$ & 22,5 & $20^{\circ} 06^{\prime} 15^{\prime \prime} 4$ & $44^{\circ} 07^{\prime} 10^{\prime \prime} 8$ & Não & \\
\hline 4 & Brumadinho & Dique 01 & 15 & $20^{\circ} 07^{\prime} 08^{\prime \prime} 9$ & $44^{\circ} 19^{\prime} 11^{\prime \prime} 3$ & Não & \\
\hline 5 & Brumadinho & Dique 02 & 20 & $20^{\circ} 07^{\prime} 14^{\prime \prime} 3$ & $44^{\circ} 19^{\prime} 20^{\prime \prime} 8$ & Não & \\
\hline 6 & Brumadinho & Dique 03 & 5 & $20^{\circ} 07^{\prime} 21^{\prime \prime} 3$ & $44^{\circ} 19^{\prime} 10^{\prime \prime} 2$ & Não & \\
\hline 7 & Brumadinho & Dique B3 Ipê & 23,5 & $20^{\circ} 07^{\prime} 09^{\prime \prime} 7$ & $44^{\circ} 18^{\prime} 57^{\prime \prime} 4$ & Não & \\
\hline 8 & Brumadinho & Dique B4 Ipê & 25 & $20^{\circ} 07^{\prime} 03^{\prime \prime} 3$ & $44^{\circ} 19^{\prime} 01^{\prime \prime} 9$ & Não & \\
\hline 9 & Brumadinho & Dique Conquistinha & 5 & $20^{\circ} 06^{\prime} 56^{\prime \prime} 8$ & $44^{\circ} 17^{\prime} 53^{\prime \prime} 4$ & Não & \\
\hline 10 & Brumadinho & DIQUE QUÉIAS & 5 & $20^{\circ} 07^{\prime} 37^{\prime \prime} 8$ & $44^{\circ} 18^{\prime} 58^{\prime \prime} 1$ & Não & \\
\hline 11 & Brumadinho & Santa Bárbara & 36 & $20^{\circ} 09^{\prime} 42^{\prime \prime} 7$ & $44^{\circ} 00^{\prime} 22^{\prime \prime} 4$ & Não & \\
\hline 12 & Brumadinho & Barragem B3 & 10 & $20^{\circ} 04^{\prime} 02^{\prime \prime} 8$ & $44^{\circ} 01^{\prime} 22^{\prime \prime} 9$ & Não & \\
\hline 13 & Brumadinho & $\begin{array}{l}\text { BARRAGEM MENEZES I } \\
\text { (Córrego do Meio) }\end{array}$ & 13,45 & $20^{\circ} 07^{\prime} 10^{\prime \prime} 7$ & $44^{\circ} 08^{\prime} 21^{\prime \prime} 2$ & Sim & 2,3 \\
\hline 14 & Brumadinho & BARRAGEM SERRINHA & 4 & $20^{\circ} 10^{\prime} 28^{\prime \prime} 8$ & $43^{\circ} 58^{\prime} 33^{\prime \prime} 6$ & Não & \\
\hline 15 & Brumadinho & Dique 04 & 3 & $20^{\circ} 07^{\prime} 10^{\prime \prime} 8$ & $44^{\circ} 19^{\prime} 27^{\prime \prime} 0$ & Não & \\
\hline 16 & Brumadinho & $\begin{array}{l}\text { DIQUE DE PÉ DE } \\
\text { PILHA/EMESA }\end{array}$ & 4,83 & $20^{\circ} 06^{\prime} 43^{\prime \prime} 2$ & $44^{\circ} 13^{\prime} 12^{\prime \prime} 4$ & Não & \\
\hline 17 & Brumadinho & Dique IV & 2 & $20^{\circ} 06^{\prime} 58^{\prime \prime} 3$ & $44^{\circ} 17^{\prime} 53^{\prime \prime} 1$ & Não & \\
\hline 18 & Brumadinho & GABIÕES & 5 & $20^{\circ} 06^{\prime} 56^{\prime \prime} 5$ & $44^{\circ} 13^{\prime} 06^{\prime \prime} 1$ & Não & \\
\hline 19 & Brumadinho & Barragem B1 & 47 & $20^{\circ} 03^{\prime} 53^{\prime \prime} 3$ & $44^{\circ} 01^{\prime} 43^{\prime \prime} 8$ & Não & \\
\hline 20 & Brumadinho & Barragem B1 Ipê & 55 & $20^{\circ} 07^{\prime} 01^{\prime \prime} 3$ & $44^{\circ} 18^{\prime} 24^{\prime \prime} 5$ & Não & \\
\hline 21 & Brumadinho & Barragem B1A Ipê & 37 & $20^{\circ} 07^{\prime} 22^{\prime \prime} 7$ & $44^{\circ} 18^{\prime} 45^{\prime \prime} 3$ & Não & \\
\hline 22 & Brumadinho & Barragem B2 & 27 & $20^{\circ} 03^{\prime} 58^{\prime \prime} 7$ & $44^{\circ} 01^{\prime} 37^{\prime \prime} 9$ & Não & \\
\hline 23 & Brumadinho & $\begin{array}{l}\text { BARRAGEM CAPIM } \\
\text { BRANCO (Inativa) }\end{array}$ & 27 & $20^{\circ} 06^{\prime} 29^{\prime \prime} 7$ & $44^{\circ} 04^{\prime} 25^{\prime \prime} 2$ & Não & \\
\hline 24 & Brumadinho & $\begin{array}{l}\text { BARRAGEM IV-A } \\
\text { (Córrego do Feijão) }\end{array}$ & 14 & $20^{\circ} 08^{\prime} 22^{\prime \prime} 2$ & $44^{\circ} 07^{\prime} 23^{\prime \prime} 1$ & Não & \\
\hline
\end{tabular}




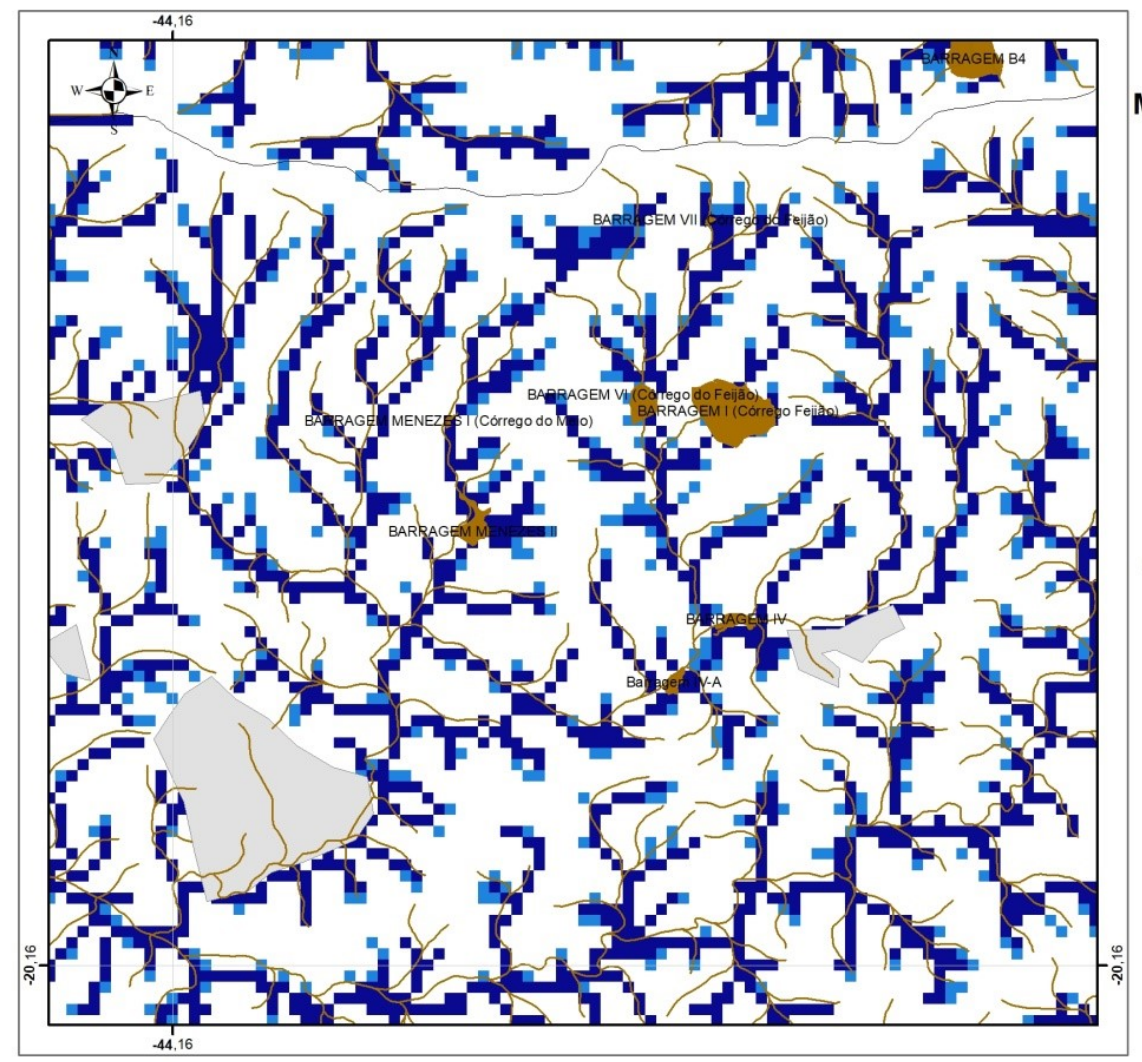

Municipio de Brumadinho

Figura 12 - Fluxo acumulado no município de Brumadinho (MG).

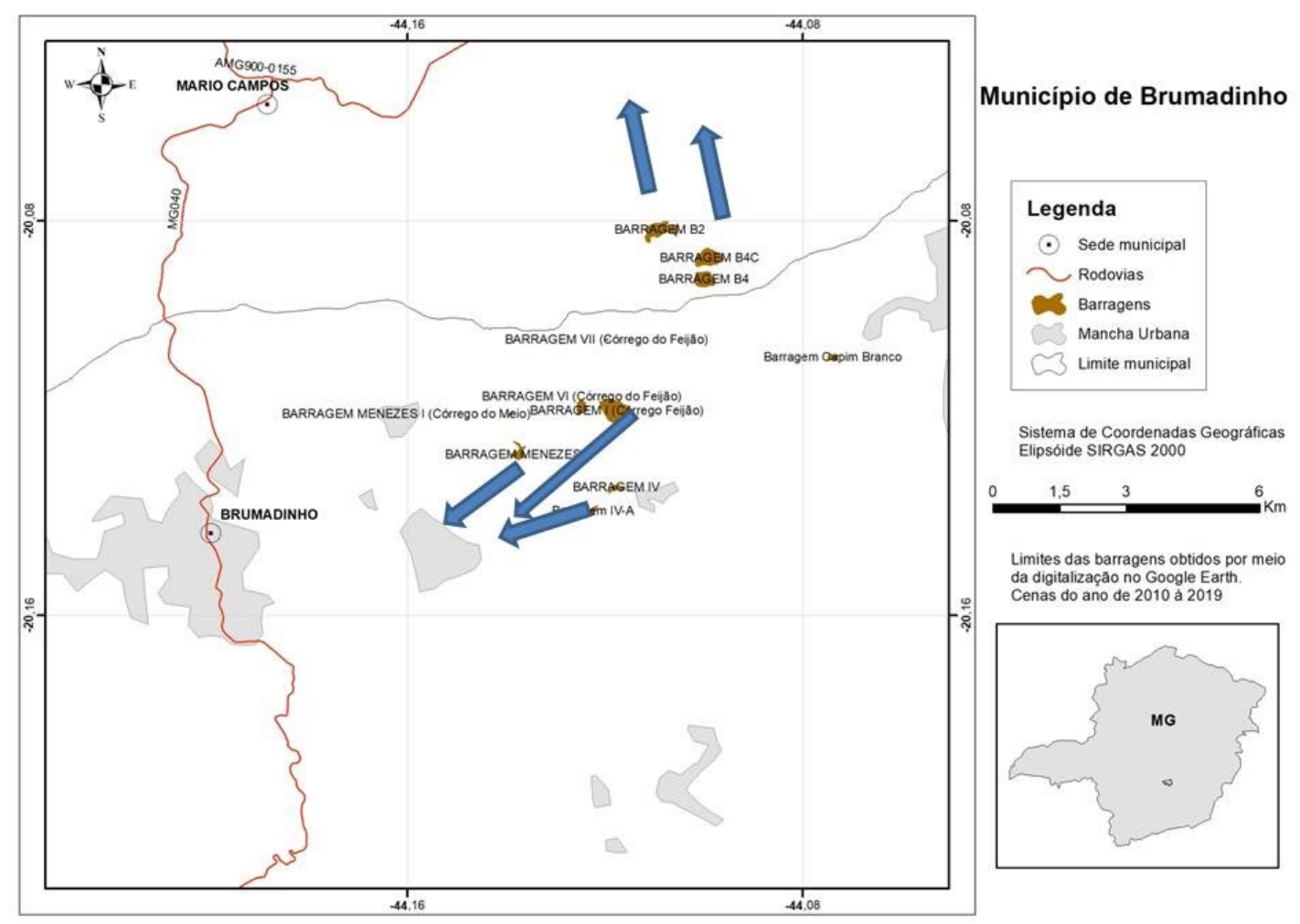

Figura 13 - Sentido do fluxo em caso de rompimento de barragens de mineração em Brumadinho (MG). 


\subsection{Caso de estudo: Congonhas (MG)}

No município de Congonhas, o IBGE estima o número de habitantes em 54.762 hab. A densidade populacional é uma das mais elevadas no estado, ou seja, 159,57/ $\mathrm{km}^{2}$. Essa importante cidade histórica fica a $80,5 \mathrm{~km}$ de Belo Horizonte, e seus habitantes exibem um PIB per capta de R\$ 51 mil.

Os dois bancos de dados consultados relatam 26 (ANM/DNPM) ou 32 (FEAM) barragens para Congonhas (Tab. 1). Nessa pesquisa foram localizadas 18 barragens (Tab. 13). Segundo a FEAM, todas elas possuem volumes menores do que 1 milhão de $\mathrm{m}^{3}$ de rejeitos acumulados. Segundo esse mesmo banco de dados, o somatório dos volumes de todas as represas do município chega a 14,6 milhões de $\mathrm{m}^{3}$ de rejeitos.

A cidade foi escolhida como um caso de estudo uma vez que a cidade passou por um pesadelo depois que a Barragem de Casa de Pedra apresentou infiltrações graves. A estrutura precisou passar por intervenções urgentes e implantar um sistema de evacuação de emergência que envolveu cerca de 4.800 pessoas que residem a apenas 250 metros do complexo. Toda essa gente precisou de treinamento sobre procedimentos de salvamento (ESTAD DE MINAS, 2018).

As principais barragens de Congonhas (MG), bem como os seus posicionamentos dentro da rede hidrográfica e em relação à área urbanizada estão ilustrados na Fig. 14. Os possíveis fluxos da onda de lama, em caso de rompimento dessas barragens estão apontados na Fig. 15.

Em caso de ruptura, boa parte dos rejeitos de uma das maiores barragens de rejeitos de mineração do estado, a Barragem da Casa de Pedra, liberaria uma massa enorme de rejeitos que inundariam boa parte da zona central da cidade (Tab. 13, Fig. 15).

Tabela 13: Barragens situadas em Congonhas (MG) de acordo com o CADASTRO NACIONAL DE BARRAGENS (2016). No caso de haver rompimento, são fornecidas as distâncias aproximadas que os rejeitos irão percorrer antes de atingir a malha urbana.

\begin{tabular}{|c|c|c|c|c|c|c|c|}
\hline $\mathbf{N}$ & Município & Barragem & $\begin{array}{c}\text { Altura } \\
\text { (m) }\end{array}$ & Latitude & Longitude & $\begin{array}{c}\text { Atinge o } \\
\text { centro se } \\
\text { romper }\end{array}$ & $\begin{array}{c}\text { Distância do } \\
\text { centro urbano } \\
(\mathbf{k m})\end{array}$ \\
\hline 1 & Congonhas & BARRAGEM 7 & 64 & $20^{\circ} 33^{\prime} 45^{\prime \prime} 4$ & $43^{\circ} 57^{\prime} 03^{\prime \prime} 1$ & Não & \\
\hline 2 & Congonhas & $\begin{array}{l}\text { BARRAGEM ALTO } \\
\text { JACUTINGA }\end{array}$ & 11,8 & $20^{\circ} 25^{\prime} 33^{\prime \prime} 6$ & $43^{\circ} 53^{\prime} 09^{\prime \prime} 5$ & Não & \\
\hline 3 & Congonhas & BARRAGEM B4 & 70 & $20^{\circ} 29^{\prime} 09^{\prime \prime} 0$ & $43^{\circ} 53^{\prime} 09^{\prime \prime} 0$ & Não & \\
\hline 4 & Congonhas & BARRAGEM B5 & 32 & $20^{\circ} 29^{\prime} 23^{\prime \prime} 0$ & $43^{\circ} 53^{\prime} 28^{\prime \prime} 0$ & Não & \\
\hline 5 & Congonhas & $\begin{array}{l}\text { BARRAGEM BAIXO } \\
\text { JOÃO PEREIRA }\end{array}$ & 15,75 & $20^{\circ} 26^{\prime} 24^{\prime \prime} 5$ & $43^{\circ} 54^{\prime} 18^{\prime \prime} 5$ & Não & \\
\hline 6 & Congonhas & $\begin{array}{c}\text { BARRAGEM } \\
\text { BARNABÉ }\end{array}$ & 15 & $20^{\circ} 25^{\prime} 32^{\prime \prime} 9$ & $43^{\circ} 53^{\prime} 30^{\prime \prime} 4$ & Não & \\
\hline 7 & Congonhas & $\begin{array}{c}\text { BARRAGEM CASA } \\
\text { DE PEDRA }\end{array}$ & 84 & $20^{\circ} 30^{\prime} 21^{\prime \prime} 0$ & $43^{\circ} 53^{\prime} 00^{\prime \prime} 0$ & SIM & 0,4 \\
\hline 8 & Congonhas & $\begin{array}{c}\text { BARRAGEM } \\
\text { GAMBÁ }\end{array}$ & 8,45 & $20^{\circ} 25^{\prime} 52^{\prime \prime} 8$ & $43^{\circ} 52^{\prime} 58^{\prime \prime} 3$ & Não & \\
\hline 9 & Congonhas & $\begin{array}{c}\text { DIQUE DA PILHA } \\
\text { DA VILA II }\end{array}$ & 29 & $20^{\circ} 27^{\prime} 08^{\prime \prime} 0$ & $43^{\circ} 53^{\prime} 59^{\prime \prime} 0$ & Não & \\
\hline
\end{tabular}




\begin{tabular}{|c|c|c|c|c|c|c|}
\hline 10 & Congonhas & $\begin{array}{c}\text { DIQUE DO } \\
\text { BICHENTO IIIA }\end{array}$ & 20 & $20^{\circ} 29^{\prime} 06^{\prime \prime} 0$ & $43^{\circ} 56^{\prime} 00^{\prime \prime} 0$ & Não \\
\hline 11 & Congonhas & Dique do Esmeril I & 24 & $20^{\circ} 28^{\prime} 13^{\prime \prime} 0$ & $43^{\circ} 56^{\prime} 11^{\prime \prime} 0$ & Não \\
\hline 12 & Congonhas & $\begin{array}{l}\text { DIQUE DO } \\
\text { ESMERIL IV }\end{array}$ & 38 & $20^{\circ} 29^{\prime} 07^{\prime \prime} 0$ & $43^{\circ} 57^{\prime} 18^{\prime \prime} 0$ & Não \\
\hline 13 & Congonhas & BAIA 5 VIGA & 5 & $20^{\circ} 29^{\prime} 45^{\prime \prime} 7$ & $43^{\circ} 55^{\prime} 03^{\prime \prime} 6$ & Não \\
\hline 14 & Congonhas & $\begin{array}{c}\text { BARRAGEM DO } \\
\text { LAGARTO }\end{array}$ & 14 & $20^{\circ} 27^{\prime} 03^{\prime \prime} 0$ & $43^{\circ} 54^{\prime} 23^{\prime \prime} 0$ & Não \\
\hline 15 & Congonhas & $\begin{array}{c}\text { BARRAGEM POÇO } \\
\text { FUNDO }\end{array}$ & 4 & $20^{\circ} 27^{\prime} 04^{\prime \prime} 0$ & $43^{\circ} 53^{\prime} 53^{\prime \prime} 0$ & Não \\
\hline 16 & Congonhas & $\begin{array}{c}\text { CONJUNTO DE } \\
\text { BAIAS VIGA }\end{array}$ & 5 & $20^{\circ} 29^{\prime} 43^{\prime \prime} 8$ & $43^{\circ} 55^{\prime} 06^{\prime \prime} 4$ & Não \\
\hline 17 & Congonhas & $\begin{array}{l}\text { Dique da Pilha Sul } \\
\text { DIQUE DO }\end{array}$ & 10 & $20^{\circ} 26^{\prime} 11^{\prime \prime} 2$ & $43^{\circ} 52^{\prime} 18^{\prime \prime} 4$ & Não \\
\hline 18 & Congonhas & $\begin{array}{c}\text { BATATEIRO DE } \\
\text { BAIXO }\end{array}$ & 14,8 & $20^{\circ} 28^{\prime} 42^{\prime \prime} 0$ & $43^{\circ} 53^{\prime} 44^{\prime \prime} 0$ & Não \\
\hline
\end{tabular}

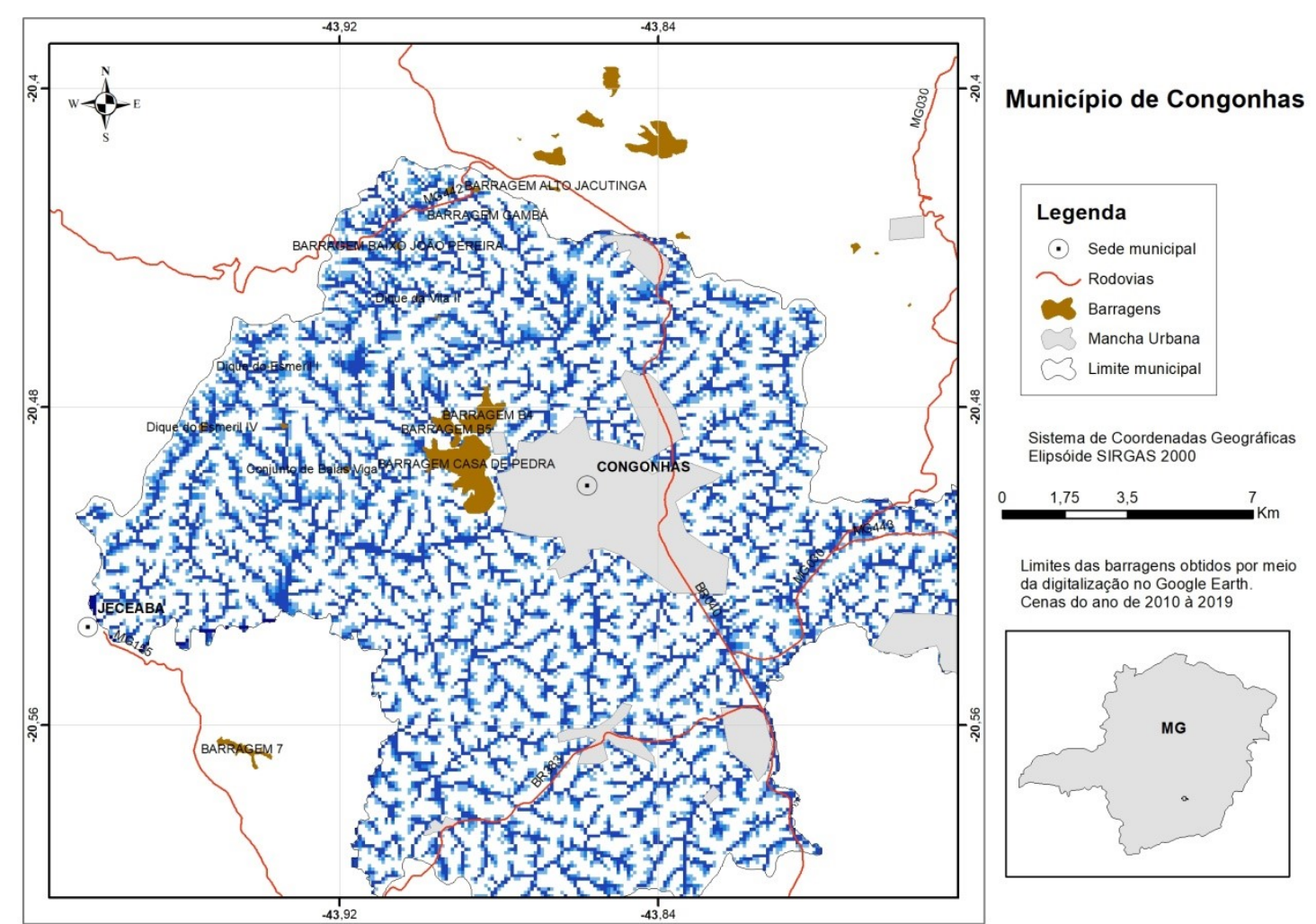

Figura 14 - Fluxo acumulado no município de Congonhas (MG) 


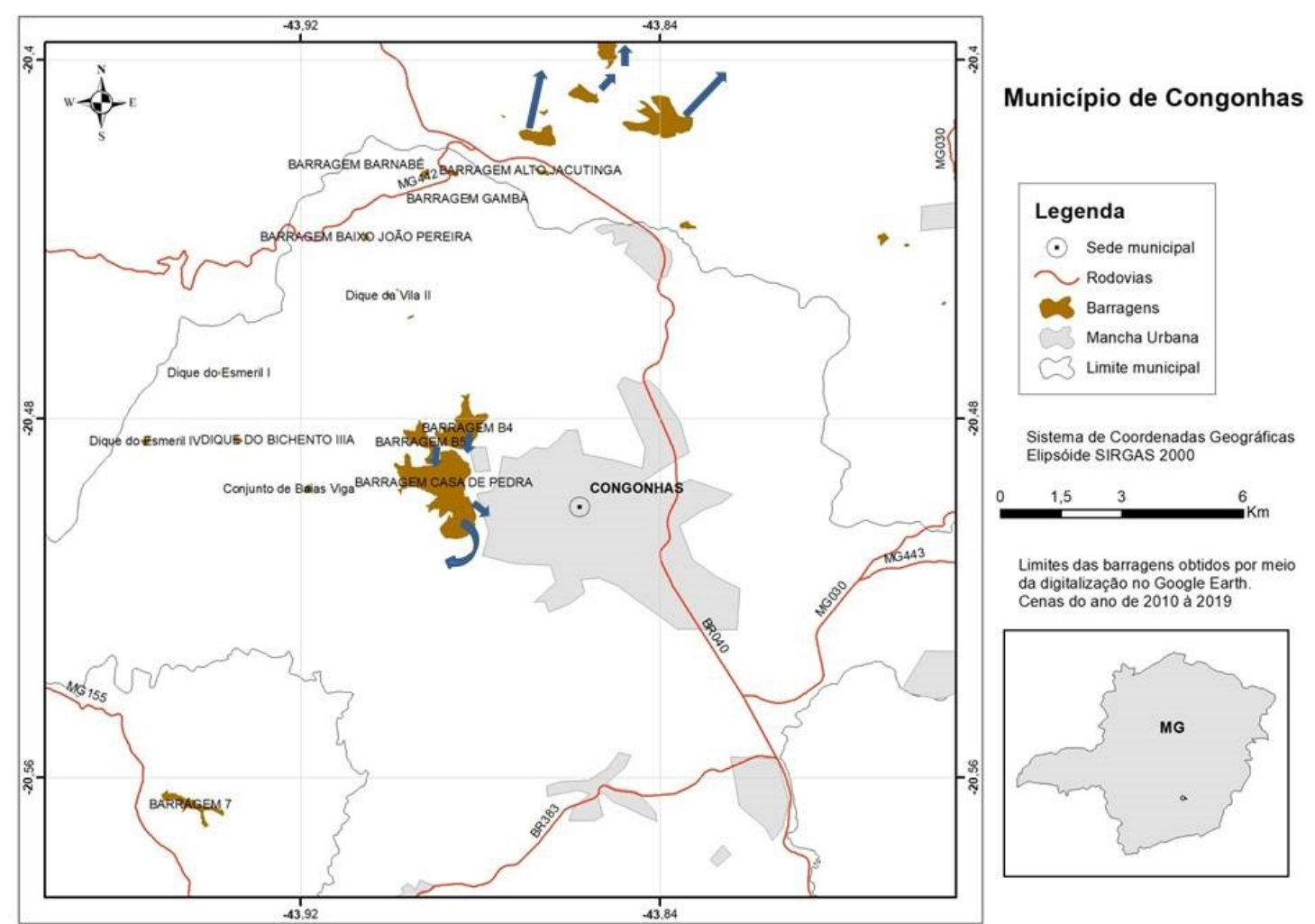

Figura 15 - Sentido do fluxo em caso de rompimento de barragens em Congonhas (MG).

\subsection{Caso de estudo: Mariana (MG)}

Em Mariana, o portal IBGE Cidades estima o tamanho da população local em 60.724 hab. A densidade populacional nesse município é de 45,40 hab. $/ \mathrm{km}^{2}$. Distando por rodovia $146 \mathrm{~km}$ de Belo Horizonte, a primeira capital mineira tem hoje um PIB per capta de R\$ 36 mil.

O município conta com 13 represas segundo o banco de dados do ANM/DNPM e 18 estruturas cadastradas na lista da FEAM (Tab. 1). No presente estudo, apenas 14 represas foram identificadas. O banco de dados da fundação mineira (FEAM) afirma que todas essas estruturas tiveram seus volumes estimados dentro da categoria pequeno porte, já que os volumes declarados para todas elas não atingem sequer 0,2 milhão de $\mathrm{m}^{3}$.

Em Mariana ocorreu um dos mais graves desastres envolvendo barragens de mineração em todo o mundo (PINTO-COELHO, 2017). Na tarde do dia 05 de novembro de 2015, a barragem de Fundão, pertencente ao complexo minerário de Germano, de propriedade da Samarco Mineradora, localizada no subdistrito de Bento Rodrigues, município de Mariana/MG, se rompeu de modo repentino.

A barragem de Fundão era uma barragem de grande porte já que tinha uma altura de 100 metros, um comprimento de 761 metros e um volume de 41 milhões de $\mathrm{m}^{3}$ de rejeitos de mineração. Desse total, 34 milhões de $\mathrm{m}^{3}$, após galgarem uma segunda barragem a jusante, a barragem de 
Santarém, foram lançados na bacia hidrográfica do rio Doce. Cerca de 16 milhões restantes ainda permanecem armazenados nessa segunda barragem, que foi parcialmente danificada, mas continua ainda de pé. Esse material continua sendo carreado, aos poucos, a jusante, em direção ao mar, por meio dos tributários e do rio Doce.

Essa tragédia causou a morte de 19 pessoas entre funcionários da Samarco, terceirizados e ribeirinhos. O rompimento da barragem praticamente destruiu o distrito de Bento Rodrigues e causou danos substanciais nas localidades de Paracatu de Baixo e Gesteira. Após percorrer quase $100 \mathrm{~km}$ no Rib. Do Carmo, a pluma de sedimentos atingiu o rio Doce e contaminou cerca de $600 \mathrm{~km}$ desse rio. Cerca de um mês após a ruptura da barragem, onda de lama atingiu a sua foz, em Regência (ES) e chegou a comprometer diversas praias, mangues e arrecifes coralinos e outros biótopos em dezenas de quilômetros do litoral do sudeste.

Após o desastre de Fundão, Mariana continua enfrentando graves problemas com outras barragens associadas à mineração. Agência Nacional de Mineração suspendeu a DCE da Barragem Campo Grande na Mina de Alegria em abril de 2019.

As principais barragens de Mariana, bem como os seus posicionamentos dentro da rede hidrográfica e em relação à área urbanizada estão ilustradas na Fig. 16. Os possíveis fluxos da onda de lama, em caso de rompimento dessas barragens estão apontados na Fig. 17. Em caso de ruptura, apenas os rejeitos do Dique de Pedra atingiriam Mariana (Tab. 14, Fig. 17).

Tabela 14: Barragens do município de Mariana (MG), segundo o CADASTRO NACIONAL DE BARRAGENS (2016).

\begin{tabular}{|c|c|c|c|c|c|c|c|}
\hline $\mathbf{N}$ & Município & Barragem & $\begin{array}{l}\text { Altura } \\
\text { (m) }\end{array}$ & Latitude & Longitude & $\begin{array}{c}\text { Atinge o } \\
\text { centro se } \\
\text { romper } \\
\end{array}$ & $\begin{array}{l}\text { Distância do } \\
\text { centro } \\
\text { urbano }(\mathbf{k m}) \\
\end{array}$ \\
\hline 1 & Mariana & $\begin{array}{c}\text { BARRAGEM } \\
\text { CAMPO GRANDE }\end{array}$ & 97 & $20^{\circ} 10^{\prime} 32^{\prime \prime} 5$ & $43^{\circ} 29^{\prime} 14^{\prime \prime} 9$ & Não & \\
\hline 2 & Mariana & Barragem Germano & 165 & $20^{\circ} 12^{\prime} 59^{\prime \prime} 1$ & $43^{\circ} 28^{\prime} 02^{\prime \prime} 2$ & Não & \\
\hline 3 & Mariana & Barragem Santarém & 33 & $20^{\circ} 13^{\prime} 49^{\prime \prime} 4$ & $43^{\circ} 26^{\prime} 31^{\prime \prime} 4$ & Não & \\
\hline 4 & Mariana & Cava do Germano & 60,5 & $20^{\circ} 11^{\prime} 55^{\prime \prime} 2$ & $43^{\circ} 29^{\prime} 46^{\prime \prime} 6$ & Não & \\
\hline 5 & Mariana & $\begin{array}{l}\text { DIQUE DA PDE } \\
\text { LAGOA SECA }\end{array}$ & 11,4 & $20^{\circ} 20^{\prime} 56^{\prime \prime} 3$ & $43^{\circ} 24^{\prime} 47^{\prime \prime} 1$ & Não & \\
\hline 6 & Mariana & DIQUE DA PERA & 9 & $20^{\circ} 20^{\prime} 50^{\prime \prime} 0$ & $43^{\circ} 25^{\prime} 50^{\prime \prime} 0$ & Sim & 0,7 \\
\hline 7 & Mariana & $\begin{array}{c}\text { DIQUE PDE } \\
\text { FOSFOROSO } \\
\text { (Alegria) }\end{array}$ & 21 & $20^{\circ} 09^{\prime} 33^{\prime \prime} 5$ & $43^{\circ} 28^{\prime} 09^{\prime \prime} 5$ & Não & \\
\hline 8 & Mariana & $\begin{array}{c}\text { BARRAGEM } \\
\text { CAPTAÇÃO } \\
\text { CÓRREGO DAS } \\
\text { ALMAS (Barr. água) }\end{array}$ & 8,5 & $20^{\circ} 09^{\prime} 29^{\prime \prime} 0$ & $43^{\circ} 28^{\prime} 05^{\prime \prime} 4$ & Não & \\
\hline 9 & Mariana & Dique do Retão & 11 & $20^{\circ} 14^{\prime} 27^{\prime \prime} 0$ & $43^{\circ} 30^{\prime} 31^{\prime \prime} 0$ & Não & \\
\hline 10 & Mariana & $\begin{array}{c}\text { DIQUE PDE } \\
\text { PERMANENTE I } \\
\text { DIQUE PDE }\end{array}$ & 7 & $20^{\circ} 11^{\prime} 04^{\prime \prime} 3$ & $43^{\circ} 26^{\prime} 15^{\prime \prime} 4$ & Não & \\
\hline 11 & Mariana & $\begin{array}{c}\text { PERMANENTE II - } \\
\text { FASE I }\end{array}$ & 7 & $20^{\circ} 12^{\prime} 27^{\prime \prime} 1$ & $43^{\circ} 27^{\prime} 16^{\prime \prime} 0$ & Não & \\
\hline
\end{tabular}




\begin{tabular}{|c|c|c|c|c|c|c|}
\hline 12 & Mariana & $\begin{array}{c}\text { DIQUE PDE } \\
\text { PERMANENTE II - } \\
\text { FASE I }\end{array}$ & 7 & $20^{\circ} 12^{\prime} 27^{\prime \prime} 1$ & $43^{\circ} 27^{\prime} 16^{\prime \prime} 0$ & Não \\
\hline 13 & Mariana & $\begin{array}{c}\text { DIQUE PDE } \\
\text { TEMPORÁRIO II }\end{array}$ & 12 & $20^{\circ} 12^{\prime} 54^{\prime \prime} 4$ & $43^{\circ} 26^{\prime} 09^{\prime \prime} 5$ & Não \\
\hline 14 & Mariana & Tanque 3 & 8,5 & $20^{\circ} 23^{\prime} 11^{\prime \prime} 1$ & $43^{\circ} 27^{\prime} 13^{\prime \prime} 2$ & Não \\
\hline
\end{tabular}

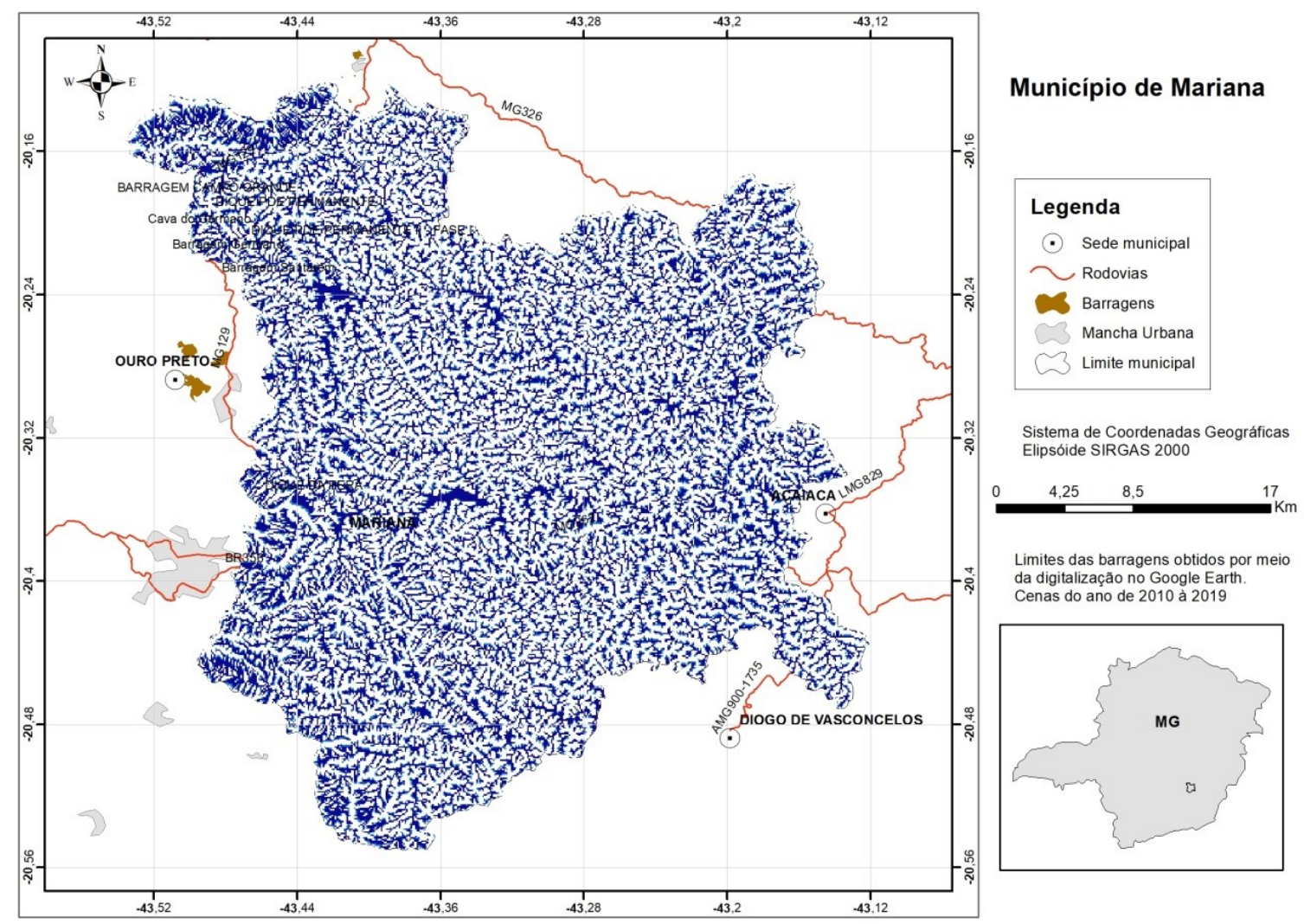

Figura 16 - Fluxo acumulado no município de Mariana (MG). 


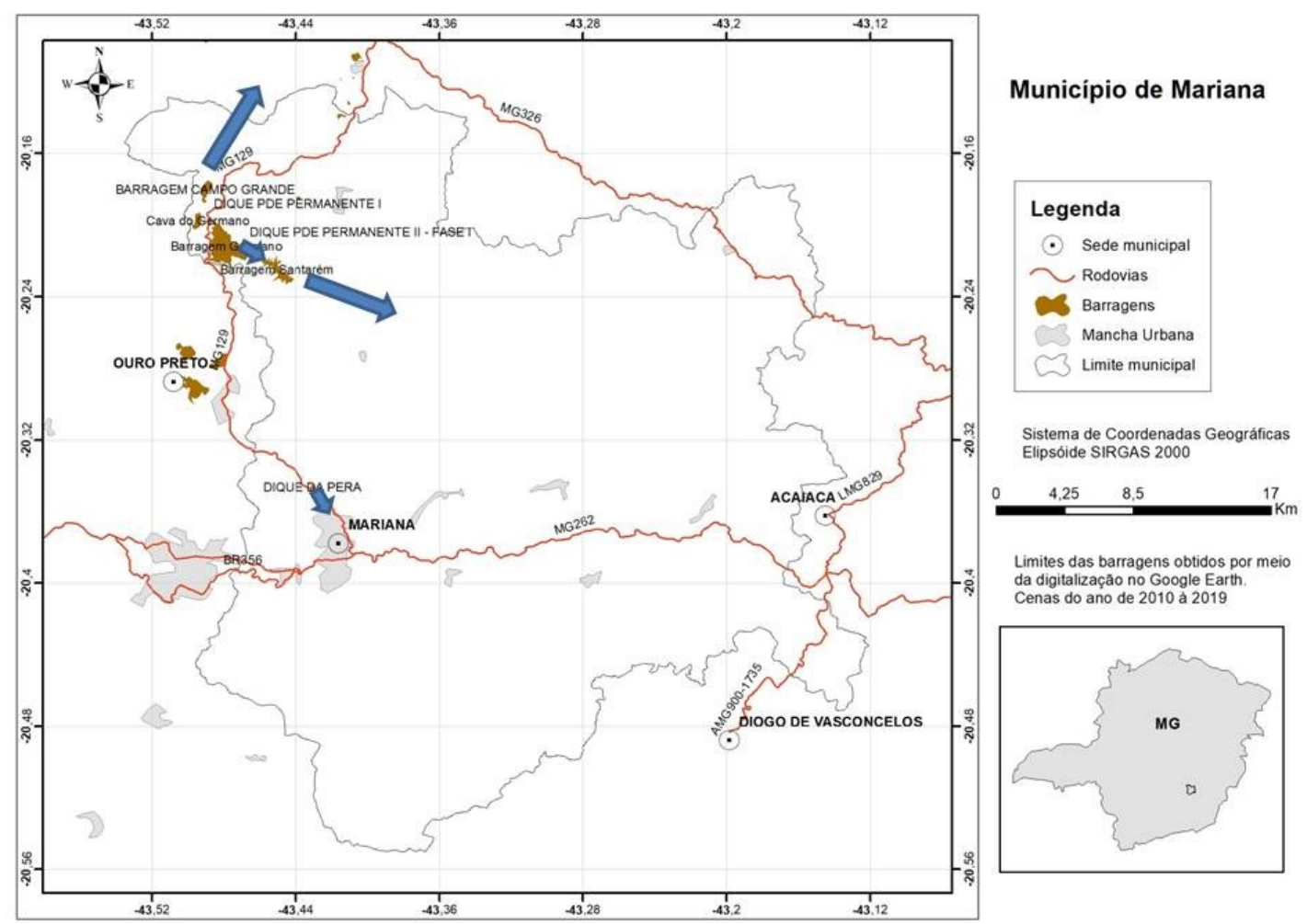

Figura 17 - Sentido do fluxo em caso de rompimento em Mariana (MG). 


\subsection{Caso de estudo: Paracatu}

Em Paracatu, vivem 93.158 habitantes que se distribuem no território municipal com uma baixa densidade, ou seja, de apenas 10,29 hab./ $\mathrm{km}^{2}$ (IBGE 2019). Distando $503 \mathrm{~km}$ de Belo Horizonte, a cidade fica em pleno bioma do cerrado e conta com um PIB per capta de R \$ 35 mil.

O município de Paracatu conta com 9 barragens cadastradas na lista da FEAM (2007) ou 10 barragens no banco de dados da ANM/DNPM (2017) e no presente estudo (Tab.15). Todas essas estruturas são consideradas como sendo de pequeno porte, segundo o volume declarado no banco de dados da FEAM. O volume total de rejeitos acumulados por todas essas estruturas é de $65.200 \mathrm{~m}^{3}$ (FEAM, 2007).

O município foi escolhido como um caso de estudo pelo elevado grau de toxidez dos rejeitos de suas barragens. A mina Morro do Ouro é a maior mina de ouro a céu aberto no mundo e a maior em produção de ouro no Brasil. Apesar dos volumes de rejeitos dessa e outras barragens de Paracatu terem sido declarados como muito baixo no site da FEAM, sabe-se que essas barragens de rejeito de Paracatu são gigantes não apenas pelo volume de material estocado, mas também por serem os maiores depósitos de arsênio do Brasil. A cada ano, a mineradora movimenta 61 milhões de toneladas de minério, e libera para o meio ambiente mais de 67.000 toneladas de arsênio, em sua forma tóxica. $\mathrm{O}$ arsênio preso nas rochas ele é inofensivo, mas quando está nos efluentes do beneficiamento estocados na barragem ele é um veneno. As barragens de rejeito da mina Morro do Ouro não são impermeabilizadas no piso e, além disso, dela vertem drenos de água, em circuito aberto (SANTOS, 2019).

As principais barragens de Paracatu, bem como os seus posicionamentos dentro da rede hidrográfica e em relação à área urbanizada estão ilustradas na Fig. 18. Os possíveis fluxos da onda de lama, em caso de rompimento dessas barragens estão apontados na Fig. 19. Em caso de rompimento de uma de suas barragens, a malha urbana de Paracatu não seria atingida pela onda de rejeitos (Fig. 19).

Tabela 15: Barragens do município de Paracatu (MG) segundo o CADASTRO NACIONAL DE BARRAGENS (2017).

\begin{tabular}{|c|c|c|c|c|c|c|c|}
\hline $\mathbf{N}$ & Município & Barragem & $\begin{array}{c}\text { Altura } \\
\text { (m) }\end{array}$ & Latitude & Longitude & $\begin{array}{c}\text { Atinge o } \\
\text { centro se } \\
\text { romper } \\
\end{array}$ & $\begin{array}{l}\text { Distância do } \\
\text { centro } \\
\text { urbano }(\mathrm{km})\end{array}$ \\
\hline 1 & Paracatu & Barragem 1 & 21 & $17^{\circ} 29^{\prime} 51^{\prime \prime} 0$ & $46^{\circ} 49^{\prime} 06^{\prime \prime} 0$ & Não & \\
\hline 2 & Paracatu & Barragem 2 & 32,5 & $17^{\circ} 30^{\prime} 40^{\prime \prime} 0$ & $46^{\circ} 49^{\prime} 40^{\prime \prime} 0$ & Não & \\
\hline 3 & Paracatu & Barragem 3 & 12 & $17^{\circ} 30^{\prime} 49^{\prime \prime} 0$ & $46^{\circ} 49^{\prime} 44^{\prime \prime} 0$ & Não & \\
\hline 4 & Paracatu & Barragem A & 21,65 & $17^{\circ} 10^{\prime} 09^{\prime \prime} 0$ & $46^{\circ} 53^{\prime} 28^{\prime \prime} 0$ & Não & \\
\hline 5 & Paracatu & Barragem Eustáquio & 74 & $18^{\circ} 08^{\prime} 45^{\prime \prime} 5$ & $46^{\circ} 54^{\prime} 03^{\prime \prime} 9$ & Não & \\
\hline 6 & Paracatu & $\begin{array}{c}\text { Barragem Santo } \\
\text { Antônio }\end{array}$ & 104 & $17^{\circ} 08^{\prime} 50^{\prime \prime} 8$ & $45^{\circ} 51^{\prime} 15^{\prime \prime} 6$ & Não & \\
\hline
\end{tabular}




$\begin{array}{ccccccc}7 & \text { Paracatu } & \begin{array}{c}\text { Tanque Específico } \\ \text { IX B }\end{array} & 15 & 17^{\circ} 10^{\prime} 31^{\prime \prime} 3 & 46^{\circ} 52^{\prime} 53^{\prime \prime} 2 & \text { Não } \\ 8 & \text { Paracatu } & \begin{array}{c}\text { Tanque Específico } \\ \text { X }\end{array} & 15 & 17^{\circ} 10^{\prime} 36^{\prime \prime} 5 & 46^{\circ} 53^{\prime} 10^{\prime \prime} 5 & \text { Não } \\ 9 & \text { Paracatu } & \begin{array}{c}\text { Tanque Específico } \\ \text { XI }\end{array} & 11,8 & 17^{\circ} 10^{\prime} 25^{\prime \prime} 0 & 46^{\circ} 53^{\prime} 02^{\prime \prime} 0 & \text { Não } \\ 10 & \text { Paracatu } & \begin{array}{c}\text { Tanque Específico } \\ \text { XII }\end{array} & 33 & 17^{\circ} 10^{\prime} 54^{\prime \prime} 0 & 46^{\circ} 52^{\prime} 55^{\prime \prime} 0 & \text { Não } \\ & & & & \end{array}$

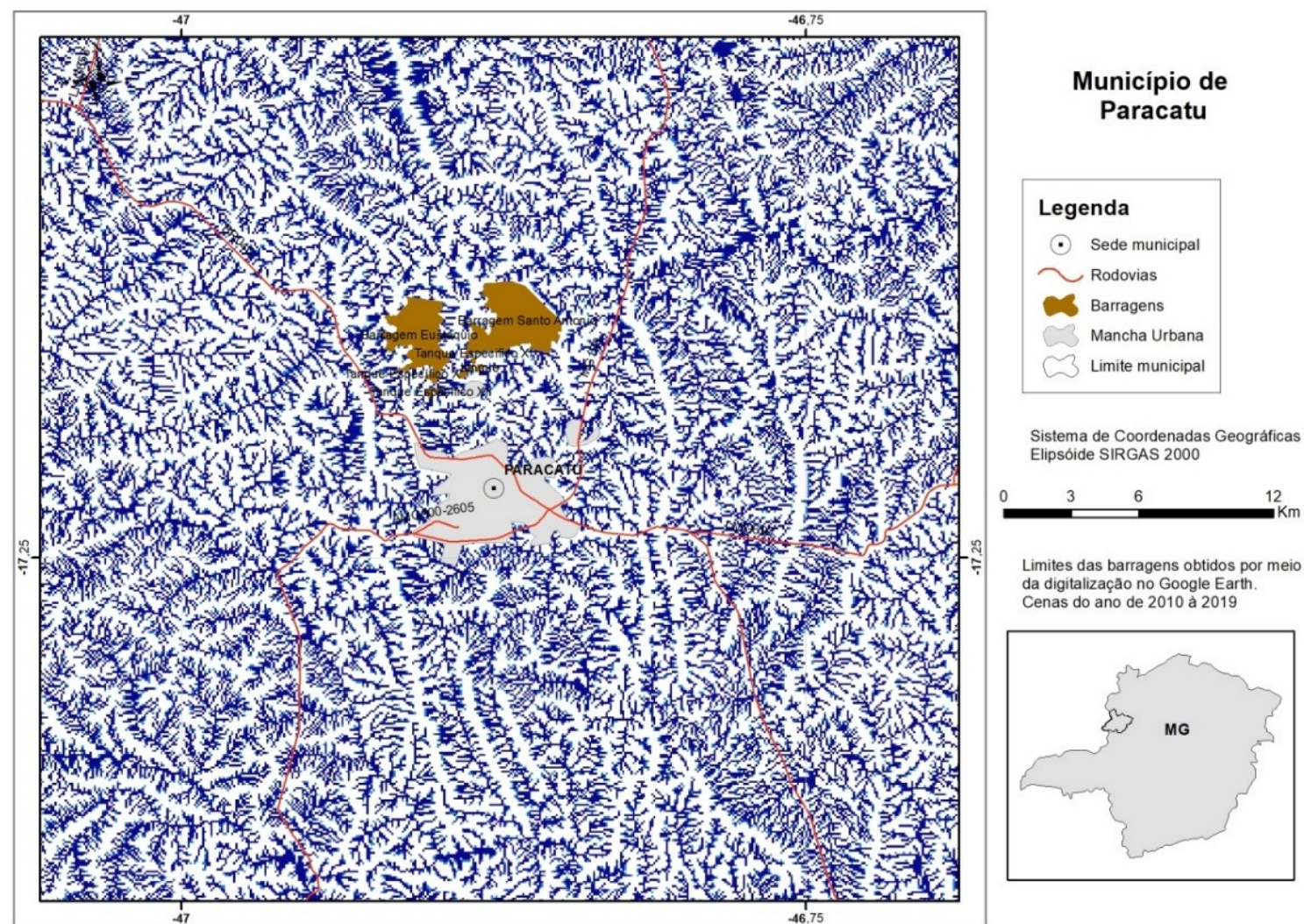

Figura 18 - Fluxo acumulado no município de Paracatu MG). 


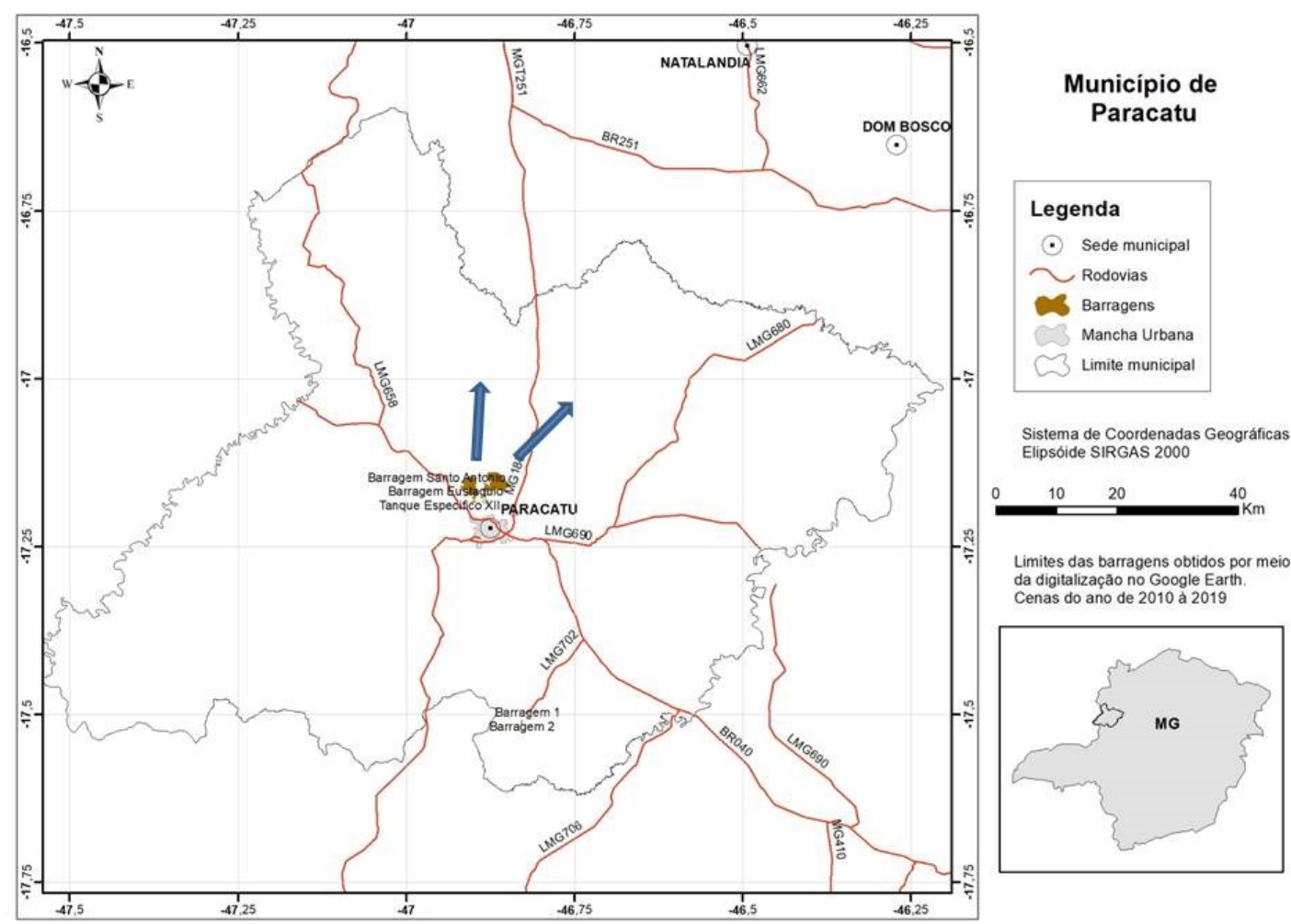

Figura 19 - Sentido do fluxo em caso de rompimento de barragens de mineração do município de Paracatu (MG).

\subsection{Caso de estudo: Barão de Cocais}

Barão de Cocais conta com uma população de 32.485 habitantes que se distribuem no território municipal com uma densidade elevada, ou seja, 83,51 hab./ $\mathrm{km}^{2}$. A cidade fica a 94,5 $\mathrm{km}$ de Belo Horizonte, e seus habitantes têm hoje um PIB per capta de apenas R\$ 20 mil (IBGE 2019).

Segundo o banco de dados da ANM/DNPM, Barão de Cocais conta com 10 represas associadas à mineração. Já a última lista da FEAM dá conta que existem no município 11 represas recebendo rejeitos de mineração. O presente estudo identificou 10 barragens (Tab. 16). Essas barragens são de médio porte com volumes variando entre 8,4 e 11,6 milhões de $\mathrm{m}^{3}$, se observarmos os dados da Fundação Estadual do Meio Ambiente de MG (FEAM, 2007).

O município foi escolhido como caso de estudo tendo em vista os alarmes recentes que foram expedidos pela própria Vale ou pelas autoridades competentes. O caso da Barragem Sul Superior da Mina de Gongo Soco é emblemático. Em 19 maio de 2019, foi dado um alarme pela própria Vale de que o talude norte da cava da mina poderia se romper a qualquer momento. $\mathrm{O}$ tremor gerado por esse rompimento poderia liquefazer a Barragem Sul Superior que está 1,5 km abaixo. Essa ameaça obrigou cerca de 500 pessoas a abandonarem - de modo permanente - de suas casas já que elas estavam localizadas na zona de autosalvamento. Outras 6.000 pessoas, que moravam em até $16 \mathrm{~km}$ da barragem, tiveram que ser treinadas e eventualmente removidas temporariamente por estarem na zona secundária de salvamento (ZSS). 
As principais barragens de Itabirito, bem como os seus posicionamentos dentro da rede hidrográfica e em relação à área urbanizada estão ilustradas na Fig. 20. Os possíveis fluxos da onda de lama, em caso de rompimento dessas barragens estão apontados na Fig. 21.

O caso de Barão de Cocais é um dos mais críticos em caso de rompimento de suas barragens. Das 10 barragens identificadas nesse estudo, nove delas lançariam seus rejeitos na malha urbana da cidade, em caso de rompimento (Fig. 21).

Tabela 16: Barragens do município de Barão de Cocais (MG) segundo o CADASTRO NACIONAL DE BARRAGENS (2017).

\begin{tabular}{|c|c|c|c|c|c|c|c|}
\hline $\mathbf{N}$ & Município & Barragem & $\begin{array}{l}\text { Altura } \\
\text { (m) }\end{array}$ & Latitude & Longitude & $\begin{array}{l}\text { Atinge } \\
\text { o } \\
\text { centro } \\
\text { se } \\
\text { romper }\end{array}$ & $\begin{array}{c}\text { Distância } \\
\text { do centro } \\
\text { urbano } \\
(\mathrm{km})\end{array}$ \\
\hline 1 & Barão de Cocais & $\begin{array}{l}\text { DIQUE DOS } \\
\text { INGLESES }\end{array}$ & 6,5 & $19^{\circ} 57^{\prime} 55,3^{\prime \prime}$ & $43^{\circ} 35^{\prime} 14^{\prime \prime} 1$ & Sim & 15,2 \\
\hline 2 & Barão de Cocais & $\begin{array}{c}\text { DIQUE DO } \\
\text { PATRIMÔNIO }\end{array}$ & 8 & $19^{\circ} 57^{\prime} 34^{\prime \prime} 0$ & $43^{\circ} 35^{\prime} 14^{\prime \prime} 0$ & Sim & 15,0 \\
\hline 3 & Barão de Cocais & $\begin{array}{c}\text { DIQUE DA } \\
\text { FAZENDINHA }\end{array}$ & 8 & $19^{\circ} 58^{\prime} 18^{\prime \prime} 2$ & $43^{\circ} 36^{\prime} 29^{\prime \prime} 0$ & Sim & 2,8 \\
\hline 4 & Barão de Cocais & $\begin{array}{c}\text { DIQUE } 02- \\
\text { GONGO SOCO }\end{array}$ & 10 & $19^{\circ} 58^{\prime} 24^{\prime \prime} 6$ & $43^{\circ} 36^{\prime} 13^{\prime \prime} 4$ & Sim & 2,2 \\
\hline 5 & Barão de Cocais & $\begin{array}{c}\text { DIQUE A - } \\
\text { GONGO SOCO }\end{array}$ & 13 & $19^{\circ} 56^{\prime} 55^{\prime \prime} 4$ & $43^{\circ} 35^{\prime} 12^{\prime \prime} 1$ & $\operatorname{Sim}$ & 13,0 \\
\hline 6 & Barão de Cocais & $\begin{array}{c}\text { DIQUE B - GONGO } \\
\text { SOCO }\end{array}$ & 14,5 & $19^{\circ} 56^{\prime} 50^{\prime \prime} 1$ & $43^{\circ} 35^{\prime} 00^{\prime \prime} 7$ & Sim & 13,0 \\
\hline 7 & Barão de Cocais & $\begin{array}{c}\text { DIQUE C - GONGO } \\
\text { SOCO }\end{array}$ & 8 & $19^{\circ} 56^{\prime} 18^{\prime \prime} 6$ & $43^{\circ} 35^{\prime} 01^{\prime \prime} 8$ & Sim & 11,9 \\
\hline 8 & Barão de Cocais & $\begin{array}{c}\text { BARRAGEM } \\
\text { LARANJEIRAS }\end{array}$ & 58,8 & $19^{\circ} 50^{\prime} 54^{\prime \prime} 4$ & $43^{\circ} 25^{\prime} 18^{\prime \prime} 5$ & Não & \\
\hline 9 & Barão de Cocais & $\begin{array}{l}\text { BARRAGEM SUL } \\
\text { INFERIOR }\end{array}$ & 35 & $19^{\circ} 58^{\prime} 32^{\prime \prime} 6$ & $43^{\circ} 36^{\prime} 02^{\prime \prime} 5$ & Sim & 1,6 \\
\hline 10 & Barão de Cocais & $\begin{array}{l}\text { BARRAGEM SUL } \\
\text { SUPERIOR }\end{array}$ & 85 & $19^{\circ} 58^{\prime} 12^{\prime \prime} 6$ & $43^{\circ} 35^{\prime} 48^{\prime \prime} 7$ & Sim & 2,4 \\
\hline
\end{tabular}




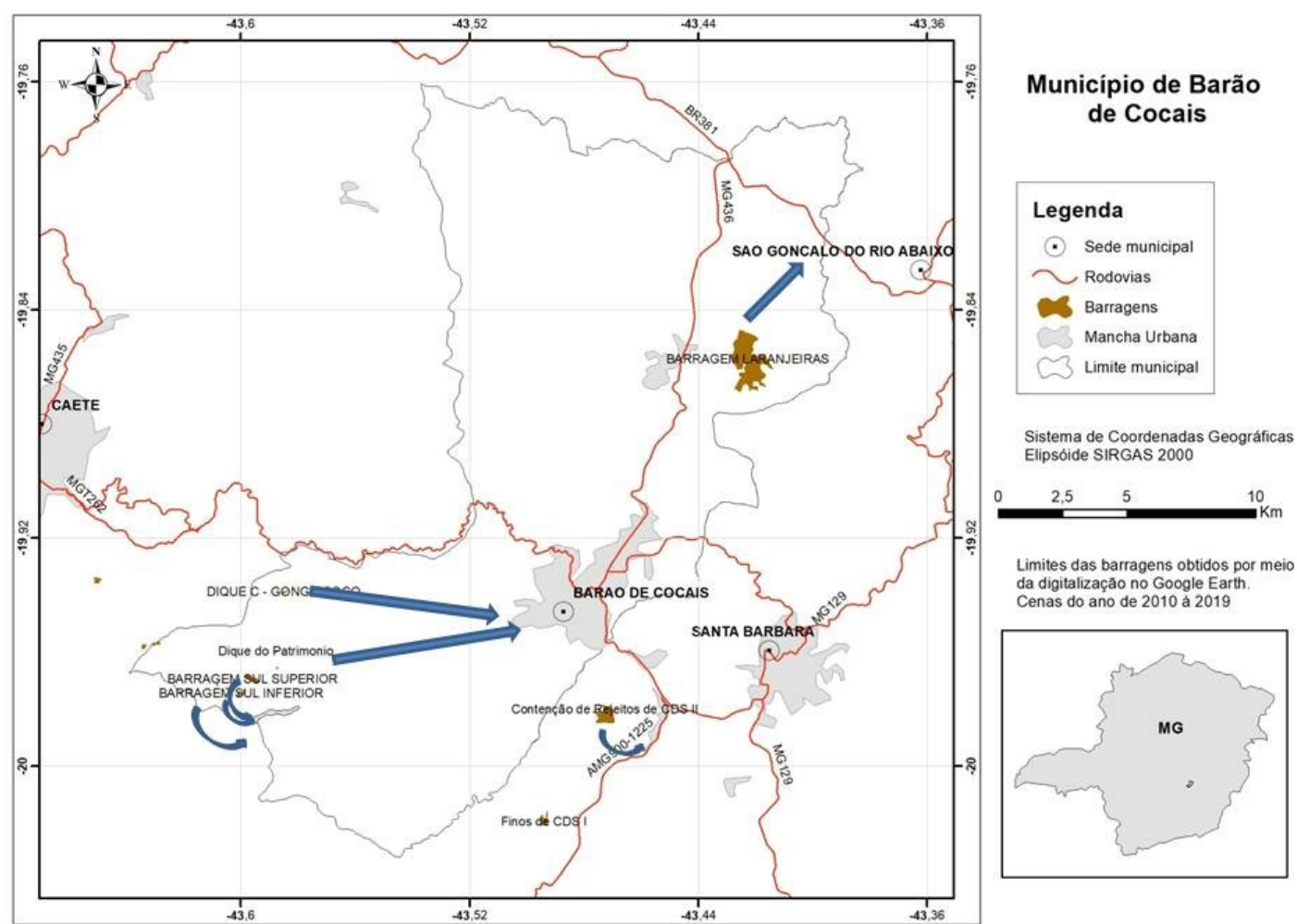

Figura 20 - Fluxo acumulado no município de Barão de Cocais MG).

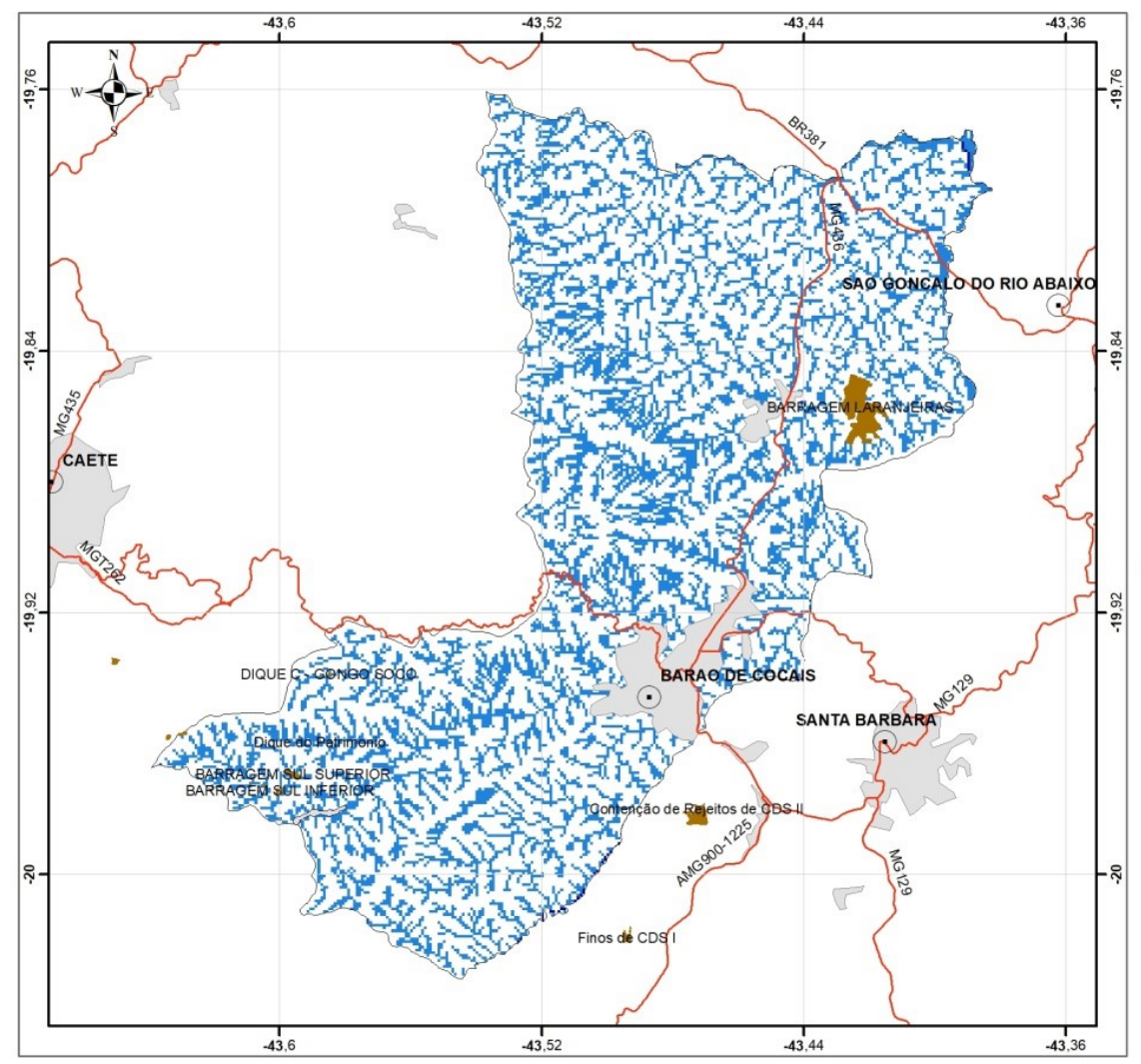

Município de Barão de Cocais

\begin{tabular}{|l}
\hline Legenda \\
$\odot$ Sede municipal \\
$\smile$ Rodovias \\
3 Marragens \\
Mimite municipal
\end{tabular}

Sistema de Coordenadas Geográficas Elipsóide SIRGAS 2000

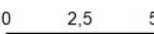

Limites das barragens obtidos por meio da digitalização no Google Earth

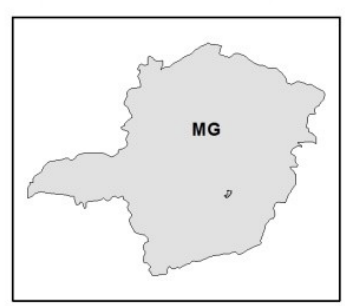

Figura 21 - Sentido do fluxo em caso de rompimento de barragens de mineração do município de Barão de Cocais (MG). 


\section{DISCUSSÃO}

Uma das razões que justificam o presente estudo refere-se à consistente repetição de graves acidentes envolvendo barragens associadas à mineração no estado de Minas Gerais (Tab. 17). Nos primeiros 20 anos do século XXI, pelo menos cinco graves acidentes ocorreram nessas estruturas no estado. Não se sabe de nenhuma outra atividade econômica nessa região que tenha causado tantas mortes em tão pouco tempo.

Os prejuízos socioeconômicos foram imensos e devem superar o patamar de vários bilhões de reais. Além da perda substancial de infraestrutura (estradas, pontes, áreas urbanas), houve também considerável perda do patrimônio histórico e cultural.

Dezenas de hectares de florestas nativas foram perdidos e centenas de quilômetros de cursos de água estão com sua qualidade de água comprometida por muitos e muitos anos. E o que é mais intrigante: a morosidade da justiça em apontar não somente as causas, mas punir exemplarmente todos os responsáveis por essa longa lista de rupturas de barragens é algo que causa repulsa em toda a sociedade civil.

Tabela 17: Sumário das principais tragédias envolvendo barragens associadas à mineração no estado de Minas Gerais.

\begin{tabular}{|c|c|c|c|c|c|c|c|}
\hline $\mathbf{N}$ & Local & Data & Empresa & Mortes & $\begin{array}{l}\text { Vol. } \\
\text { Vaz. }\end{array}$ & Socio economia & Ambiental \\
\hline 1 & Cava 1 & $22 / 06 / 2001$ & $\begin{array}{l}\text { Rio Verde } \\
\text { Mineração }\end{array}$ & 5 & $\begin{array}{c}600 \mathrm{mil} \\
\mathrm{m}^{3}\end{array}$ & $\begin{array}{l}\text { Interrupção da estrada } \\
\text { municipal que liga a BR } \\
040 \text { ao distrito de São } \\
\text { Sebastião de Águas } \\
\text { Claras, causando a } \\
\text { interrupção do tráfego. }\end{array}$ & $\begin{array}{l}\text { O vazamento destruiu } \\
\text { uma área aprox.de } 43 \\
\text { hectares de Mata } \\
\text { Atlântica. }\end{array}$ \\
\hline 2 & $\begin{array}{l}\text { Barragem } \\
\quad \text { São } \\
\text { Francisco }\end{array}$ & 02/01/2007 & $\begin{array}{l}\text { Cataguazes } \\
\text { Mineração }\end{array}$ & 0 & $\begin{array}{l}\text { 2,0 } \\
\text { milhões } \\
\text { de } \mathrm{m}^{3}\end{array}$ & $\begin{array}{l}\text { Lama invadiu as cidades } \\
\text { de Miraí e Muriaé, } \\
\text { chegando aos rios Fubá e } \\
\text { Muriaé e outras cidades } \\
\text { mineiras e fluminenses } \\
\text { Lama tóxica inundo } \\
\text { cerca de } 400 \text { imóveis } \\
\text { comerciais e residenciais } \\
\text { e comerciais, deixando } \\
\text { cerca de } 2.000 \text { pessoas } \\
\text { desabrigadas. }\end{array}$ & $\begin{array}{l}\text { Poluição severa do } \\
\text { córrego do Fubá, rio } \\
\text { Muriaé e } \\
\text { comprometimento da } \\
\text { qualidade de água no } \\
\text { Rio Paraíba do Sul. }\end{array}$ \\
\hline 3 & $\begin{array}{c}\text { Barragem } \\
\text { B-1 }\end{array}$ & $15 / 09 / 2014$ & $\begin{array}{l}\text { Herculano } \\
\text { Mineração }\end{array}$ & 3 & n.d. & $\begin{array}{l}300 \text { residências sem } \\
\text { fornecimento de água e } \\
\text { de energia elétrica. }\end{array}$ & $\begin{array}{l}\text { Impactos ambientais } \\
\text { na qualidade das } \\
\text { águas ao longo da } \\
\text { bacia hidrográfica do } \\
\text { Rio das Velhas e } \\
\text { ameaça ao } \\
\text { abastecimento de } \\
\text { água de Belo } \\
\text { Horizonte. }\end{array}$ \\
\hline 4 & $\begin{array}{l}\text { Barragem } \\
\text { Fundão }\end{array}$ & $05 / 11 / 2015$ & Samarco & 19 & $\begin{array}{c}34 \\
\text { milhões } \\
\text { de } \mathrm{m}^{3}\end{array}$ & $\begin{array}{l}\text { Destruição e completo } \\
\text { abandono do distrito de } \\
\text { Bento Rodrigues. Danos } \\
\text { generalizados em }\end{array}$ & $\begin{array}{l}\text { Após percorrer quase } \\
100 \mathrm{~km} \text { no Rib. Do } \\
\text { Carmo, a lama de } \\
\text { rejeitos chegou ao rio }\end{array}$ \\
\hline
\end{tabular}




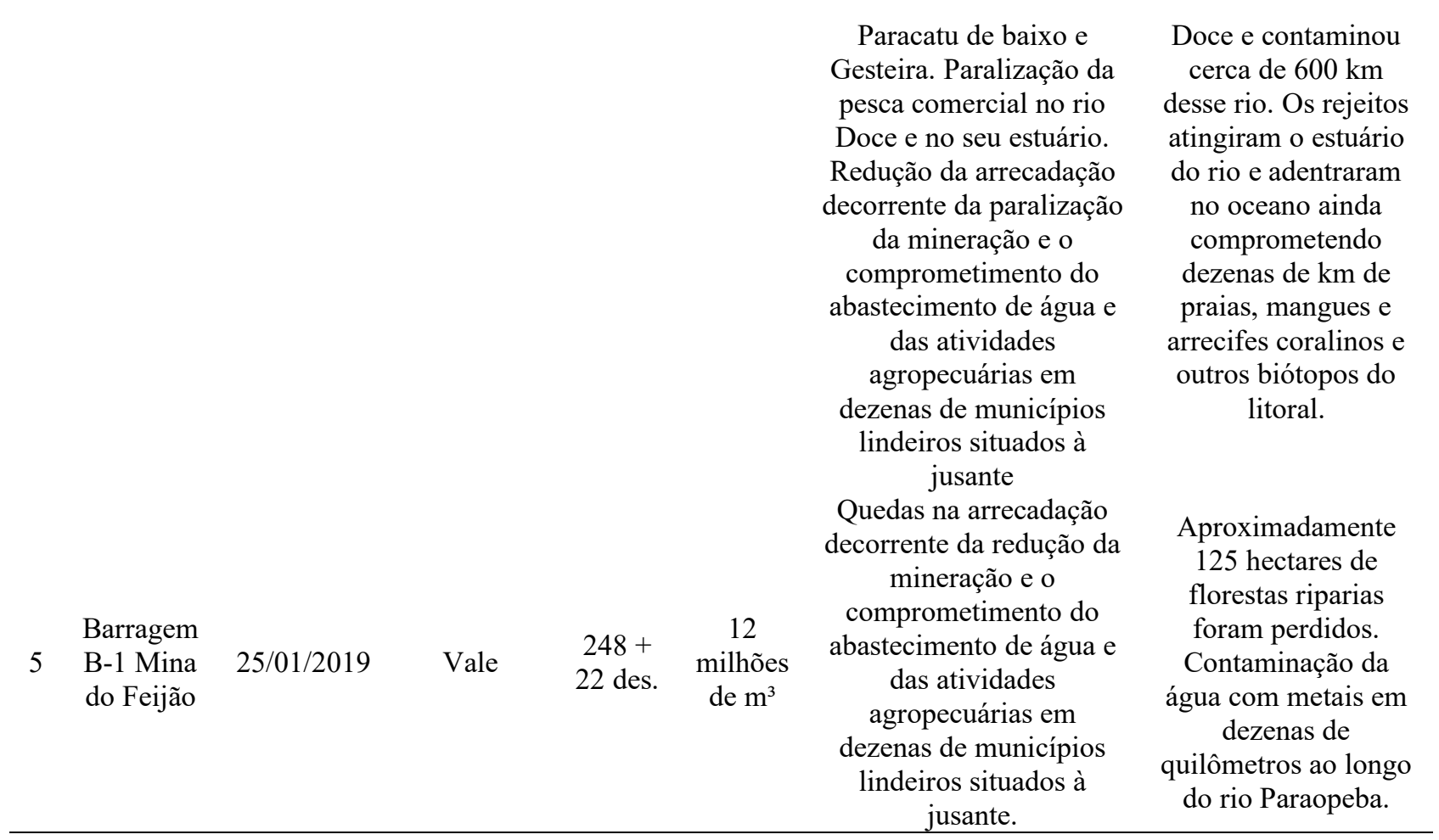

Outro tipo de aspecto que deve ser ressaltado é a baixa confiabilidade do atual sistema de gestão de reservatórios associados à mineração no país. Essa afirmativa se baseia nos seguintes pontos:

(a) A maioria das barragens de rejeitos foi licenciada, construída e sofreu expansões devidamente autorizadas pelo poder público através do método do "alteamento a montante". Esse método é caracterizado pela construção de diques uns sobre os outros, onde o novo dique é apenas parcialmente suportado pelo dique pré-existente. Uma parte do novo dique sempre deverá apoiar-se apenas no rejeito sólido. O método é sabidamente o menos seguro de todos segundo a literatura especializada;

(b) Não há registros sobre a categoria de risco - CRI ou o potencial de danos associados - PDA para um grande número de estruturas no estado;

(c) O presente estudo mostra que a maioria dos municípios com grande número de barragens da mineração existe não somente uma grande proximidade entre essas estruturas e a malha urbana, bem como a hidrografia local mostra que partes significativas dessas cidades seria atingida em poucos minutos após um acidente;

(d) Há discrepâncias e inconsistências importantes quando se compara os bancos de dados oficiais. O número de barragens que recebem rejeitos varia de um banco de dados para outro dentro do mesmo ano. As estimativas de volume das barragens necessitam de revisão. 
(e) Os dois bancos de dados oficiais (ANM/ANM/DNPM e FEAM) não têm descrições oficiais e precisas dos desastres já ocorridos com o inventário dos prejuízos em termos de vidas humanas, perda da biodiversidade, perdas patrimoniais e prejuízos socioeconômicos.

(f) Um número crescente de publicações especializadas (vide uma revisão em Pedroza, 2017) têm apontado para a necessidade de uma revisão de todo o sistema de gestão das represas associadas à mineração, em todo o país. Não se trata aqui apenas de novas leis ou regulamentos, nem mesmo de criação de novas autarquias ou agências de governo, mas simplesmente exigir mais articulação, mais eficiência, mais transparência e, sobretudo, colocar a sustentabilidade dessas estruturas como prioridade no atual sistema de gestão ambiental de reservatórios.

É importante ressaltar que mais de 60\% (61,6\%) das 365 barragens mineiras cadastradas na ANM/DNPM estão sob a responsabilidade de apenas 10 companhias mineradoras. E cerca de $77 \%$ $(76,7 \%)$ delas estão sob a responsabilidade de apenas 20 companhias. Isso quer dizer que seria extremamente fácil o controle e o monitoramento dessas barragens, pois a mineração, ao contrário do agronegócio, não está pulverizada em centenas de empreendimentos. Os números da Vale são impressionantes: a companhia tem 120 barragens sobre seu controle (33\% de todas as barragens de mineração de Minas Gerais). Não obstante, a imprensa divulgou amplamente que em outubro de 2019, após o estado ter passado por inúmeras tragédias ligadas a mineração nada menos do que 18 barragens da Vale ainda estavam com suas DCEs negativadas (HOJE EM DIA, 2019).

A pesquisa também identificou 10 municípios em situação crítica em relação às barragens associadas à mineração. A pesquisa considerou os seguintes critérios para incluir um dado município nessa situação:

(a) número de barragens associadas à mineração superior a 10;

(b) uma ou mais estruturas de grande porte ou com potencial para gerar grandes danos humanos ou ambientais;

(c) existência de desastres com mineração no passado.

(d) potencial poluidor da represa com dados comprovados de grande acúmulo de metais ou outros contaminantes que possam colocar em risco as populações do entorno.

Acreditamos que todos os municípios acima identificados deveriam adotar políticas públicas específicas para a questão das barragens em seu território, o que não existe - de fato - até agora. Essas políticas deveriam envolver aspectos tão variados como saúde pública, serviços ecossistêmicos, zoneamento urbano, etc. Uma pergunta que não quer se calar: como cidades como Itabira ou Congonhas permitiram o parcelamento urbano em áreas tão próximas do sistema do Pontal ou da Barragem da Casa de Pedra? 
Outro ponto a ser considerado é o fato de que as duas mais recentes tragédias envolvendo barragens de mineração do estado (Barragem do Fundão, em Mariana e a Barragem B-1 da Mina do Feijão em Brumadinho) ocorreram em barragens que estavam com toda a documentação relativa à sua segurança em dia (PARREIRAS, 2019). É evidente que o sistema de certificações, laudos, monitoramento e mesmo a legislação pertinente deve ser revisto. Se não houve erro no sistema, então houve falha humana e, nesse caso, os eventuais culpados têm que responder na Justiça. O que não pode é ficar tudo como está.

\section{CONCLUSÕES}

Há uma grande concentração de barragens associadas à mineração nas áreas mais habitadas do estado de Minas Gerais. Alguns dos municípios mineiros com as maiores densidades populacionais em seu território, tais como Nova Lima ou Congonhas, possuem uma grande concentração dessa tipologia de barragens (mineração). Cerca de 300 barragens mineiras de mineração (ANM/DNPM=293, FEAM = 305 barragens), ou seja, 80\% do total desse tipo de barragens, estão concentradas em 20 municípios, onde vivem 3,78 milhões de pessoas (19,5\% da população mineira).

Os dois bancos de dados consultados apresentam resultados divergentes em relação às barragens associadas à mineração. Até mesmo o número dessas estruturas dentro de um município e considerando a mesma tipologia pode variar um banco de dados para o outro. Variáveis importantes tais como mudanças no CNPJ dos empreendedores ou variáveis morfométricas dos reservatórios tais como o volume necessitam de revisões urgentes.

Os bancos de dados oficiais sobre as barragens não trazem informações oficiais sobre os desastres ocorridos no estado. As providências se limitaram a pura e simples exclusão das barragens rompidas do banco de dados. Os reservatórios Cava-1 (Rio Verde, Macacos), São Francisco (Cataguazes Mineração), B-1 (Herculano, Itabirito), Fundão (Samarco) e B-1 Feijão (Vale, Brumadinho) vão sendo paulatinamente excluídos dos bancos de dados oficiais, sem qualquer justificativa. Acreditamos que a sociedade tem o direito ao acesso às informações tidas como “oficiais" em relação a todos os desastres ocorridos com represas de mineração em Minas Gerais e em todo o Brasil. Dados sobre o volume da onda de lama, número de vítimas fatais, inventário dos impactos ambientais e perda do patrimônio municipal e privado somente podem ser garimpadas em relatórios do governo disseminados em dezenas de órgãos, matérias de jornais ou TV. As contribuições acadêmicas sobre o assunto normalmente demoram muitos anos para ser publicadas.

Em termos de morfometria das represas, os dois bancos oficiais de dados consultados se limitam a fornecer apenas as coordenadas geográficas das barragens (há muitas coordenadas erradas), 
altura e o volume de rejeitos acumulados (idem). Não são fornecidos dados sobre os parâmetros morfométricos primários (área inundada, perímetro, profundidade máxima, profundidade média, profundidade relativa). Não há sequer menção aos parâmetros morfométricos secundários (índice de desenvolvimento de volume, índice de desenvolvimento de perímetro, declividade média e fator de envolvimento). Todos esses parâmetros morfométricos bem como a descrição batimétrica atualizada dos reservatórios e de suas bacias hidrográficas são características extremamente importantes para o estabelecimento de um Plano de Gestão e Segurança de Barragens. Se tais informações estivessem disponíveis e fossem continuamente atualizadas as ações de salvamento e recuperação de vítimas ou do inventário dos danos ambientais em caso de uma ruptura seriam muito mais eficazes e haveria mais agilidade na sua execução.

\section{RECOMENDAÇÕES}

No plano empresarial, recomendamos que os empreendedores que fazem uso de represas e barragens em seus negócios - não importa a sua tipologia - reconheçam o fato que essas estruturas não devem ser vistas como um patrimônio de uso exclusivo da empresa. Embora sejam criações do homem, dada sua magnitude, esses lagos artificiais passam a ser elementos importantes da paisagem. Nesse sentido, as barragens obrigatoriamente interagem com as populações do entorno, independente da vontade do empreendedor. O mesmo é válido para os gestores públicos de estados e municípios onde existam águas represadas. O não reconhecimento dessa verdade pode sair muito caro e até mesmo inviabilizar o negócio, a longo prazo.

$\mathrm{Na}$ esfera municipal, recomenda-se que os municípios considerados críticos nesse estudo articulem-se buscando não somente harmonizar e padronizar as legislações municipais sobre a matéria, mas que possam elaborar planos estratégicos de desenvolvimento em comum, compartilhando recursos e pessoal especializado com vistas a aumentar as medidas de prevenção a acidentes, a segurança, a sustentabilidade dos seus territórios e a conscientização geral de suas populações sobre os riscos que as barragens associadas à mineração podem apresentar.

Nos planos dos estados e da federação, recomenda-se uma maior integração entre as fundações estaduais e a União no sentido de harmonizar, integrar e compartilhar melhor seus bancos de dados sobre as barragens associadas à mineração, bem como de outras tipologias (hidroeletricidade, setor sucroalcooleiro, indústrias, etc.). A ideia é facilitar o acesso aos usuários e disponibilizar informações atualizadas, corretas e que possam auxiliar também os pesquisadores a trabalhar com essa grande massa de dados. 
Recomenda-se ainda melhorar e disponibilizar ao público, em geral, a completa descrição morfométrica de todas as barragens do Brasil incluindo obrigatoriamente tanto os parâmetros morfométricos primários quanto os parâmetros morfométricos secundários.

A Agência Nacional de Mineração deveria desenvolver um plano nacional de gestão ambiental de reservatórios em conjunto com outras agências que são responsáveis por outras tipologias de barragens (ex: ANA). É importante ressaltar que um plano de gestão ambiental vai muito além da segurança e operação das barragens. Uma gestão moderna e sustentável de um reservatório, seja ele de qualquer tipologia, envolve aspectos tais como a proteção ou recomposição da biodiversidade, manutenção ou incremento dos serviços ecossistêmicos, compatibilização e introdução de múltiplos usos, controle, mitigação e compensação de impactos ambientais.

No plano do Judiciário, sugere-se que haja uma maior divulgação na sociedade das decisões tomadas em relação a todos os desastres ocorridos com barragens de mineração no estado. Houve culpados? E nesse caso, quais foram as punições concedidas? Quais foram os termos de ajuste assinados? Quais foram as indenizações efetivamente pagas? Quais são as ações ainda pendentes? Qual é a segurança jurídica para que a atividade de mineração prossiga e cresça de modo sustentável?

Quanto ao Ministério Público, também é sugerida uma maior transparência nessa matéria junto à sociedade. Isso é válido tanto para o Ministério Público Federal quanto pelo Ministério Público do Estado de Minas Gerais. É inegável que há uma percepção na sociedade civil de impunidade em relação aos desastres ocorridos e, talvez, ela seja decorrente exatamente dessa falta de transparência das ações do Judiciário nessa matéria.

Finalmente, deve-se mencionar o papel relevante que os órgãos de imprensa desempenharam junto a sociedade civil quando o assunto refere-se às barragens de mineração em Minas Gerais. A grande maioria dos veículos da mídia trataram essa questão com grande liberdade, profissionalismo e fidelidade aos fatos. A imprensa tem sido, muitas vezes, uma preciosa fonte de informações para a sociedade, contribuindo assim para que a mineração seja hoje um tema que não somente desperta o interesse geral, mas também um assunto que tem mobilizado amplos setores da opinião pública que naturalmente passa a exigir dos poderes constituídos nas três esferas (União, estados e municípios) uma melhoria substancial de suas práticas ambientais e uma busca verdadeira da sua sustentabilidade.

\section{AGRADECIMENTOS}

Os autores agradecem à Pró-Reitoria de Pesquisas - PROPE da Universidade Federal de São João del-Rei - UFSJ pelo apoio recebido para a publicação desse capítulo de livro. O trabalho recebeu ainda o suporte da CAPES, do Programa de Pós-Graduação em Geografia da UFSJ, do Programa de 
Pós-Graduação em Ecologia, Conservação e Manejo da Vida Silvestre da UFMG e do Instituto de Ciências Puras e Aplicadas, Universidade Federal de Itajubá - UNIFEI, Itabira (MG).

\section{REFERÊNCIAS}

ANM - AGÊNCIA NACIONAL DE MINERAÇÃO. Resolução n. 13 estabelece medidas regulatórias objetivando assegurar a estabilidade de barragens de mineração, notadamente aquelas construídas ou alteadas pelo método denominado "a montante" e dá outras providências. 8 págs. 08 de agosto de 2019.

ANM - AGÊNCIA NACIONAL DE MINERAÇÃO. Departamento Nacional de Produção Mineral - DNPM. Cadastro Nacional de Barragens de Mineração. 2019. Disponível em: http://www.anm.gov.br/assuntos/barragens/pasta-cadastro-nacional-de-barragens-de-acao/cadastronacional-de-barragens-de-mineracao. Acesso em: 01. dez. 2020.

BARIFOUSE, R. Mineração: cidade onde a Vale nasceu vive cercada por 33 vezes o volume de rejeitos de barragem que se rompeu em Brumadinho. BBC News Brasil, São Paulo. 2019. 13p. 2019.

COPAM - Deliberação Normativa Número 87. Altera e complementa a Deliberação Normativa COPAM 62 de 17/12/2002 que dispõe sobre critérios de classificação de barragens de contenção de rejeitos, de resíduos e de reservatório de água em empreendimentos industriais e de mineração no Estado de Minas Gerais. Belo Horizonte, 7p.

DNPM - DEPARTAMENTO DE PRODUÇÃO MINERAL. Portaria No.70.389 cria o Cadastro Nacional de Barragens, o Sistema Integrado de Gestão e Segurança de Barragens de Mineração e outras providências, 2017. $43 \mathrm{p}$.

DNPM - DEPARTEMTNO NACIONAL DA PRODUÇÃO MINERAL. Classificação das barragens de mineração - Data Base Dezembro/2016.

DNPM - DEPARTAMENTO DE PRODUÇÃO MINERAL. Portaria Número 14. Estabelece prazo de entrega para o Plano de Ação de Emergência de Barragem de Mineração (PAEBM) para as prefeituras, 2018. 1p.

FEAM - FUNDAÇÃO ESTADUAL DO MEIO AMBIENTE. Lista das Barragens de Mineração de Minas Gerais/ FEAM. 2011. Disponível em: http://www.feam.br/images/stories/arquivos.xls. Acesso em: 01 dez. 2020.

FEAM - FUNDAÇÃO ESTADUAL DO MEIO AMBIENTE. Lista das Barragens de Mineração de Minas Gerais/ FEAM. 2012. Disponível em: http://www.feam.br/images/stories/arquivos. Acesso em: 01 dez. 2020.

FEAM - FUNDAÇÃO ESTADUAL DO MEIO AMBIENTE. Lista das Barragens de Mineração de Minas Gerais/ FEAM. 2013. Disponível em: http://www.feam.br/images/stories/inventario/2013/lista\%20de\%20barragens\%20-2013.xls. Acesso em: 01 dez. 2020.

FEAM - FUNDAÇÃO ESTADUAL DO MEIO AMBIENTE. Lista das Barragens de Mineração de Minas Gerais/ FEAM. 2014. Disponível em: 
http://www.feam.br/images/stories/2015/DECLARACOES_AMBIENTAIS/GESTAO_DE_BARR AGENS/lista\%20de\%20barragens_2014_publicao.xls. Acesso em: 01 dez. 2020.

FEAM - FUNDAÇÃO ESTADUAL DO MEIO AMBIENTE. Lista das Barragens de Mineração de Minas Gerais/ FEAM. 2015. Disponível em: http://www.feam.br/images/stories/2016/BARRAGENS/Lista_de_Barragens_Divulga\%C3\%A7\%C 3\%A3o_V02.xlsx. Acesso em: 01 dez. 2020.

FEAM - FUNDAÇÃO ESTADUAL DO MEIO AMBIENTE. Lista das Barragens de Mineração de Minas Gerais/ FEAM/2016. Disponível em: http://www.feam.br/images/stories/2017/BARRAGENS/Planilha_Divulga\%C3\%A7\%C3\%A3o_Ba rragens.xlsx. Acesso em: 01 dez. 2020.

FEAM - FUNDAÇÃO ESTADUAL DO MEIO AMBIENTE. Lista das Barragens de Mineração de Minas Gerais/ FEAM/2017. Disponível em:

http://www.feam.br/images/stories/2018/BARRAGENS/PLANILHA_DIVULGA\%C3\%87\%C3\%8 3O.xlsx. Acesso em: 01 dez. 2020.

FEAM - FUNDAÇÃO ESTADUAL DO MEIO AMBIENTE. INVENTÁRIO DE BARRAGEM DO ESTADO DE MINAS GERAIS ANO 2017. 2017. 40p.

FEAM - FUNDAÇÃO ESTADUAL DO MEIO AMBIENTE. Lista das Barragens de Mineração de Minas Gerais/ FEAM. 2018. Disponível em: http://www.feam.br/images/stories/2019/BARRAGENS/PLANILHA_DIVULGA\%C3\%87\%C3\%8 3O.xlsx. Acesso em: 01 dez. 2020.

FJP - FUNDAÇÃO JOÃO PINHEIRO. Produto Interno Bruto de Minas Gerais. Belo Horizonte (MG), 2018. 48p.

HOJE EM DIA. Vale tem 18 barragens sem declaração de estabilidade. Portal Hoje em Dia, Jornal "Hoje em Dia", Belo Horizonte (MG). 01 de outubro de 2019.

IBGE - INSTITUTO BRASILEIRO DE GEOGRAFIA E ESTATÍSTICA. Portal Cidades. 2019.

NEVES, L. P. Segurança de barragens - Legislação federal brasileira em segurança de barragens comentada. Universidade de Brasília. Brasília, 2018. 67p.

PARANAÍBE, G. Novo estudo força a saída de mais 23 famílias de área de risco de barragem em Itatiaiuçu. Jornal Estado de Minas, Belo Horizonte (MG). 07 abr. 2019.

PARREIRAS, M. Barragem de Brumadinho não estava entre as 50 sem garantia de estabilidade. Jornal Correio Brasiliense, Brasília (DF). 25 jan. 2019.

PEDROZA, L. Reavaliação do sistema de classificação de barragens realizado pelo DNPM. 2017. 149 F. Dissertação (Mestrado em Engenharia Geotécnica) - Escola de Minas, Universidade Federal de Ouro Preto, Ouro Preto, 2017.

PINTO-COELHO, R. M.; HAVENS, K. Gestão de Recursos Hídricos em Tempos de Crise. Porto Alegre: Grupo A/ARTMED, 2016. 228p. 
PINTO-COELHO, R. M. Existe governança das águas no Brasil? Estudo de caso: o rompimento da Barragem de Fundão, Mariana (MG). Arquivos do Museu de História Natural e Jardim Botânico. Belo Horizonte. v. 24, n. 1, p. 16-43, 2017.

PIRES, B.; PINTO-COELHO, R. M. A Vale prefere investir nos melhores advogados a pagar a conta do desastre”. Jornal El País, São Paulo. 04 fev. 2019.

PMB - PREFEITURA MUNICIPAL DE BRUMADINHO. Dossiê Brumadinho. Brumadinho (MG), 2019. 39p.

PRESIDÊNCIA DA REPÚBLICA. Lei 12.334. Lei estabelece a Política Nacional de Segurança de Barragens destinada a acumulação de água para quaisquer usos, à disposição final ou temporária de rejeitos, e à acumulação de resíduos industriais, cria o Sistema Nacional de Informações sobre Segurança de Barragens e dá outras providências. 8 págs. 20 de setembro de 2010.

RIBEIRO, L.; PINTO-COELHO, R. M. Professor da UFMG cita iniciativas que podem recuperar áreas devastadas. Jornal Estado de Minas, Belo Horizonte (MG). 28 nov. 2015.

RUCHKYS, U. A.; MACHADO, M. M. Patrimônio geológico e mineiro do Quadrilátero Ferrífero, Minas Gerais - Caracterização e iniciativas para e educação e o ecoturismo. Boletim Paraense de Geociências, v. 70, p. 120-136, 2013.

SANTOS, M. S. Barragens que matam em silêncio. Paracatu-MG. Disponível em: https://paracatu.net/view/8358-barragens-de-rejeitos-que-matam-em-si. Acesso em: 01 dez. 2020.

SILVA, O. P. A mineração em Minas Gerais: passado, presente e futuro. Geonomos, Belo Horizonte, v. 3, n. 1, p. 77-86, 1995.

SIMONATO, T. C.; MAGALHÃES, A. S.; DOMINGUES, E. P. Urbanização, economia e mineração em Minas Gerais: aspectos contemporâneos e conflitos históricos. In: ENAMPUR. 17., Belo Horizonte. Anais... Belo Horizonte: CEDEPLAR, 2017. p. 1-13.

TEIXEIRA, T. L. Estrada de Ferro Vitória a Minas: elementos para a gestão da paisagem ferroviária. 2013. 145 f. Dissertação (Mestrado em Arquitetura) - Universidade Federal do Espírito Santo, Vitória, 2013. 